\title{
خصائص منشأة عميل المراجعة وجودة المراجعة \\ والعلاقة ما بين تأخير إصدار تقرير المراجعة وكفاءة قرارات أصحاب \\ المصالح (دراسة تحليلية)
}

\author{
إعداد \\ الأستاذ الدكتور \\ نجوى محمود أحمد أبو جبل \\ أستاذ المراجعة بكلية التجارة- جامعة طنطا
}


خصائص منشأة عميل المراجعة وجودة المراجعة والعلاقة ما بين تأخير إصدار تقرير المراجعة وكفاءة قرارات أصحاب المصالح (دراسة تحليلية)

الأستاذ الدكتور

نجوى محمود أحمد أبو جبل الأن

أستاذ المراجعة بكلية التجارة- جامعة طنطا

ملخص البحث

تمثل فترة تأخير تقرير مراقب الحسابات أحد الموضوعات الهامة التي شغلت الفكر المحاسبي في

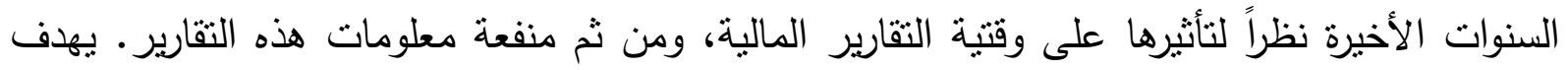

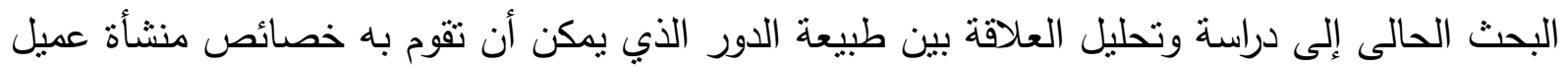

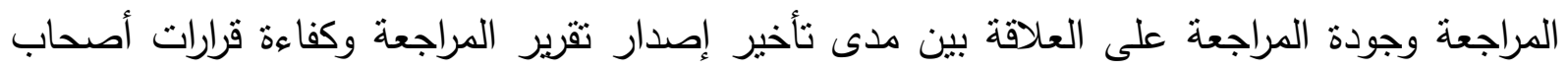

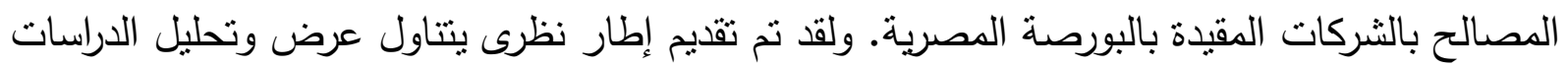

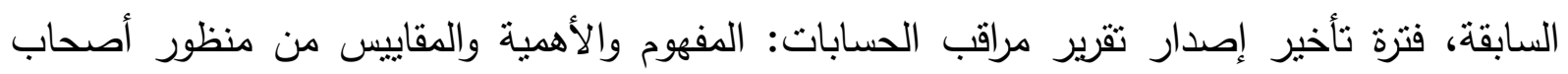
المصالح ، كفاءة قرارات أصحاب المصالح من المنظور المحاسبى، تحليل العلاقة بين تأخير إصدار تقرير مراقب الحسابات وكفاءة قرارات أصحاب المصالح ، جودة المراجعة الخارجية : المفهوم والأهمية ، تحليل أثز خصائص منثأة عميل المراجعة على نأخير إصدار تقرير مراقب الحسابات وكفاءة قرارات

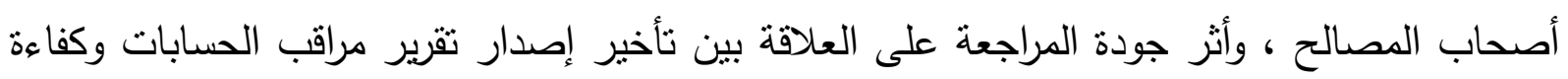

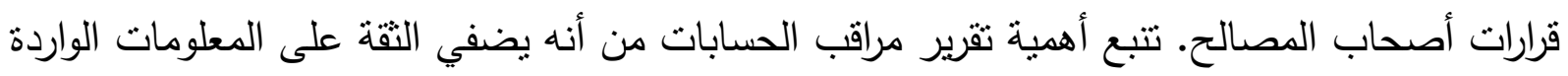

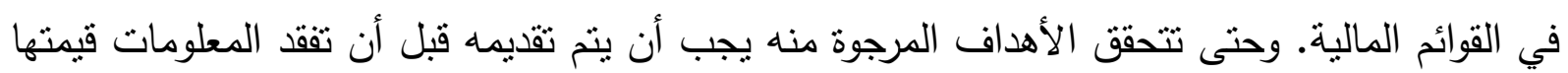

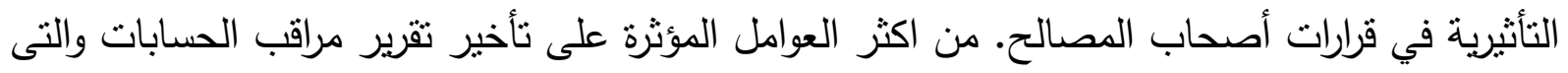

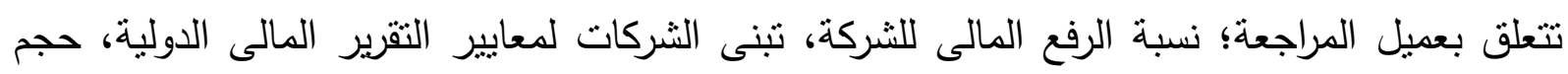

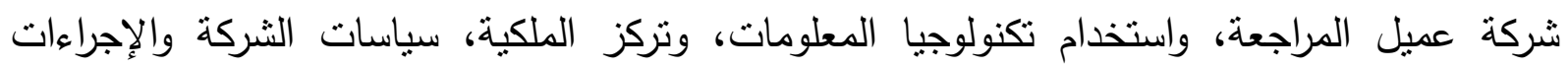
المتبعة فيها متل قوة نظام الرقابة الداخلية والنظام المحاسبي ودرجة تعقيده. ومن أكثر العوامل المؤثرة

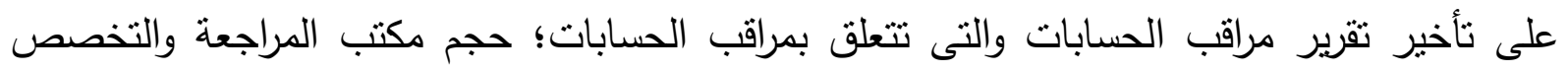
الصناعي لمراجع الحسابات والفترة الزمنية لإزتباط المراجع بالثركة وطبيعة إجراءات الثرات المراجعة وتوقيتها.

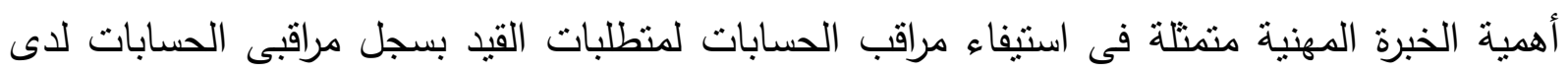

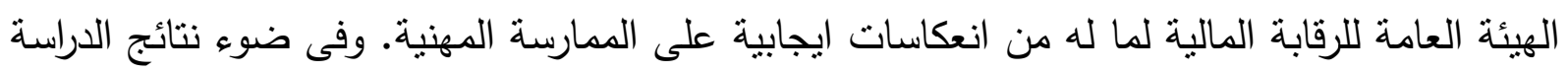
تم تقديم مجموعة من التوصيات. الكلمات المفتاحية:

مؤشرات جودة المراجعة- تأخير تقرير مراقب الحسابات- إستقلال مراقب الحسابات- نظام الرقابة الداخلية-

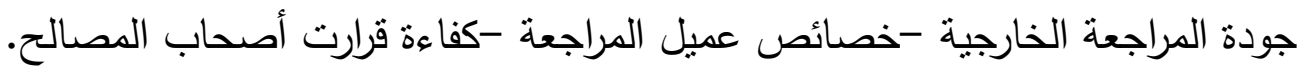


تقع مسئولية إعداد القوائم المالية علي إدارة الثركة بهدف تلبية إحتياجات كافة أصحاب المصالح من المعلومات التي توصلها هذه القوائم لتساعدهم في إتخاذ قراراتهم المختلفة، إلا أن هذه المعلومات لا يمكن الاعتماد عليها قبل أن يتم مراجعتها بواسطة مراقب حسابات مستقل يصدر تقريره عن عملية المراجعة والذي يتضمن رأيه في مدي صدق وعدالة القوائم المالية، ولذلك يعتبر تقرير مراقب الحسابات المنتج النهائي لعملية المراجعة، وتتبع أهميته في درجة الثقة التي يضفيها على القوائم المالية المنشورة، والتي يعتمد عليها مستخدمي القوائم المالية في اتخاذ قراراتهم الاستمارية. كما يعتبر التقرير هو المنتج النهائى لأداء عملية التوكيد، والذى يعتبر بمثابة الأداة التى يتم من خلالها توصيل مراقب الحسابات لاستتناجه لأصحاب المصالح بثأن ما إذا كانت تأكيدات الإدارة فى تقريرها عن الاستدامة تتمشى مع

متطلبات القياس والإفصاح السارية التى اتفق عليها مع عميله. (عبد الرحيم، 9 1 ـ ب) وتجدر الاثارة فى هذا الصد، يعتبر توقيت إصدار تقرير مراقب الحسابات من المتغيرات التي يمكن أن تؤثر على منفعة المعلومات المقدمة في ذلك التقرير، فتقديم التقرير في الوقت المناسب يساعد مستخدميه على تحقيق الاستفادة المرجوة منه. حيث يؤثز التأخير في إصدار تقرير المراجعة على جودة المعلومات المحاسبية، من خلال التأثير على التوقيت المناسب لهذه المعلومات.

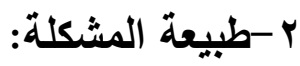

يتمنت الهدف النهائى للمراجعة الخارجية في اضفاء الثقة والمصداقية على تلك المعلومات التى تحتويها القوائم المالية ـ الا أنه في السنوات الأخيره ، وخاصة في ظل الأزمة المالية العالمية ، ظهرت العديد من الفضائح المالية في عالم الأعمال على مسنوى العالم والتى كان من شأنها التأثير على مصداقية المعلومات المالية المنشورة وبالتبعية تقويض ثقة مستخدمى القوائم المالية في مصداقية عملية المراجعة كمهنة مستقلة. إن وقتية التقارير المالية مرهونة بمجموعة من المحددات، لعل أهمها إكمال وإصدار تقرير المراجعة في الوقت المناسب، حيث من ناحية تمنع قوانين سوق الأوراق المالية في بعض الدول حول العالم نشر القوائم المالية دون إرفاق تقرير مراقب الحسابات عن هذه القوائم المالية، ومن ناحية أخرى تتخفض منفعة القوائم المالية، دون تقرير مراجعة يوصل نوكيد معقول Reasonable Assurance بشأن خلو القوائم المالية دن التحريفات الجوهرية Material Misstatements، وأن القوائم المالية أعدت في جميع جوانبها الهامة طبقا للمعايير المحاسبية المطبقة، وبالأحرى إطار إعداد التقارير المالية المطبق (ISA, No.r. . ) ) و ومن ثم فإن الفوائد المرجوة من وقتية نشر القوائم المالية لن تأني دون وقتية موازية لتقرير المراجعة. (يوسف، · r.r) وفي عام • 1 • قسم الاطار المشترك الصادر عن مجلس معايير المحاسبة المالية ومجلس معايير المحاسبة الدولية الخصائص النوعية المعلومات المحاسبية الى مجموعتين؛ الخصائص الرئيسية وتشمل 
الملاءمة والتثثيل العادل، والخصائص الداعمة وتشمل كلاً من القابلية للمقارنة والتوقيت المناسب والقابلية للتحقق ، والقابلية للفهه، مع وجود قيود وتتمنل في زيادة العائد على التكلفة والأهمية النسبية(FASB,2010) . ويعرف التوقيت المناسب بانه القدرة على توفير المعلومات المحاسبية لكافة الأطراف ذات العلاقة وقت الحاجة اليها ، وداخل الحيز الزمنى لاتخاذ القرارات ، ويعد التوقيت المناسب

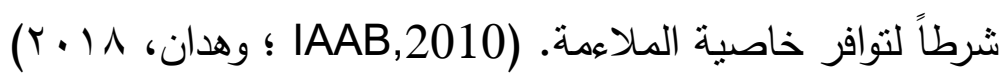
يتضح مما سبق أن، القضية البحثية التى تتصدى لها هذه الدراسة تتمثل فى التساؤل التالى، ما هو

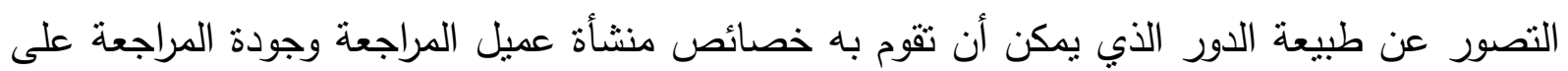
العلاقة بين مدى تأخير إصدار تقرير المراجعة وكفاءة قرارات أصحاب المصالح بالثركات المناء المقيدة

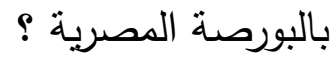

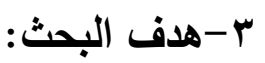

يهدف البحث الحالى الى استعراض وتحليل أثز خصائص منشأة عميل المراجعة وجودة المراجعة

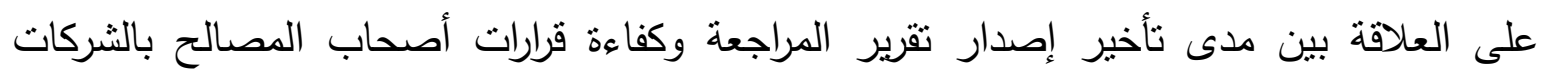
المقيدة بالبورصة المصرية من خلال دراسة نظرية وتحليلية.

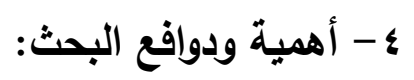

تتبع أهمية ودوافع البحث من جانبين الأكاديمى والعملى، فعلى الجانب الأكاديمى هناك ندرة فى

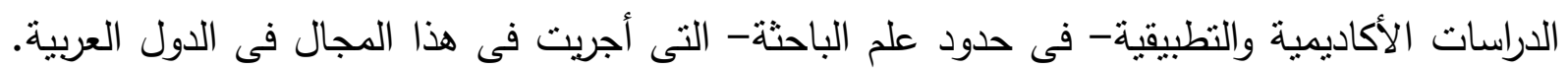

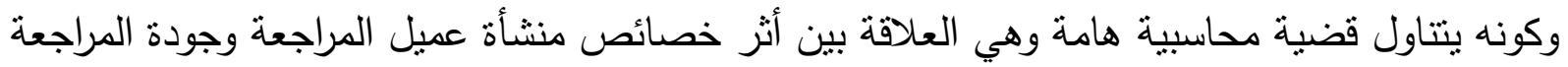
على العلاقة بين مدى تأخير إصدار تقرير المراجعة وكفاءة قرارات أصحاب المصالح بالثركات المقيدة

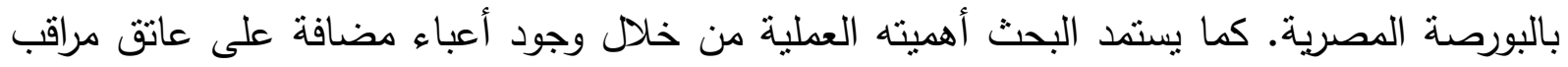

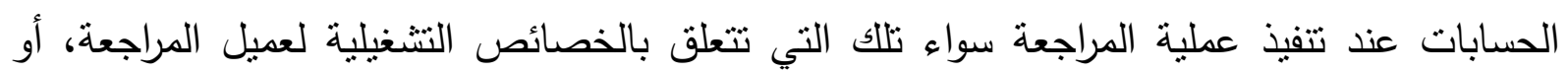

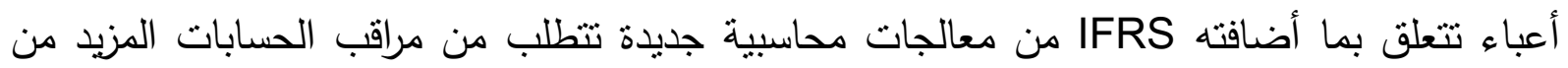

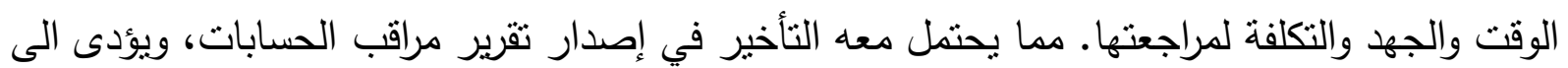

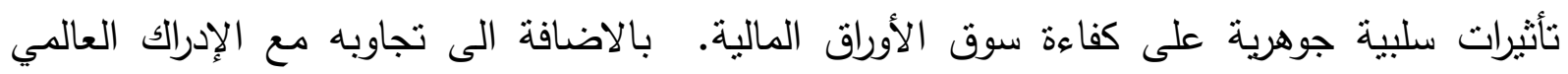

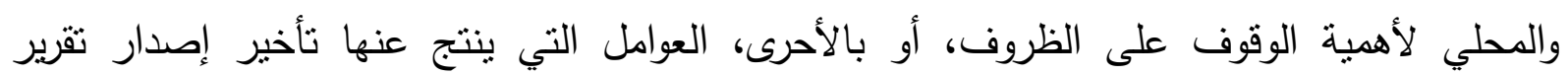
المراجعة، وتتسبب في الوقت ذاته في انخفاض مستوى نفعية المعلومات الواردة في القوائم المالية.

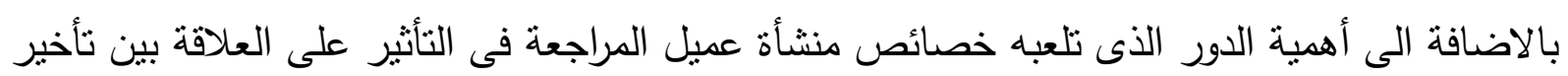
إصدار تقرير المراجعة وكفاءة قرارات أصحاب المصالح بالثركات المقيدة بالبورصة المصنية المصرية. 
تحاول الباحثة فى هذه الدراسة استعراض وتحليل أثز خصائص منشأة عميل المراجعة وجودة

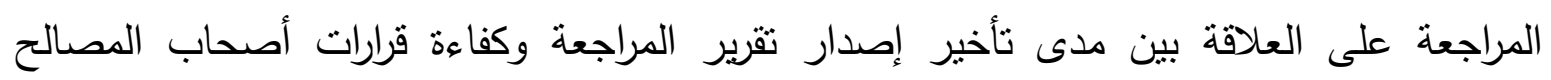

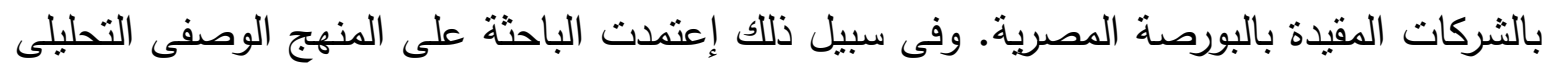

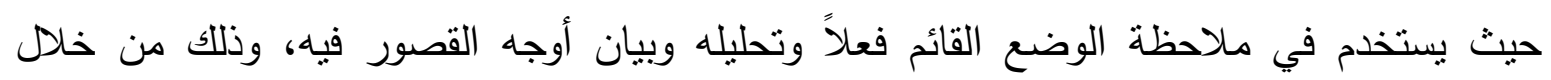

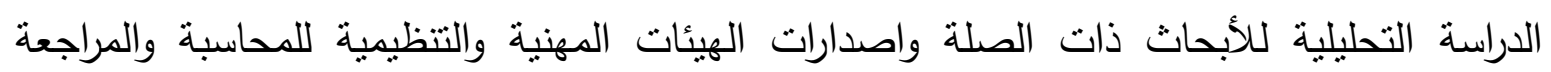
لصباغة الاطار النظرى للاراسة. צ- خطة البحث: انطلاقا من مشكلة البحث وتحقيقاً لأهدافه، وفى ضوء حدوده، سوف يتم استكماله على النحو التالى:

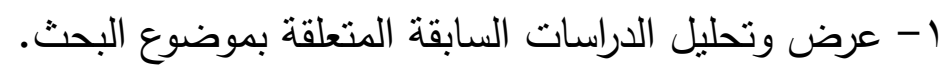
r- فترة تأخير إصدار تقرير مراقب الحسابات: الدفهوم والأهمية والمقاييس من منظور أصحاب الصاب المصالح. ب-كفاءة قرارات أصحاب المصالح من المنظور المحاسبى. ع-تحليل العلاقة تحليل العلاقة بين تأخير إصدار تقرير مراقب الحسابات وكفاءة قرارات أصحاب المصالح. 0- جودة المراجعة الخارجية : المفهوم والأهمية. ج-تحليل أثز خصائص منشأة عميل المراجعة على تأخير إصدار تقرير مراقب الحسابات وكفاءة الحاءة

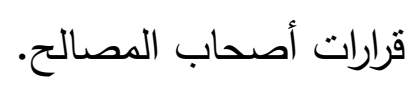

V - تحليل أثز جودة المراجعة على العلاقة بين تأخير إصدار تقرير مراقب الحسابات وكفاءة قرارات

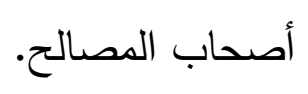

\section{1/1/ عرض وتحليل الدراسات السابقة المتعلقة بموضوع البحث:}

يعد تقرير مراقب الحسابات هو وسيلة الاتصال بين مراقب الحسابات والمستقيدين من القوائم المالية، وفي كثير من الأحيان هو وسيلة الاتصال الوحيدة بينهم. حيث يعتمد مستخدمي القوائم المالية

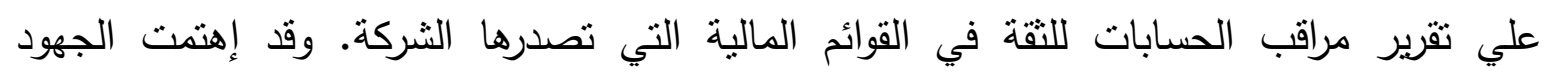
المحاسبية بقضية تأخير إصدار تقرير المراجعة وعلاقته بجودة التقارير المالية، وتوصلت إلى وجهات التهات

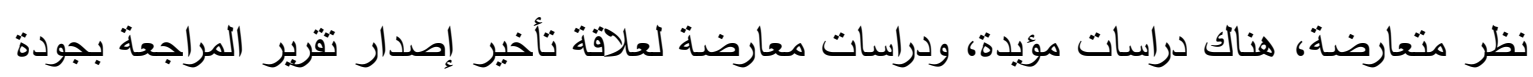

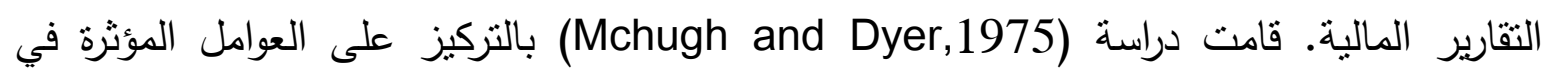

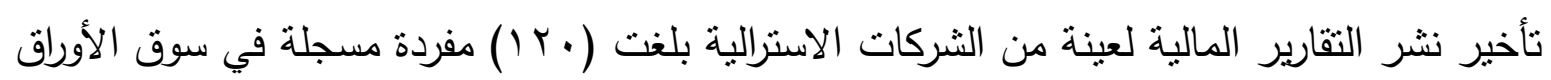

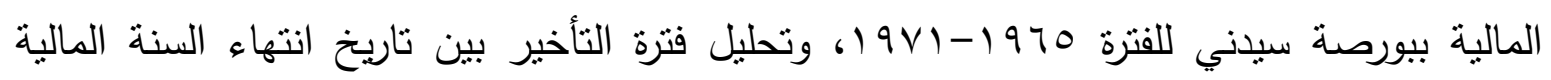
وإصدار التقارير ، إلى عدة فنرات في محاولة لبيان نأثير طول فترة الثأخير في منفعة التقارير المالية. 
ولتحقيق هدف الدراسة افترضت الدراسة أن الثركات كبيرة الحجم لا ترغب أو غير قادرة على تخفيض

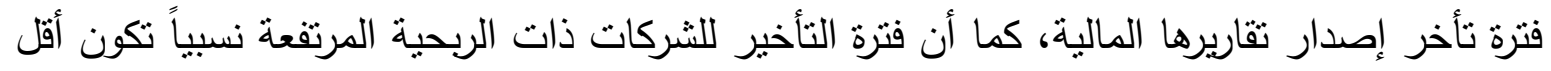
منها للشركات ذات الربحية المنخفضة. كما استهدفت دراسة(Whitred,1980) التعرف على تأثاثير

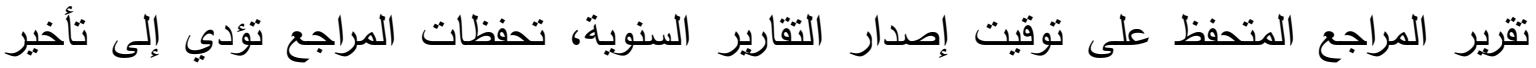

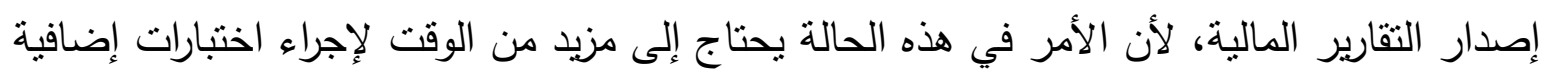

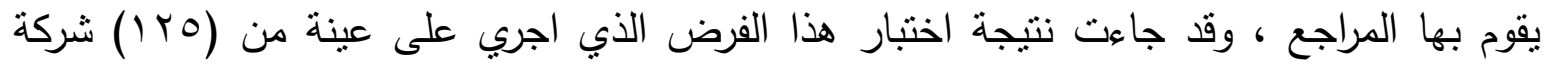
أمريكية خلال الفترة 970 1971، مؤيدة لوجود علاقة بين الأهمية النسبية للنحفظ وفترة تأخير

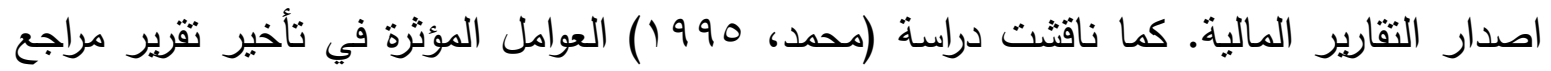
الحسابات، والبحث في تأثثر ثلات مجموعات من المتغيرات المؤثرة في نأخير إصدار التقارير المالية هي؛ مجموعة المتغيرات التي تتعلق بخصائص الثركة وتتمنل في؛ العناصر غير التئ العادية للقوائم المالية، ونطاق نشاط الثركة، وتداول أسهم الثركة في السوق المالي، وحجم الثركة، وطبيعة النشاط،

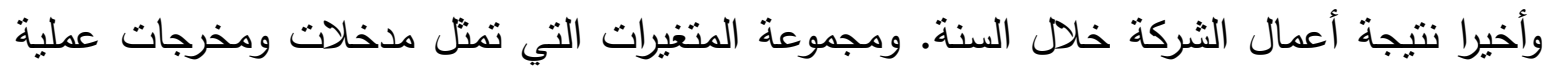
المراجعة وتتمنل فى حجم مكتب المراجعة، وموعد بدء عملية المراجعة، ورأي المراجع ومجموعة المتغيرات التي تعبر عن العلاقة بين الثركة والمراجع وتتمنل في طول فترة العلاقة بين الثنركة والمراجع والخدمات المقدمة من قبل المراجع. وقد توصلت الى وجود ارتباط بين فترة تأخير إصدار

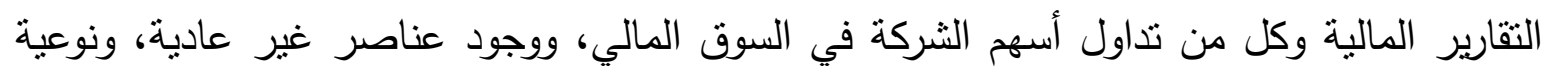
تقرير المراجع، ولكن القدرة التقسيرية لنموذج الانحدار الخاص بالدراسة كانت منخفضة جدا. كما

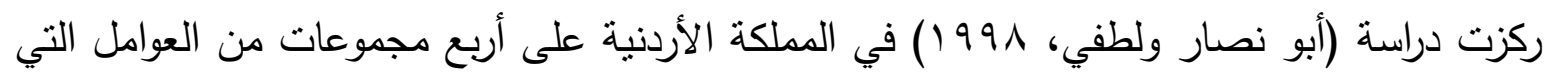

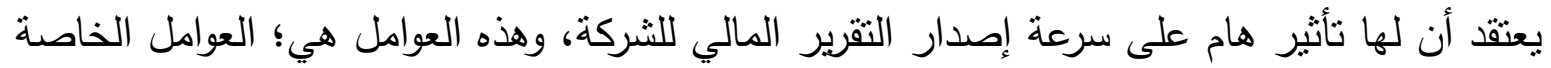
بالثركة مثل حجمها وطبيعة نشاطها، سياسات الثركة والإجراءات المتبعة فيها منل قوة نظام الرقابة الداخلية والنظام المحاسبي ودرجة تعقيده، العلاقة بين مكتب المراجعة وادارة الثركة، وحجم مكتب المراجعة وطبيعة إجراءات المراجعة وتوقيتها. وتوصلت الى أن لهجوعة المتغيرات الخاصة بضعف

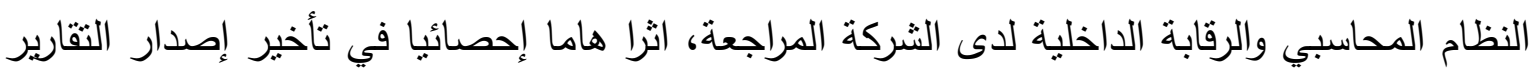

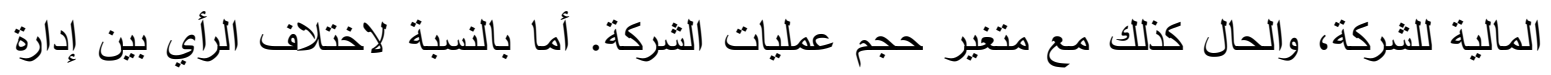

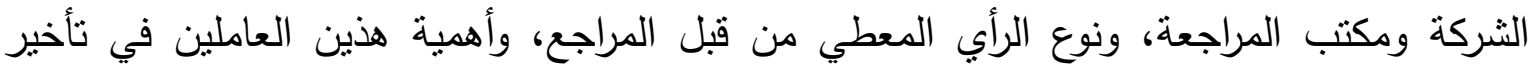
إصدار التقارير المالية بنسبة أكبر.

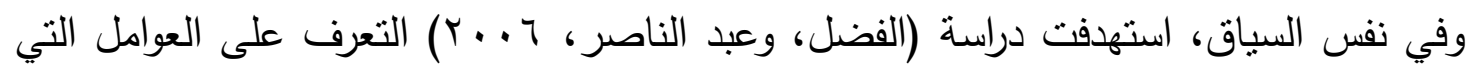
يمكن أن تؤدي إلى تأخير إصدار التقارير السنوية للشركات في كل من العراق والأردن. ونم استخدام

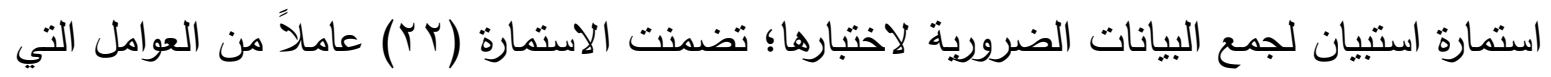

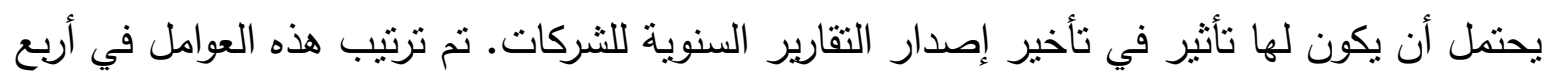


مجموعات نرتبط الأولى بالثركة، والثانية بمعايير المراجعة وقواعد السلوك المهني، والثالثة بمكتب

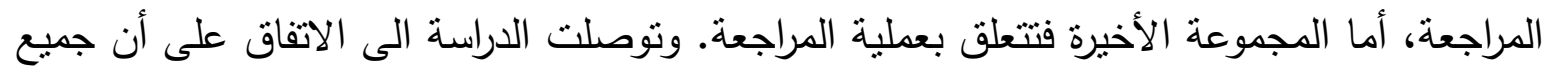

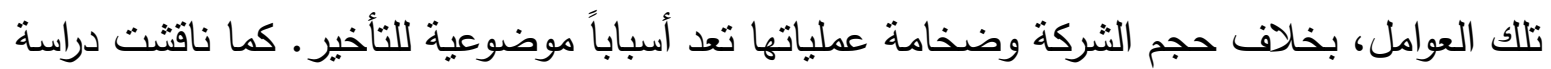
(Bonson et al., 2008)

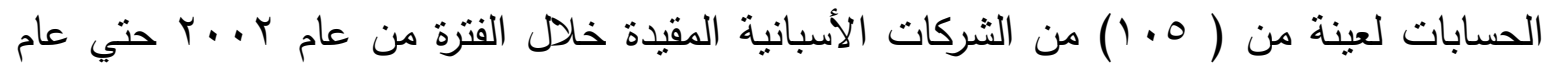

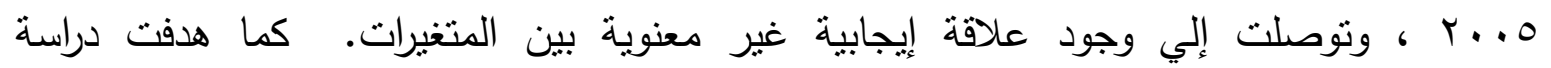

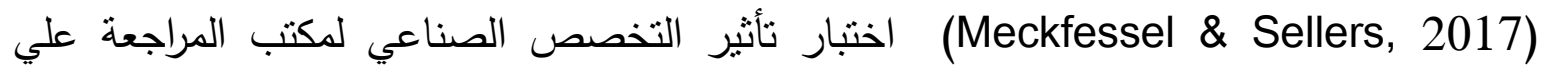

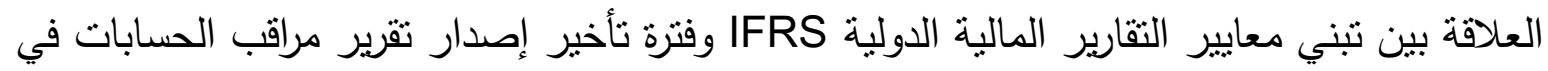

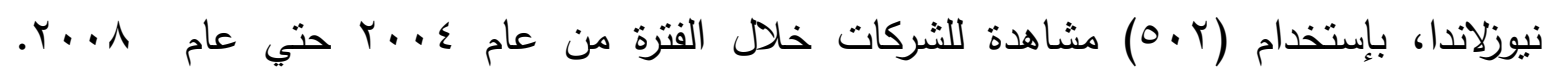

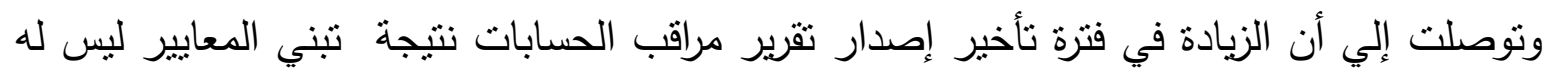

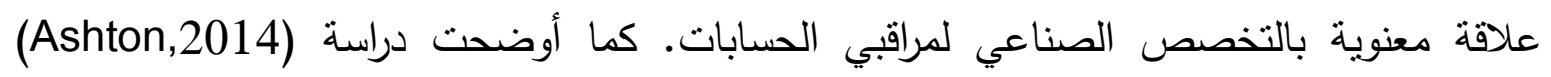

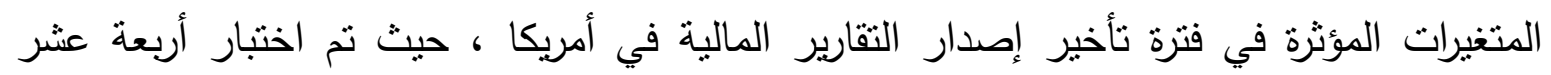
متغيرة منها تسعة متغيرات تتعلق بخصائص الثركة والخمسة الباقية تتعلق بمكتب المراجعة، وقد

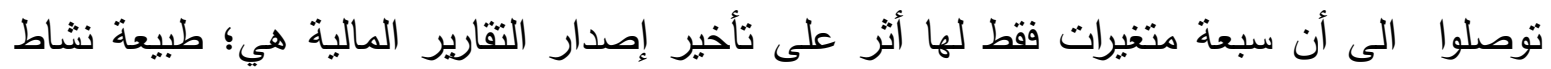

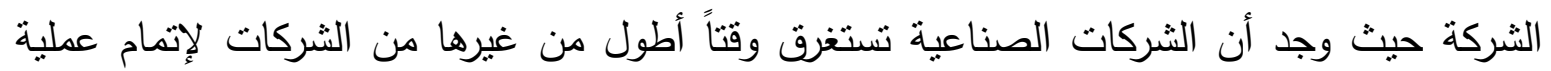

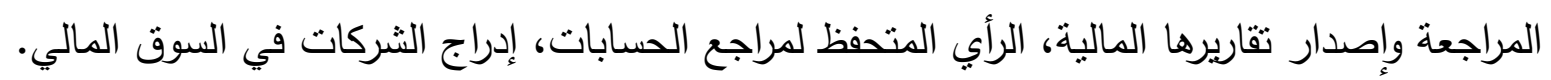
الثركات المدرجة في السوق المالي تستغرق وقتا أقصر لإصدار تقاريرها المالية السنوية من مثيلاتها غير الددرجة في السوق. كما ناقتت دراسة (Nguyen et al.,2015) اختبار تاثير تنبي معايير IFRS ومتغيرات رقابية أخري تتمنل في؛ حجم الثركة وعمر الشركة ونوع مكتب المراجعة علي فترة تأخير إصدار تقرير

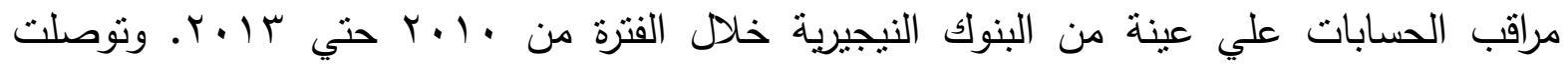

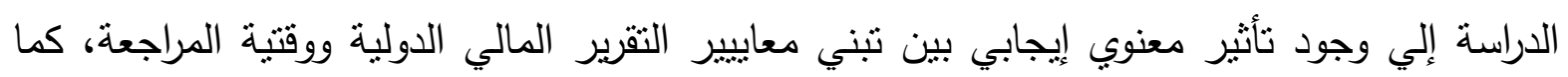

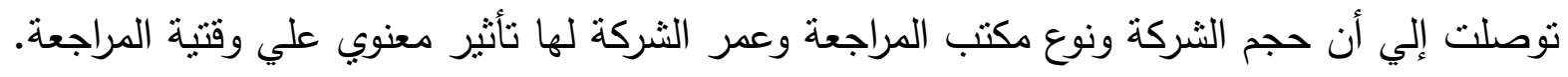

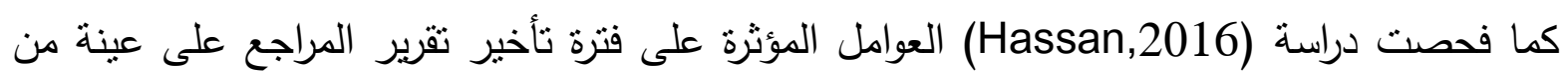

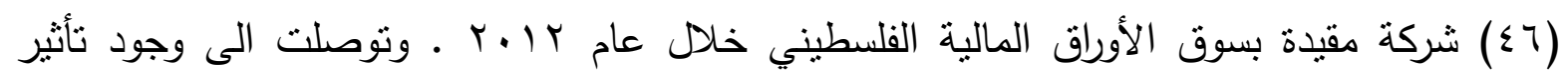

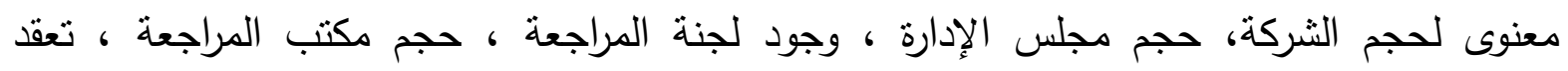

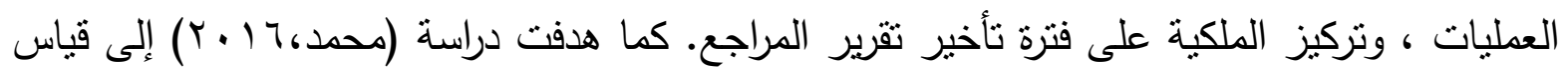

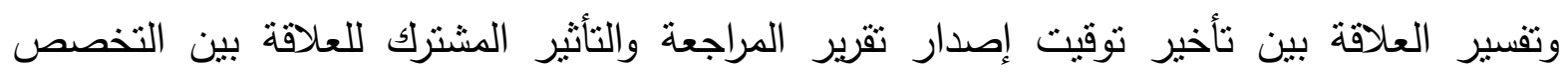

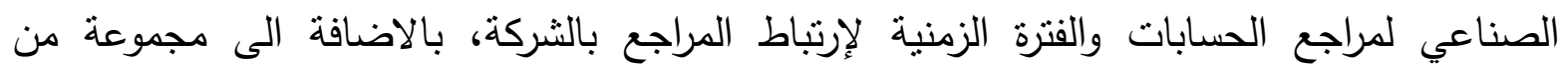

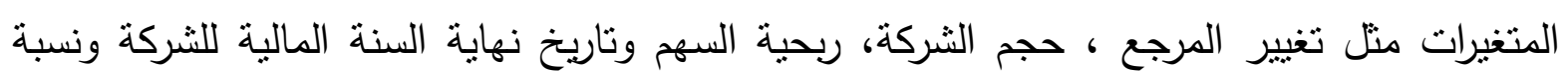


السيولة بالثركة ومعدل العائد على الاصول. وتوصلت الدراسة إلى وجود علاقة ذات دلالة معنوية

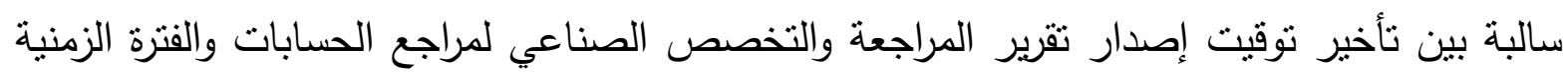
لإرتباط المراجع بالثركة وربحية الثركة. ووجود علاقة إيجابية ذات دلالة معنوية بين تأخير نوقيت إصدار تقرير المراجعة وتغيير المرجع وحجم الثركة. ولا توجد أى علاقة بين نهاية السنة المالية للشركة

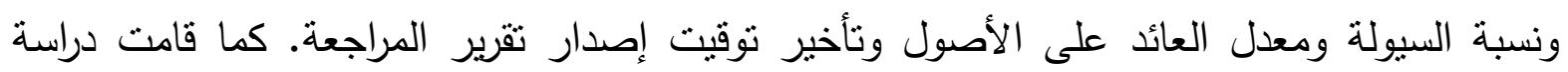

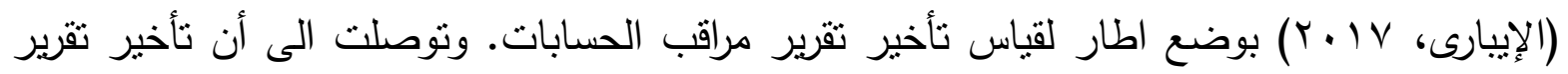
مراقب الحسابات له تأثير جوهرى فى تحديد قيمة منشأة العميل (القيمة السوقية لحقوق المساهمين)،

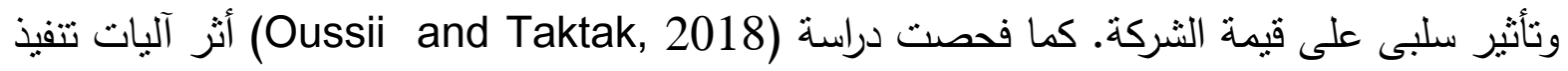
المراجعة المختلفة على وقتية تقرير مراقب الحسابات، كمقياس بديل لجودة المراجعة.

باستقراء الأدبيات السابقة يتضح أن هناك فجوة معرفية فى مجال العلاقة بين أثر خصائص منشأة

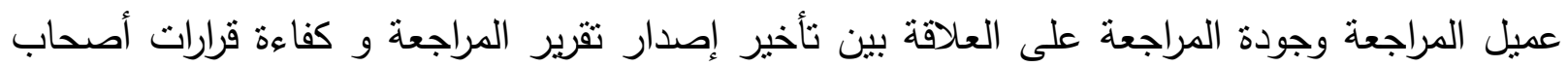
المصالح بالثركات، ، كما اختلفت الدراسات السابقة حول متوسط فترة إصدار القوائم المالية للشركات المساهمة المقيدة بالبورصة المصرية والمعتمدة من مراقب الحسابات. كما أنها لم تعطي الانتباه الكافى لتوضيح ما هى منطلبات تطوير مسئوليات المراجعين تجاه تحسين جودة المراجعة. وقد وجدت الباحثة في

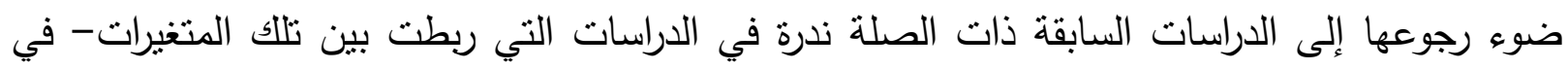
حدود علم الباحثة- التي تتاولت العلاقة بين خصائص منثأة عميل المراجعة وجودة المراجعة على العلاقة بين تأخير إصدار تقرير المراجعة.

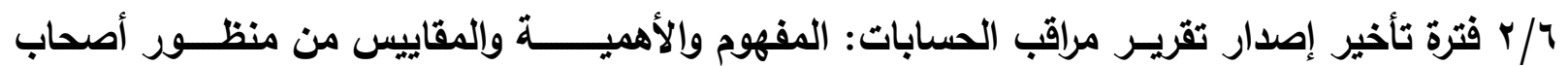

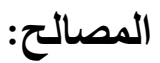
يعد تقرير مراقب الحسابات عن نتاج المراجعة التي قام بها للقوائم المالية السنوية ، والذي يبدي فيه رأيه بشأن مدي صدق وعدالة هذه القوائم في التعبير عن نتائج الثركة ومركزها المالي، كما يعد أداة

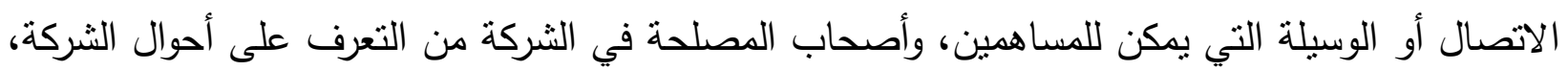

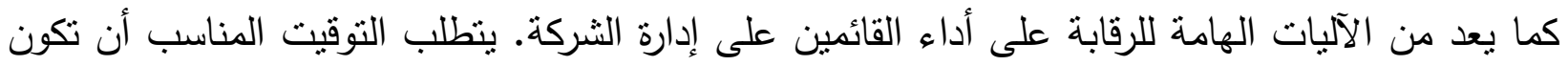

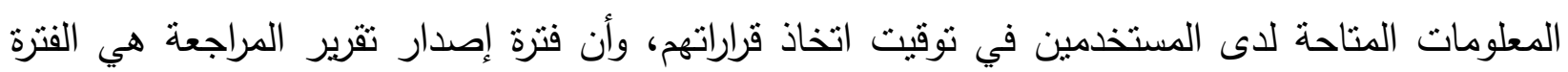

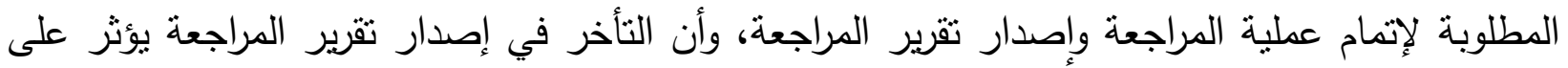

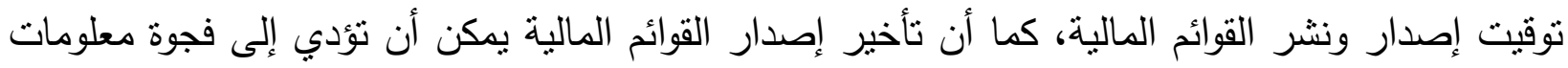

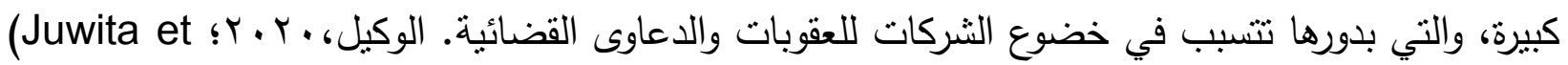

al.,2020)

تتبع أهمية تقرير مراقب الحسابات في درجة الثقة التي يضفيها على القوائم المالية المنشورة ، والتي

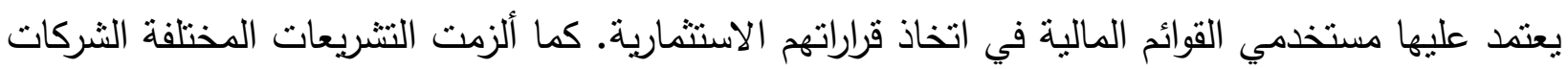


التي تتشر قوائمها المالية أن تكون هذه القوائم مصحوبة بتقرير مراقب الحسابات، كما تعد هذه الأهمية هى المبرر الأساسي في الطلب على خدمة مراجعة القوائم المالية من قبل مستخدمي هذه القوائم. ونظراً لأهمية

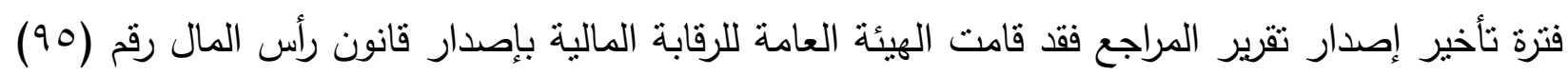

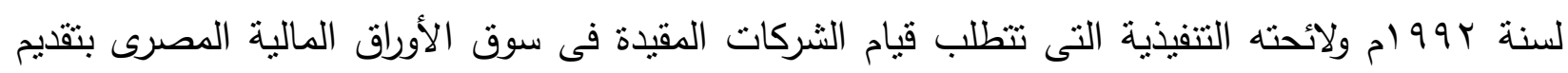

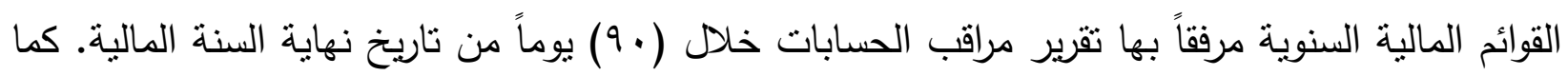

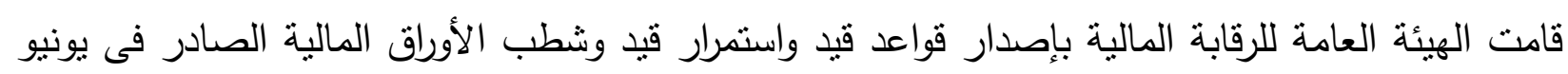

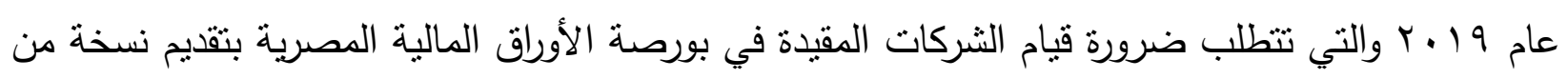

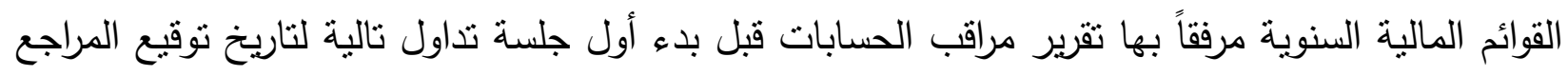

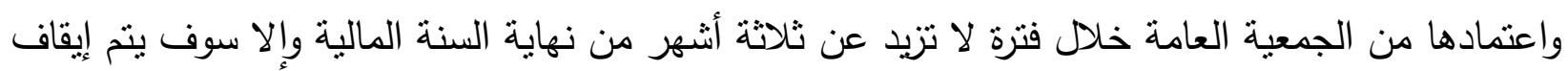

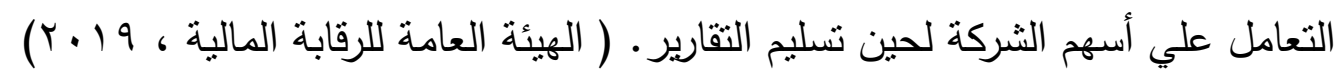
وتجدر الاشارة فى هذا الصدد، تعتبر الوقتية في تقديم المعلومات من الخصائص النوعية المعززة

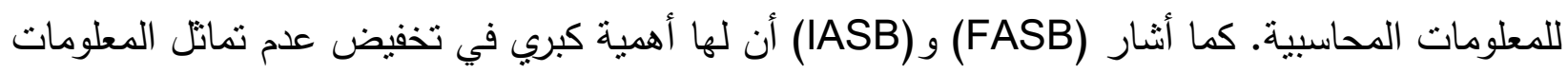

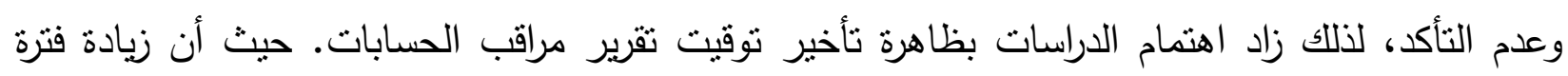

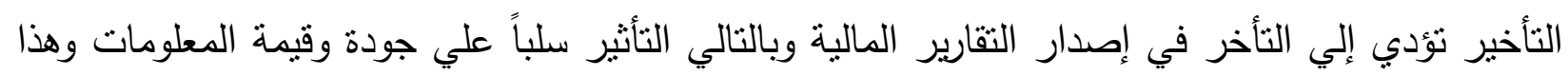

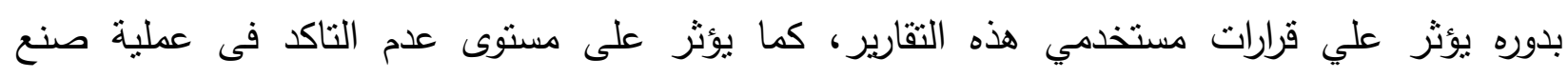
القرار · (Dao\& Pham, 2014) يعبر التأخير في تقرير المراجعة عن المدة من نهاية السنة المالية للثركة حتي تاريخ إصدار تقرير

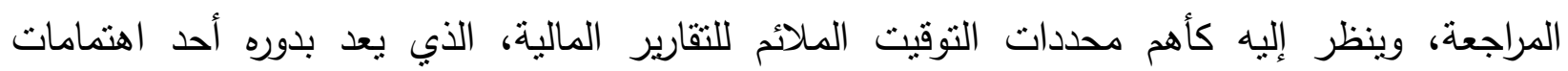
المستثرين والادارة ومراقبي الحسابات على السواء، ويؤدي إلى تحسين اتخاذ القرار والحد من عدم تماتل

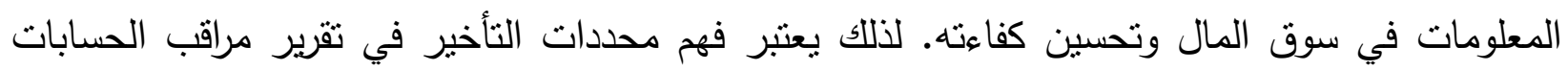
وأهمية التوقيت الملائم للتقرير ، ومن ثم التوقيت الملائم للقوائم المالية للشركات وآثاره المختلفة أمراً هاماً

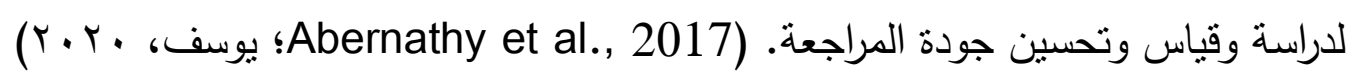

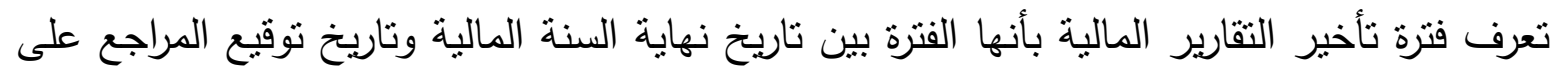
تقرير المراجعة (Rusmin and Evans,2017; Hassan,2016) ، كما تعرف أيضاً بأنها طول الفترة

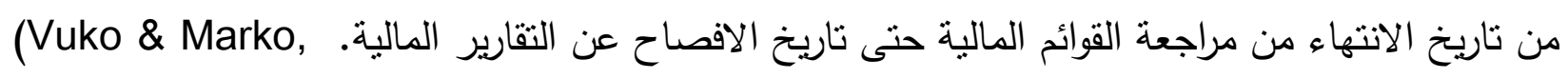

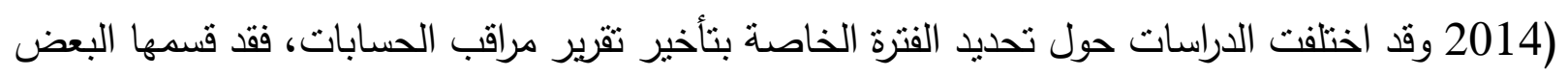
(Pizzini et al., 2015)

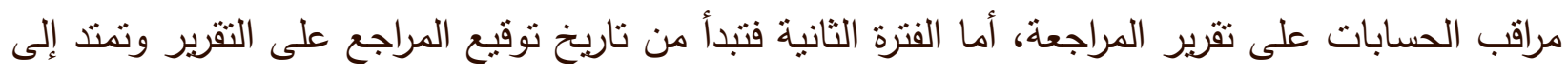

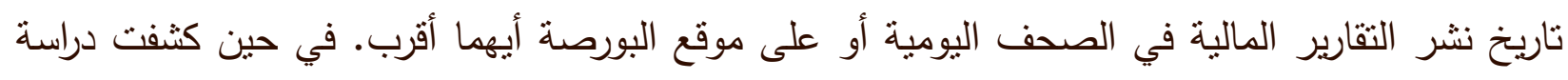

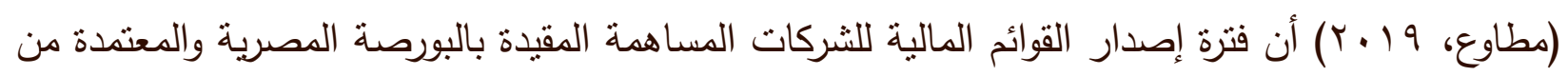




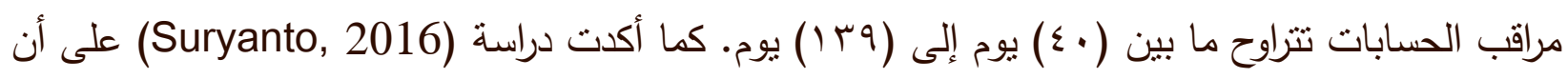

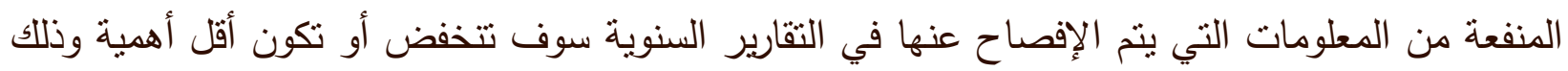

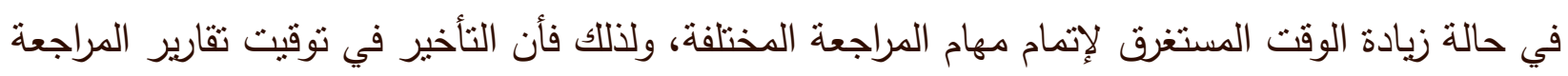

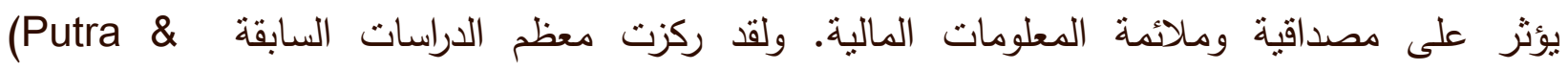
عratiwi,2018 ; Sultana et al., 2015)

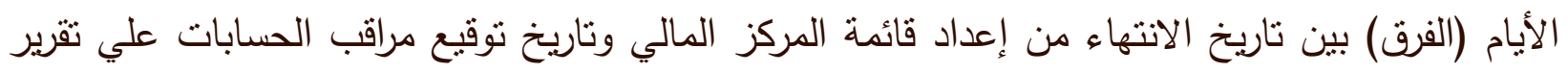

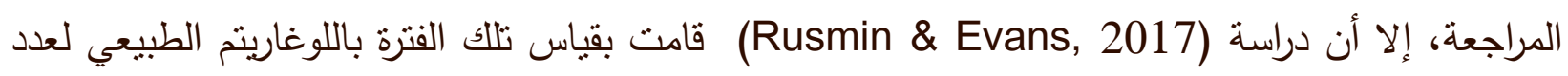

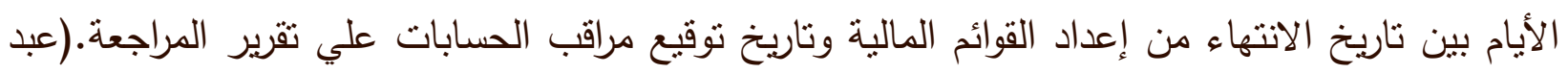

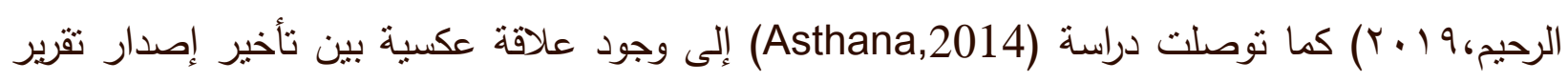

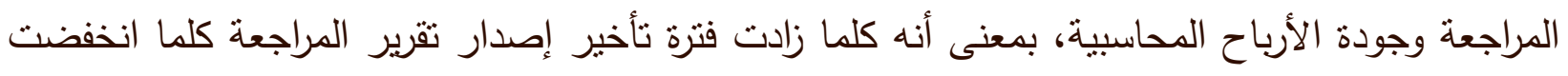

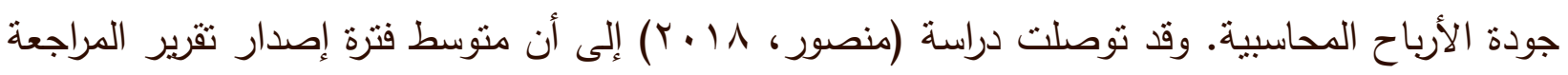

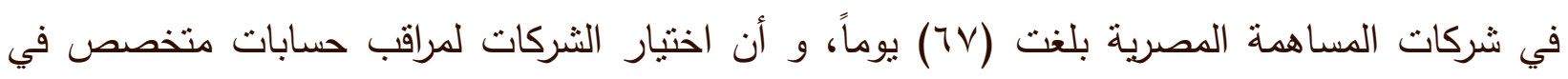

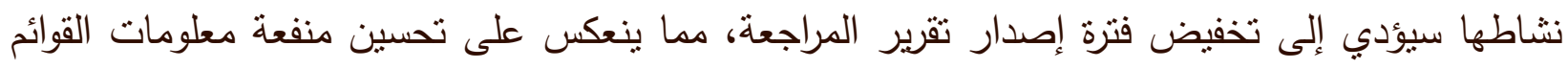
المالية. وأن فترة تأخير إصدار تقرير المراجعة في شركات المساهمة المصرية تراوحت ما بين (9) أيام إلى إلى

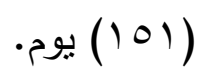
ترجع أهمية تخفيض فتزرة تأخير النقارير المالية الى حاجة الأطراف المختلفة ذات الصلة للمعلومات في

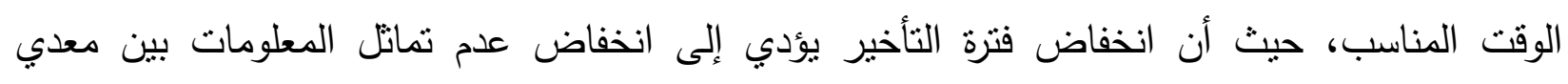

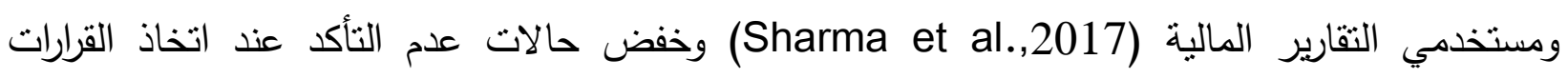

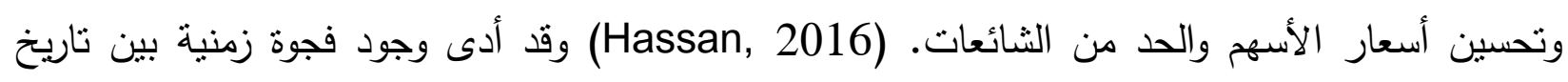

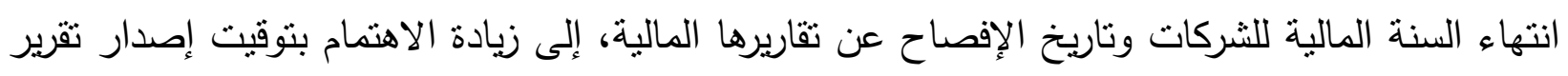

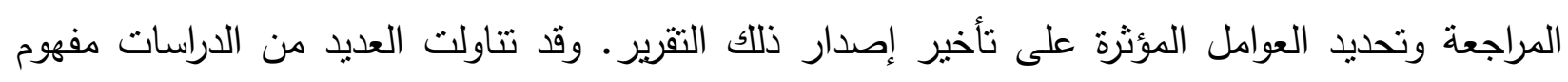

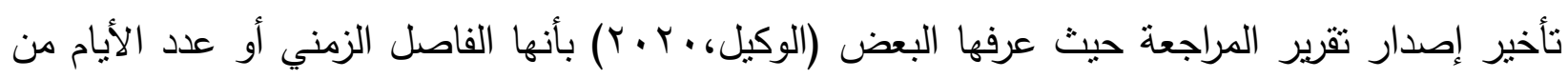

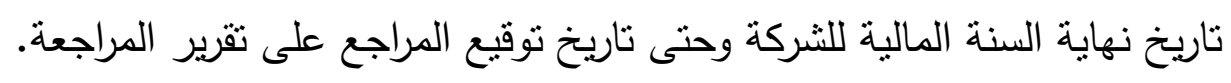

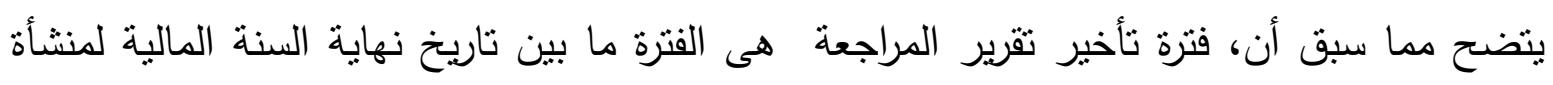

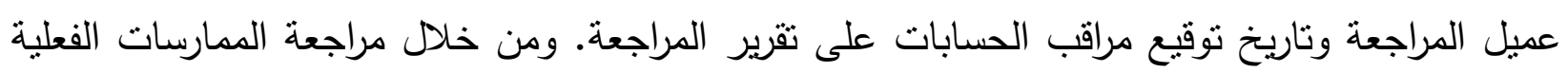

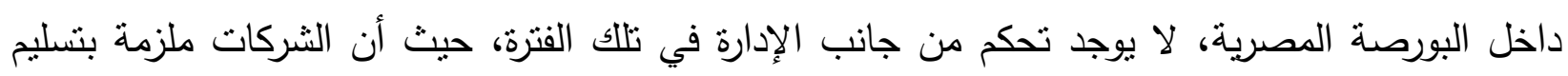

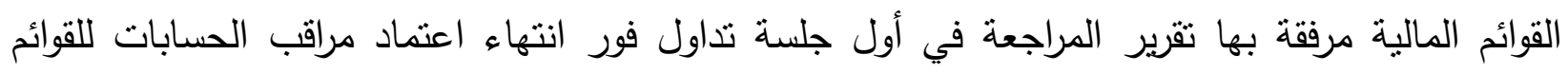

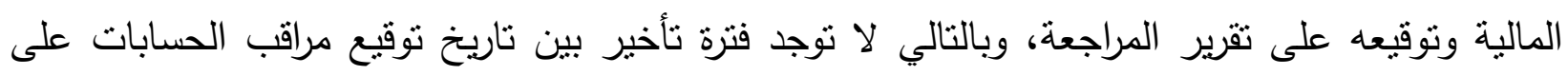

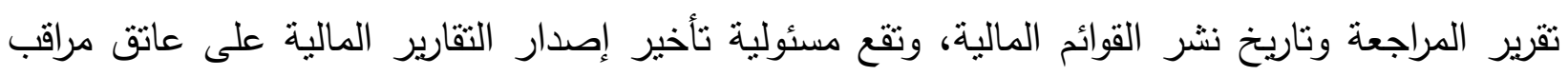

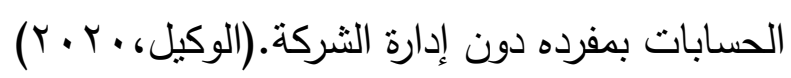


- دور الجهات التنظيمية في الدول المختلفة فى الاهتمام بوقتية التقارير المالية:

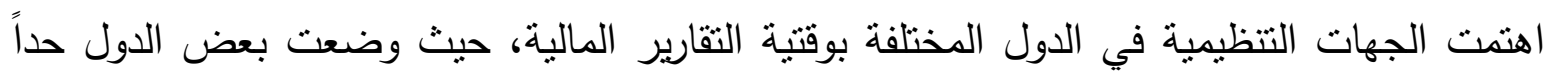
أقصى للفترة التي يتم فيها نشر هذه التقارير، وتبنت بعض الدول قواعد لتقليل هذه الفترة. ففي الولايات

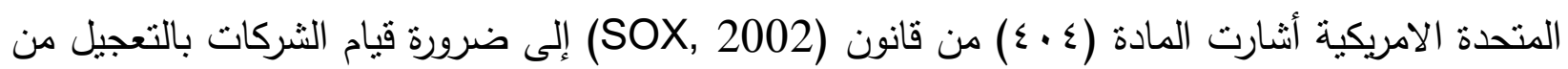

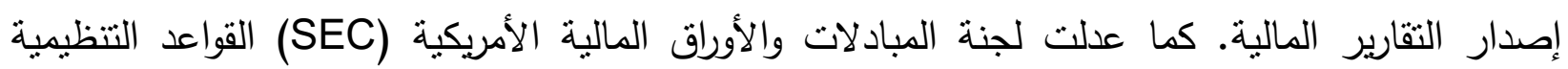

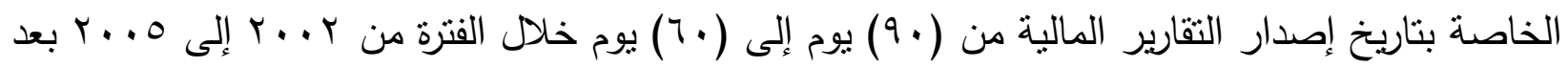

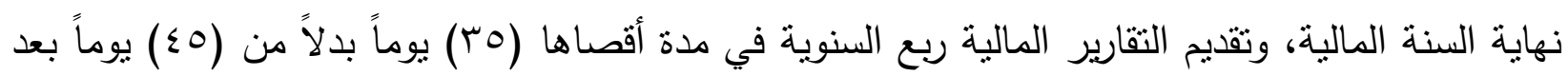
نهاية كل ربع سنة. (Sahnoun \& Mohamed, 2009) يتوقف توقيت نشر القوائم المالية على فترة إصدار تقرير المراجعة من قبل مراقب الحسابات، حيث كلما زادت فترة إصدار تقرير المراجعة كلما زاد التأخير في نشر القوائم المالية، وهذا بدوره يؤثر سلباً في قرارات مستخدمي القوائم المالية. كما أن تأخير عرض النتائج المالية يؤدي إلى نأخير الإفصاح عن المعلومات، ويفتح الباب أمام نشر الثائعات حول أداء

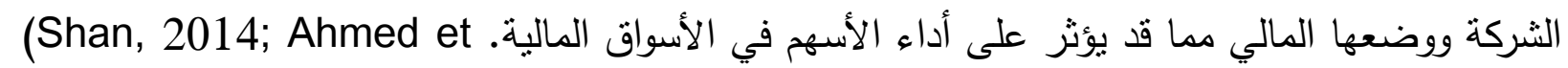

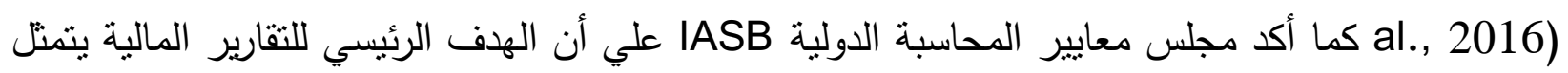
في توفير المعلومات الهامة لمستخدمي هذه التقارير التي نساعدهم في إتخاذ القرارات الاقتصادية الرشيدة، علي أن ينت نشرها في التوقيت المناسب قبل أن تفقد قيمتها وأهينها في إتخاذ القرارات ولتحقيق الفائدة المرجوة منها. وفى مصر أكدت معايير المحاسبة المصرية المُعدلة لسنة 10 ـ ب على ضرورة توفير المعلومات المتاحة لمتخذي القرارات في الوقت المناسب لتكون قادرة على التأثير في قراراتهم. كما ألزم قانون الثركات

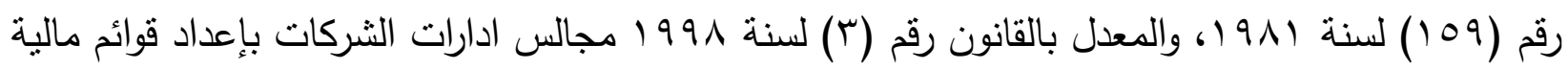

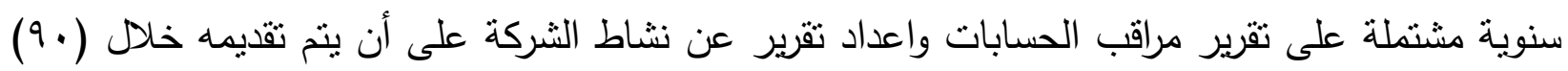

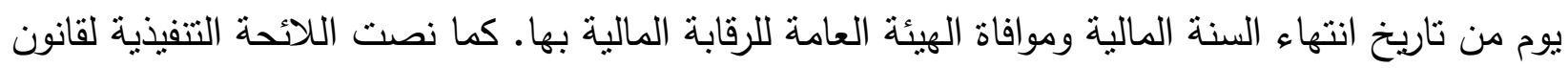
رأس المال رقم (90) لسنة ب99 (بأنه على الثركات المقيدة بالبورصة أن تقدم القوائم المالية السنوية مرفقاً

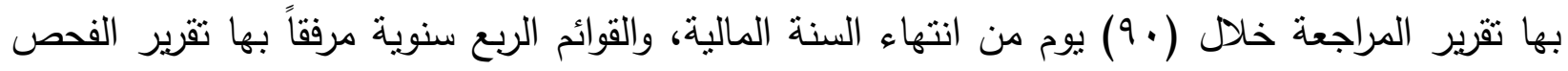

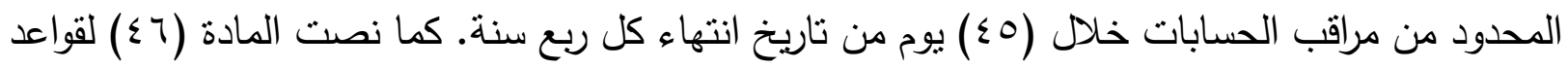

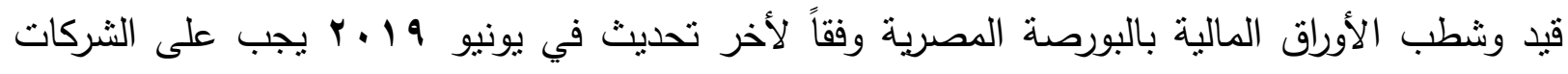

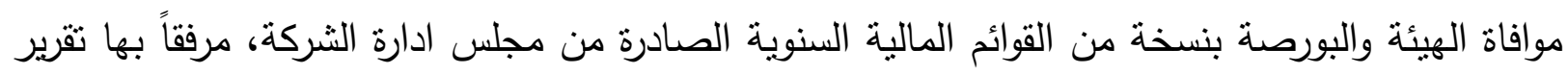

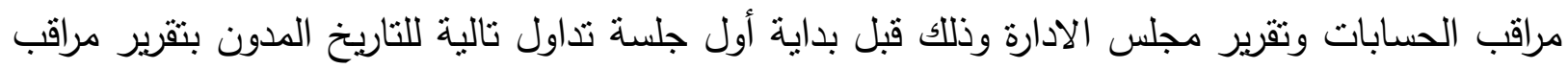

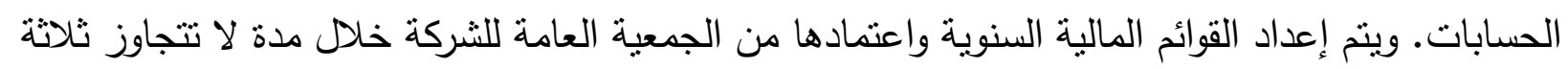

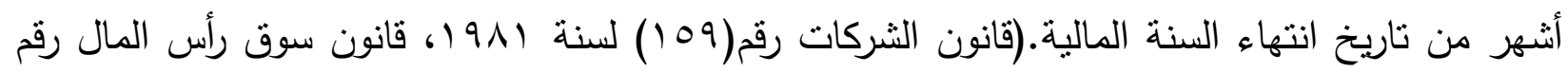

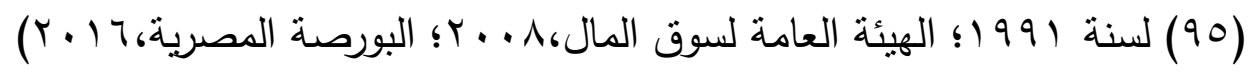




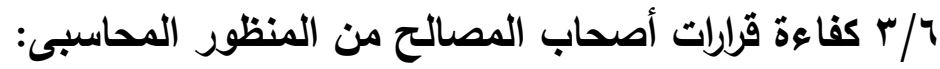

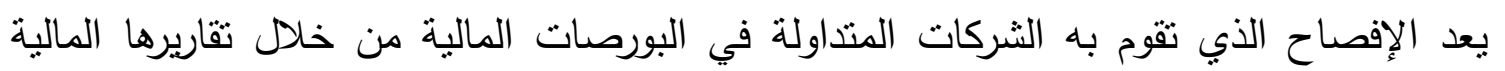

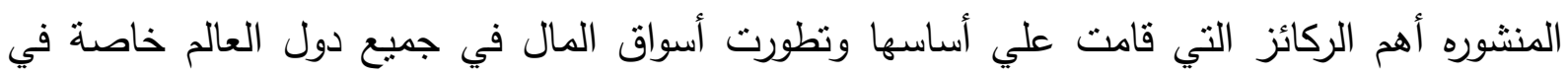
الدول المتقدمة، لأن تلك التقارير تعد مصدر من المصادر الرئيسية لحصول المتعاملين في تللك الأسواق علي المعلومات التي يحتاجونها لاتخاذ قراراتهم الإستثمارية. وقد بدأ إهتمام المستخدمين الخارجيين

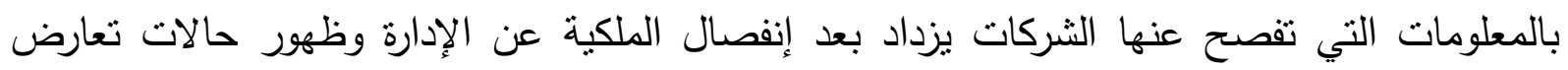

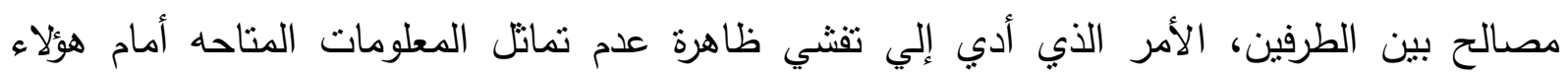
المستخدمين مما جعل التقارير التي تقوم الثركات بنشرها هي أهم وسيله للإتصال بين الإدارة وهؤلاء فئه

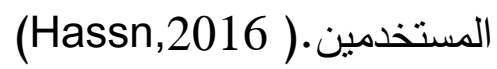

وتبرز أهمية دراسة القرارات الاستثمارية وغيرها من قرارات أصحاب المصالح باعتبار القرار

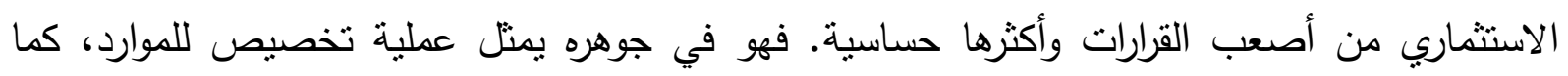

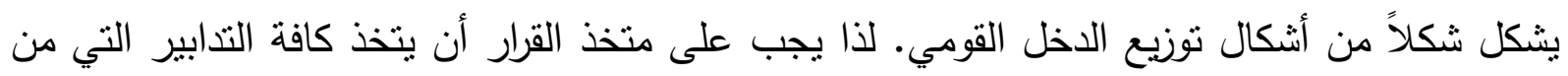

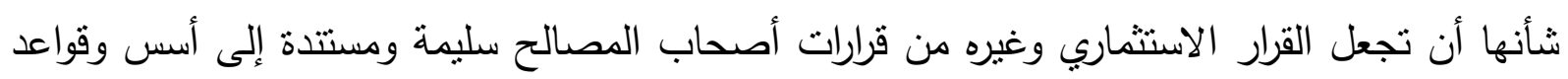
تحمي الموارد النادرة من الضياع. (Hashim,2017) عدم توافر المعلومات في أب سوق للأوراق المالية

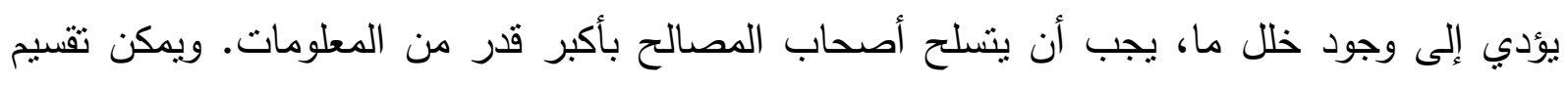
مصادر الحصول على المعلومات إلى قسمين؛ معلومات تهم المستخدمون الخارجيون من مستثمرين

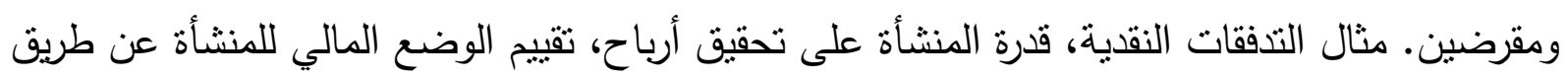

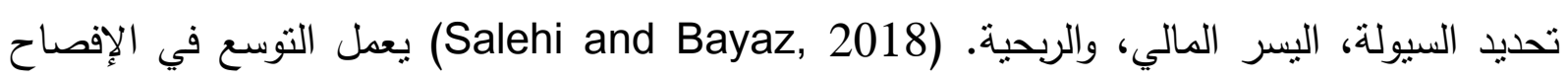

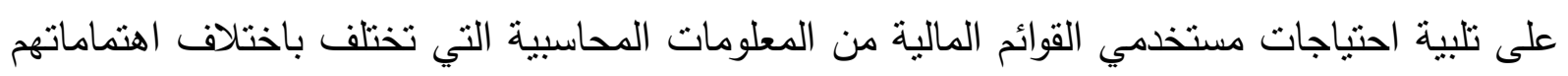

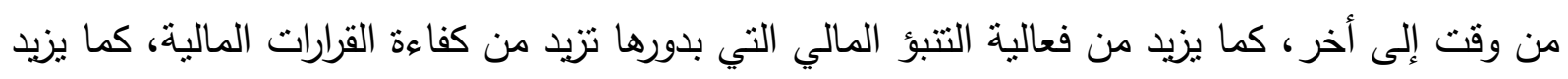

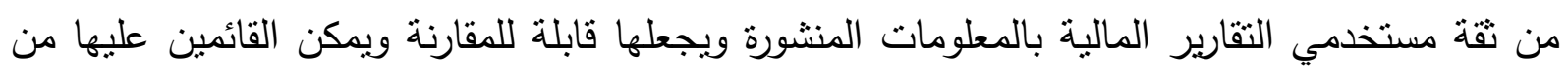

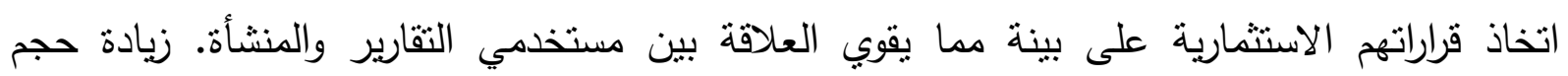

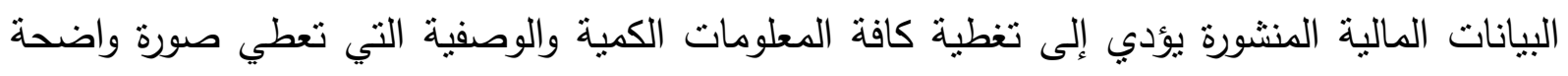
عن أعمال المنشأة. (Rusmin \& Evans, 2017) يعتمد الاستثمار في الأوراق المالية وتداولها بالدرجة الأولى على الإفصاح عن البيانات والمعلومات عن جميع أنثطة الثركات التي ينت التعامل

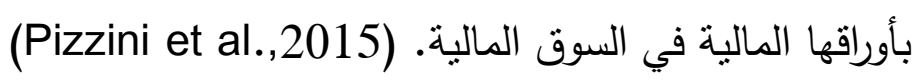
تستقيد الثركات من نوفير المزيد من المعلومات للمستخدمين الخارجيين من خلال تخفيض تكلفة

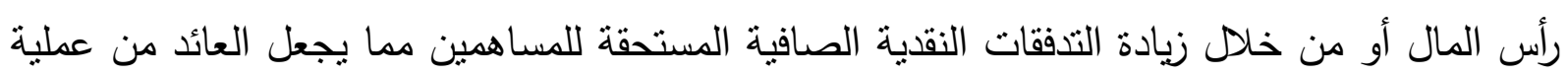

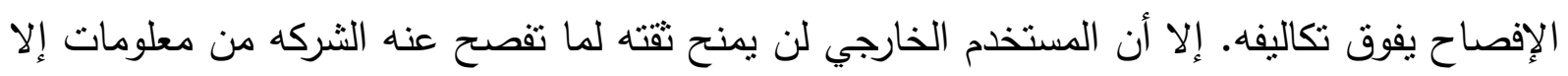

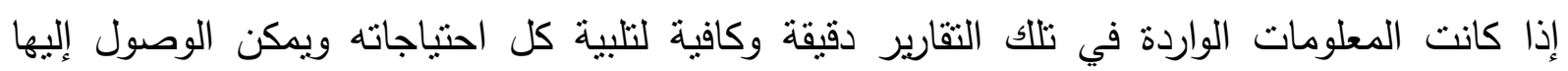




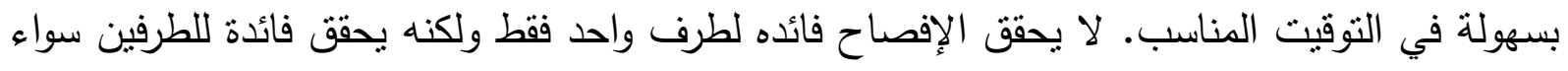

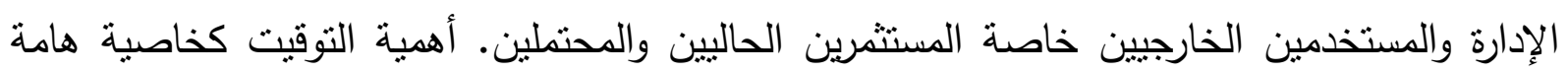

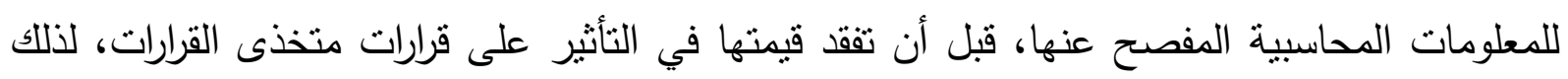

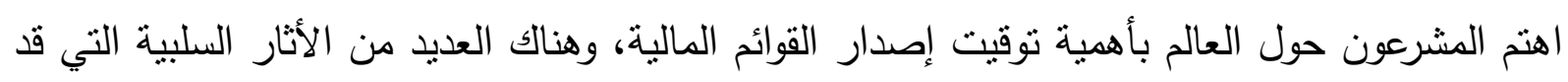

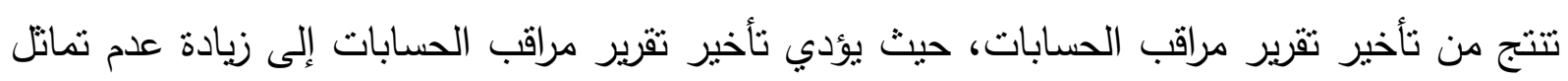

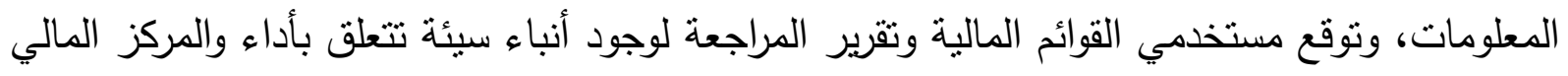

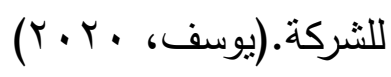

\section{- أنواع المعلومات اللازمة لاتخاذ قرارات أصحاب المصالح:}

تقوم استمرارية التعامل في الأسواق المالية الخاصة بالمستثرين على توافر عدة مستويات من

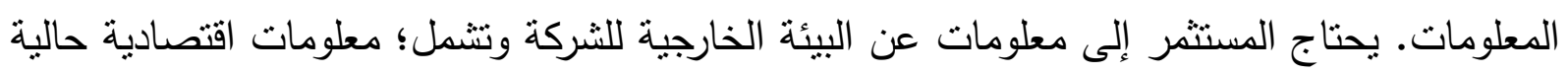

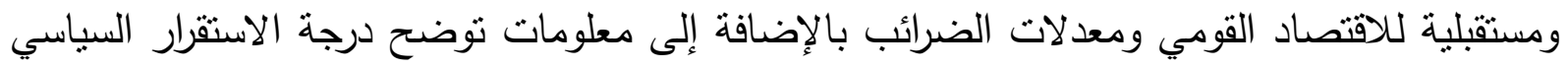
عامة واستقرار سياسات الاستثمار خاصة ومعلومات اجتماعية ومعلومات أخرى عن بورصة الأوراق

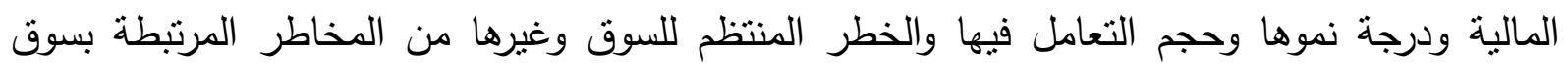

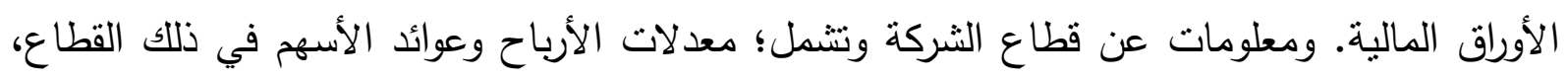

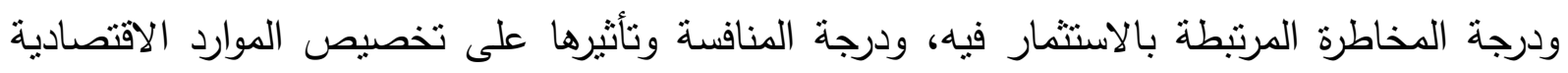

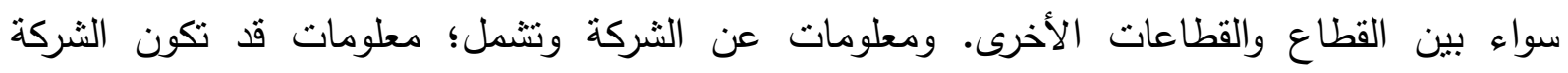

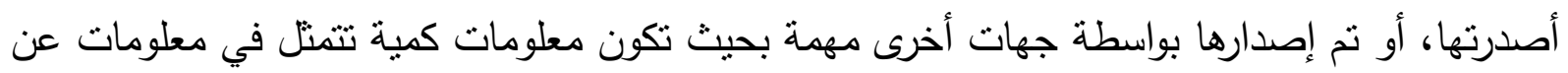

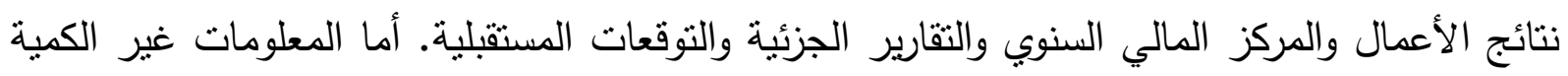

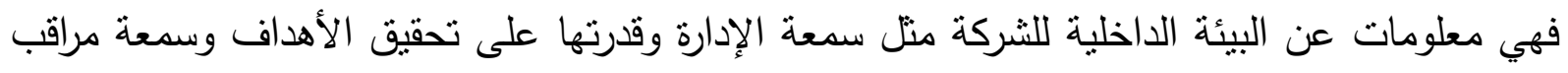

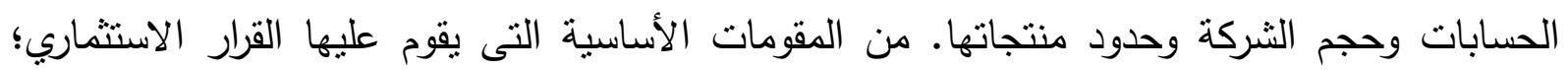

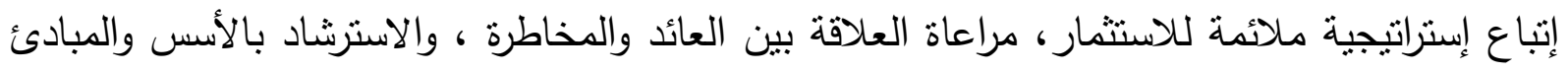

العلمية لاتخاذ القرار • (Oussii and Taktak,2018)

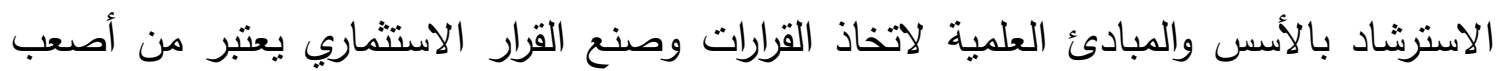

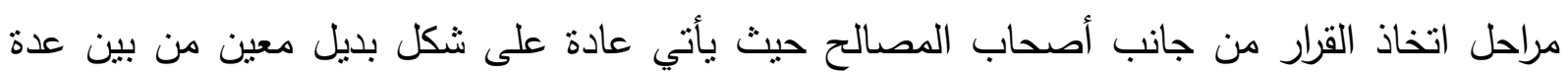

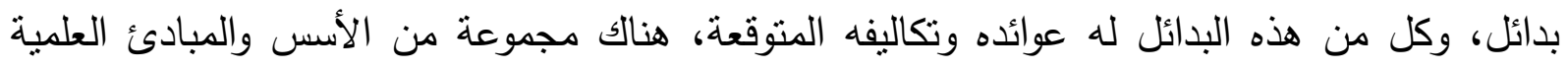

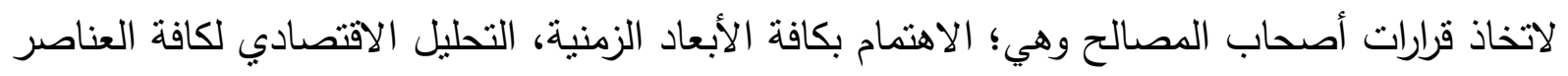

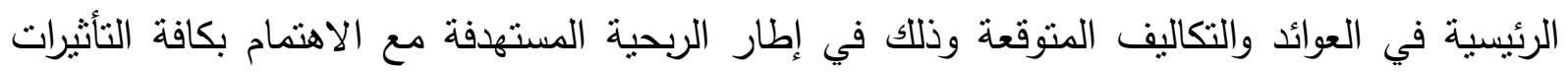

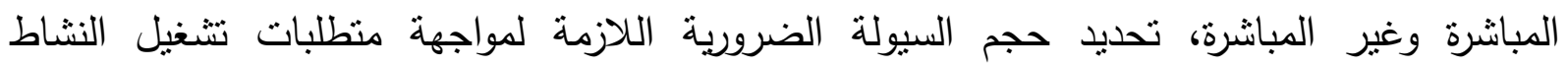

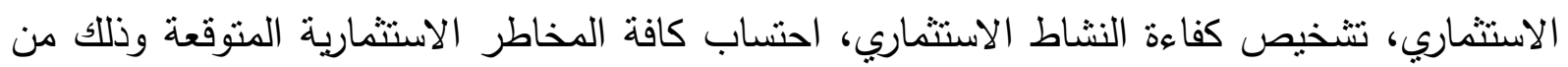
خلال تحليل كمي لهذه المخاطر، حسم إطار الربحية لتحديد مجال كل نوع من أنواع العوائد النقدية 
والمالية والمادية والبشرية والمعلوماتية، الالتزام بكافة التتريعات والسياسات والإجراءات والالتزامات

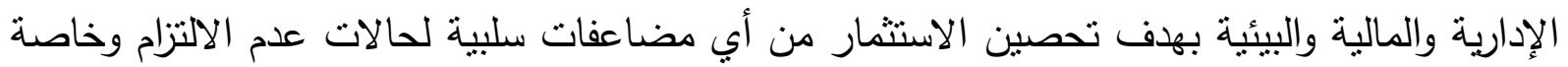

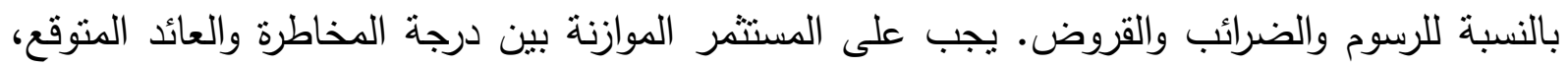

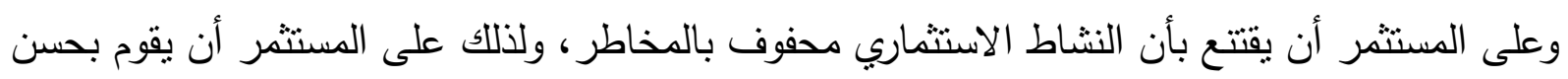
اختيار المشروع الذي يستطيع تحمل مخاطره. 7/ء تحليل العلاقة بين تأخير إصدار تقرير مراقب الحسابات وكفاءة قرارات أصحاب المصالح:

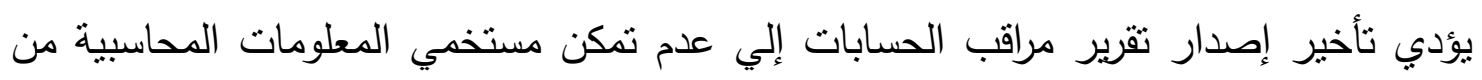

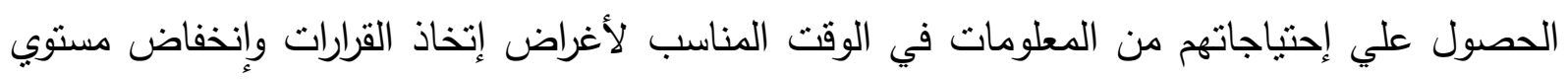
جودة المعلومات من وجهة نظر مستخدميها، مما يؤثر سلباً علي نفعية المعلومات الواردة في القوائم

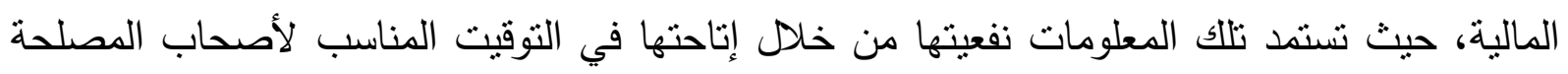

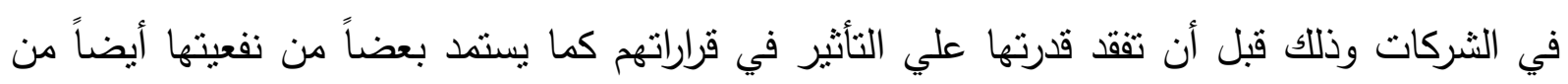

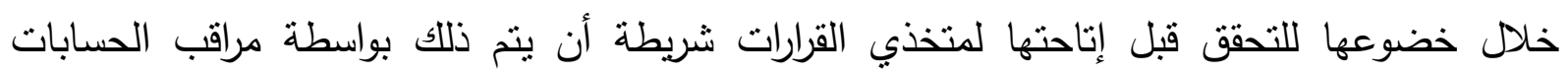

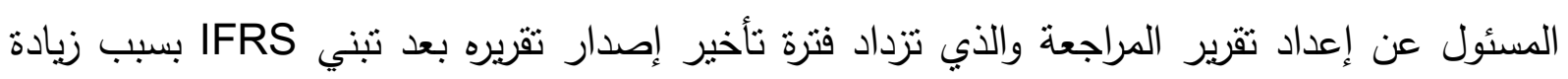

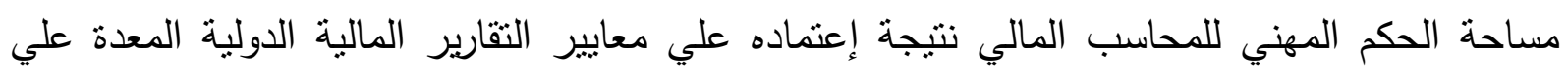

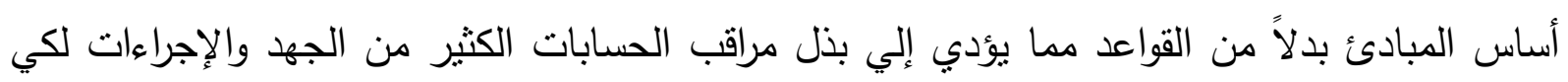

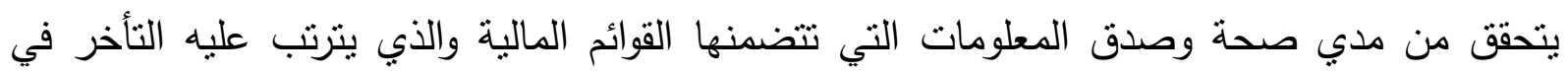

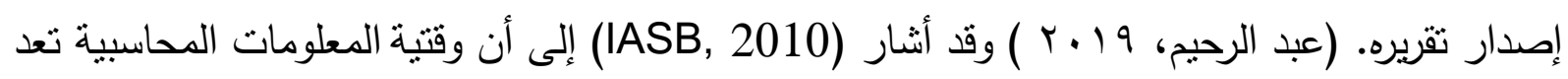

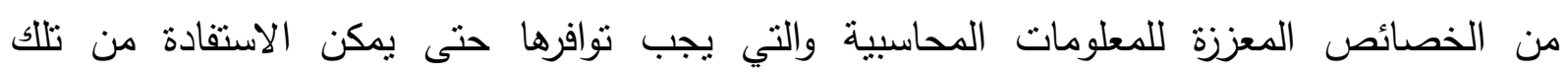

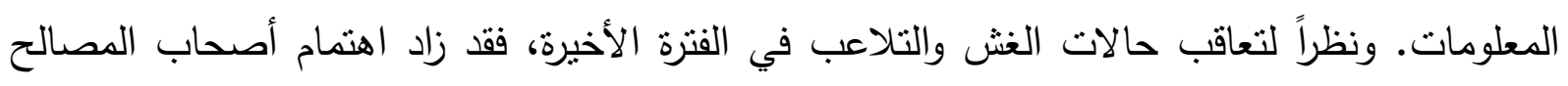
بتقرير مراقب الحسابات لما له من أهمية في اضفاء المصداقية على المعلومات الواردة في القوائم المالية،

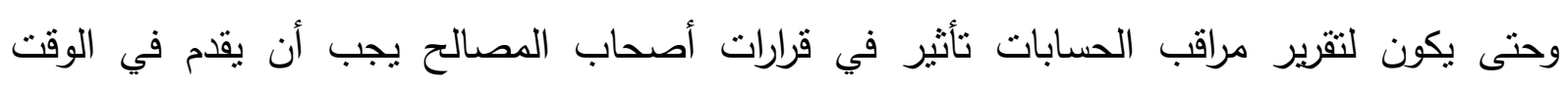

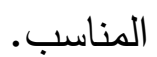

وفى هذا الصدد، تثير بعض الدراسات (Nguyen et al., 2015) إلى أن الثركات قد تبتعد

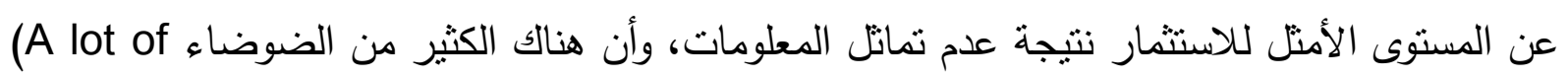

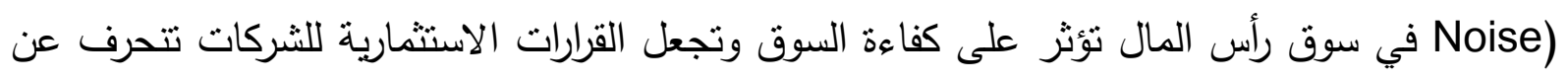

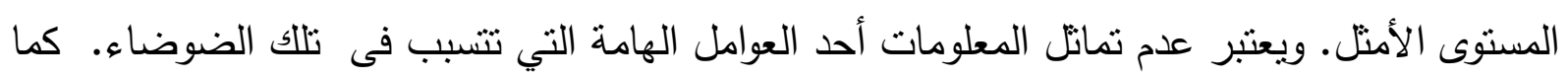

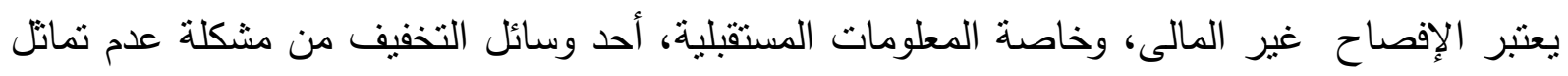

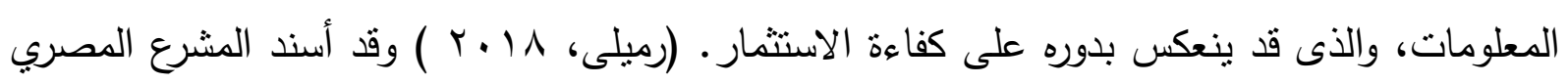

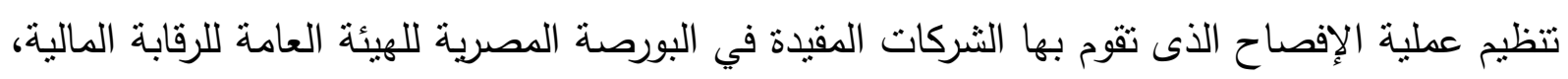
ويتكون الإطار القانونى لسوق رأس المال المصري من عدة تشريعات وقواعد تتيح للايئة القيام بدور فعال 
فى حماية المستثمرين وتتظيم السوق بالإضافة إلى أنها تتيح التطوير المستمر والدائم للإطار الرقابى

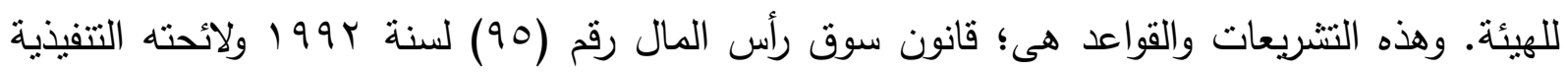

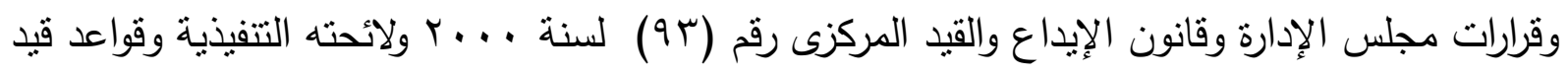

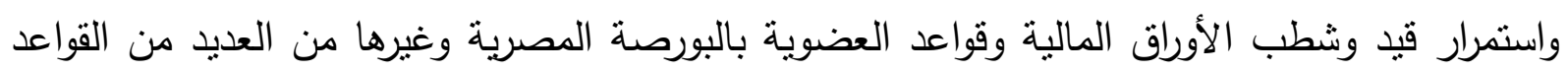
التى تعمل على نتظيم العمل داخل السوق ـ كما يوجد عدد من التشريعات ذات العلاقة بسوق رأس المال ومن بينها قانون الثركات وقانون مكافحة غسل الأموال وقانون الضرائب ولائحتهم التنفيذية. (هيئة العامة

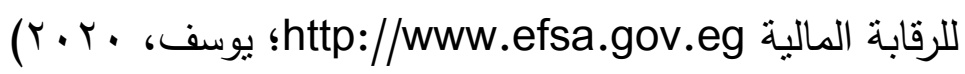

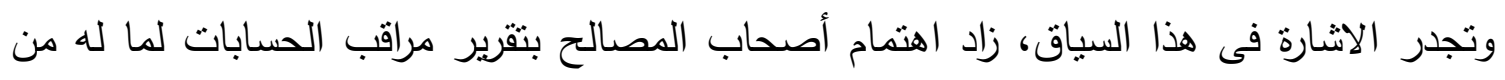

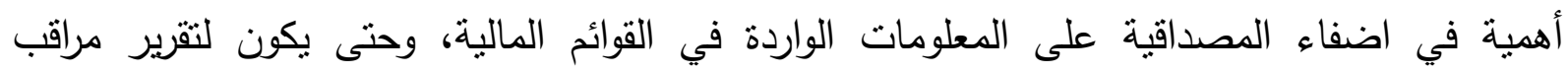

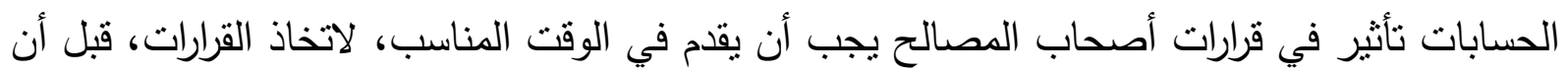

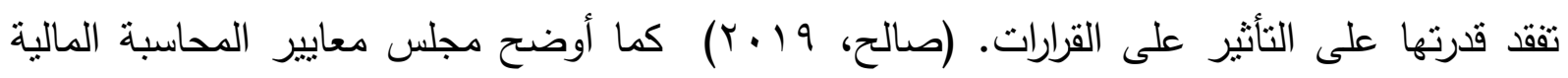

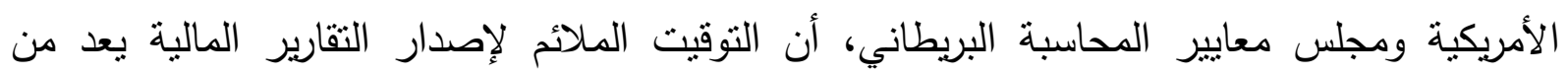
العناصر الأساسية الواجب توافرها لكي تكون المعلومات الدحاسبية ملائمة لاتخاذ القرار . لإنيل

(FASB, 1991; Accounting Standard Board,1980)

هناك العديد من الآثار السلبية التي قد تتتج من تأخير تقرير مراقب الحسابات، حيث يؤدي تأخير

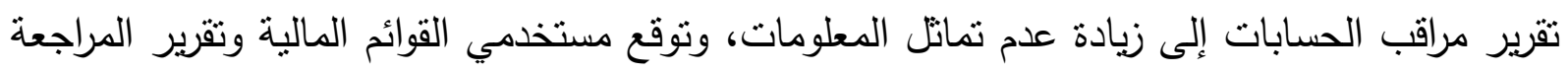

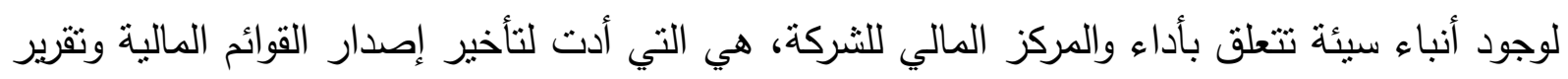

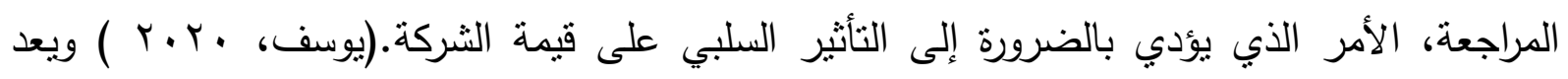

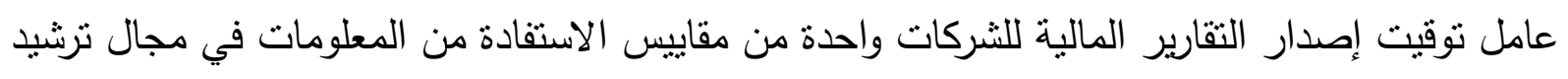

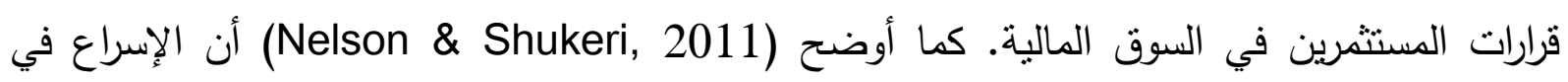

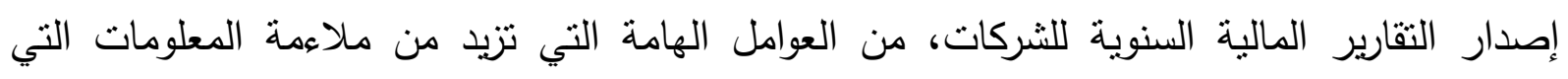

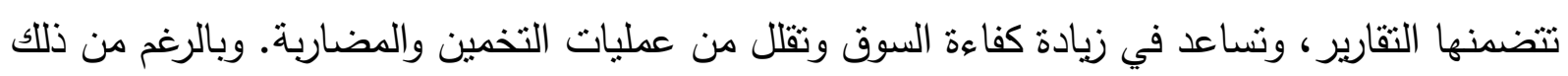

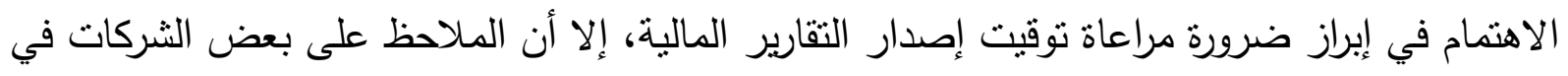

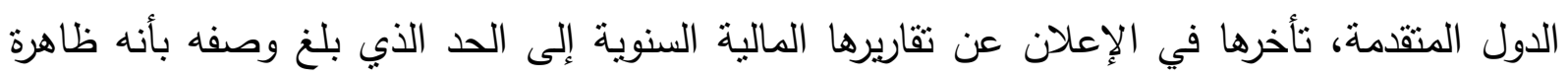

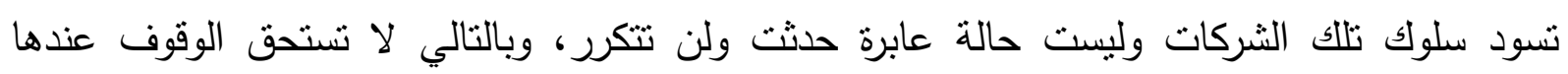

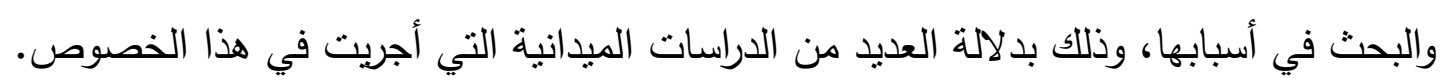

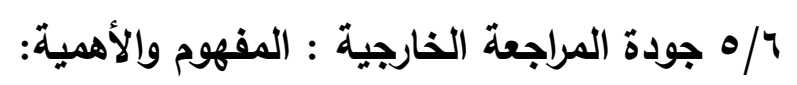
تعتبر جودة المراجعة Audit Quality من الأمور الهامة محل اهتمام أصحاب الهمابه المصالح

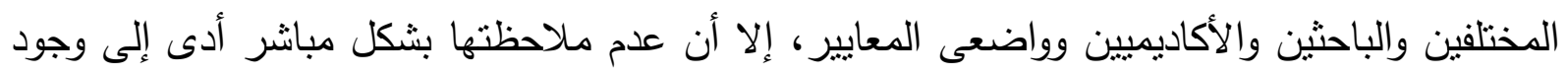

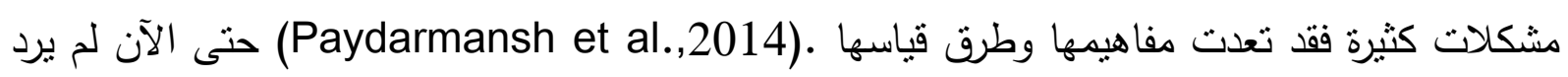


مفهوم شامل ومتكامل لجودة المراجعة. تعريف جودة المراجعة تعريفاً يحمل فى طياته الجوانب المختلفة لجودة المراجعة. وقد حاولت دراسة كل من Mohammed and Malek 2008; Chang and (تقديم مفهوم شامل لجودة المراجعة، وأوضحت أن المفهوم الثامل يجب أن يشتمل على الثى

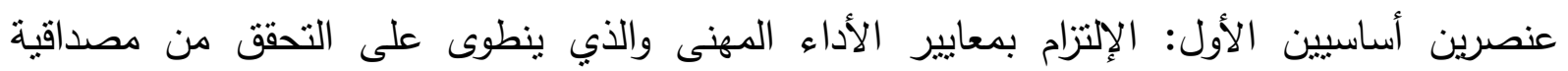

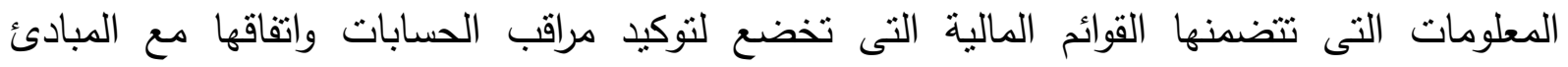
المحاسبية المقبولة قبولاً عاماً وكذللك تأكيد مراقب الحسابات على عدم إحتواء هذه القوائم على تحريفات

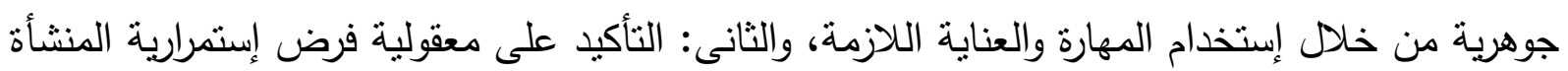

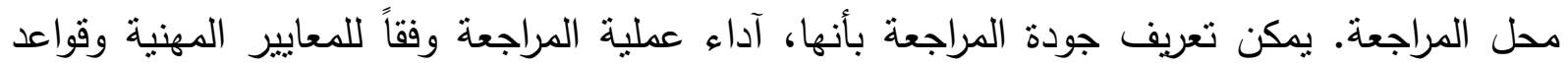

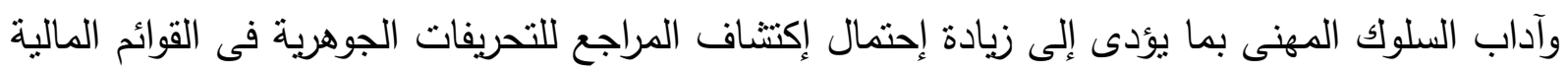
والتقرير عنها بما يحقق أعلى قدر ممكن من إثباع الإحتياجات المختلفة لجميع الأطراف المعنية. (Mohammed et al.,2018; IAASB,2011) هى درجة مرتفعة من التوكيد بأن مراقب الحسابات قد حصل على دليل كافى وملائم على أن القوائم المالية تعبر بعدالة عن الأداء التشغيلي والمركز المالي للشركة. تنوقف جودة دودة المراجعة على على القدرة الفنية

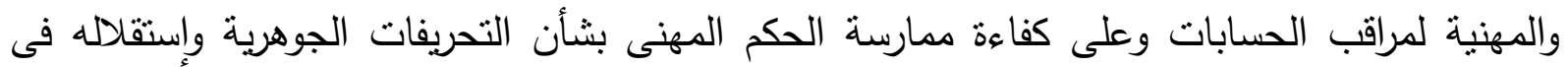
كافة مراحل عملية المراجعة، علاوة على إلتزام مراقب الحسابات بمعايير وآداب وسلوك المهنة وذلك الكئك للوفاء بإحتياجات أصحاب المصالح. هناك مقاييس متعددة لقياس جودة المراجعة ولا يوجد اتفاق حول أي مقياس هو الأفضل، وبرغم تعدد هذه المقاييس إلا أنه يمكن تصنيفها على أساس مخرجات أو مدخلات عملية المراجعة. وقد إهنت

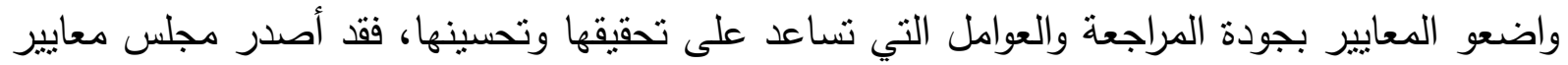

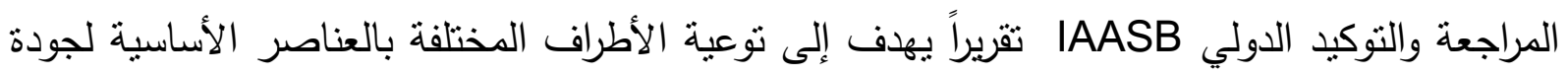

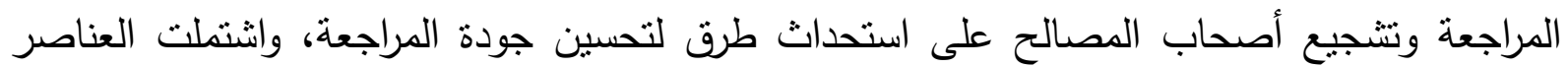
الأساسية الني تخلق بيئة تتجع على تتفيذ المراجعة بدرجة مرتفعة من الجودة كلا من:

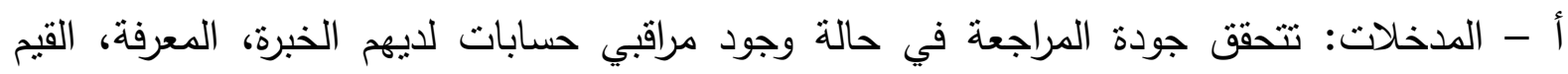
والأخلاقيات بالإضافة إلى الوقت الكافي لإتمام عملية المراجعة.

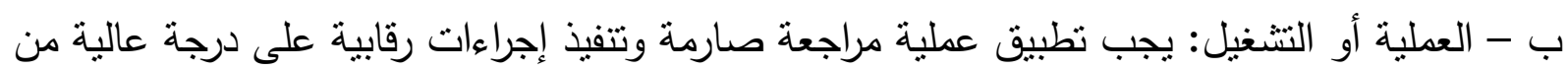
الجودة بما يتقق مع القواعد والإجراءات والمعايير القابلة للتطبيق. ج - المخرجات: تؤدى جودة المراجعة إلى إنتاج تقارير ومعلومات وقتتية ونافعة للأطراف المختلفة. كما أكد اطار (IAASB,2014) على ضرورة تفاعل أصحاب المصالح ودعمهم لتحقيق جودة التهات المراجعة والتركيز على الدور الذي تلعبه العوامل المحيطة والتي تثمل القواعد والإجراءات المتعلقة بالثقرير المالي، حوكمة الثركات، نظم المعلومات، اطار النقرير المالي القابل للنطبيق، والعوامل الثقافية لتبل 
والبيئية والتتظيمة. وقد نص معيار المراجعة الدولى رقم (·r ( ) الرقابة على جودة أعمال المراجعة Quality control for audit work

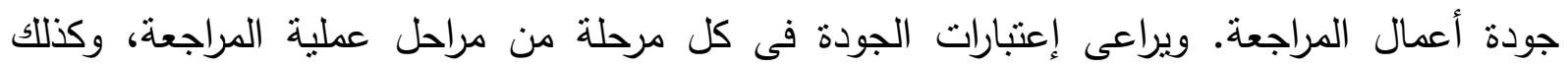
إجراءات عملية المراجعة والقائمين على تتفيذها والإشراف عليها بحيث بصدر تقرير المراجع وهو محصلة

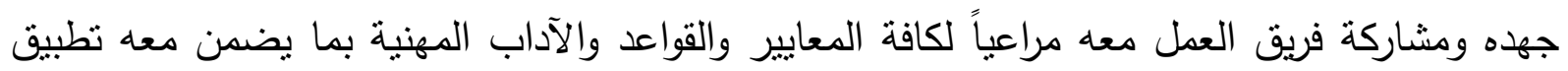

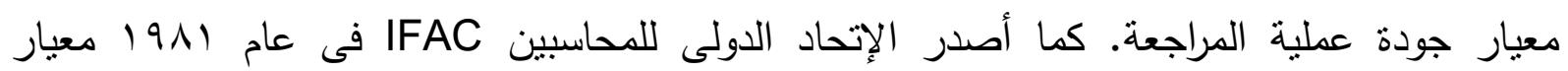

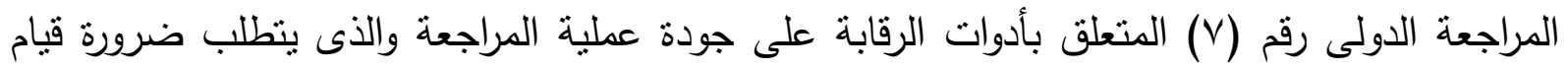

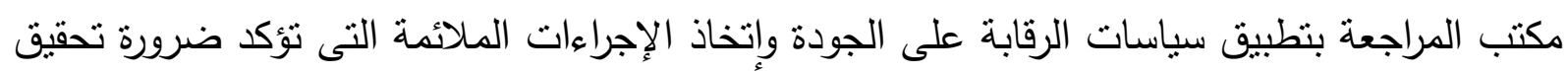
الأغراض التالية؛ الخصائص الثخصية، المهارات، الكفاءات، تخصيص فريق العمل، التوجيه والإشراف،

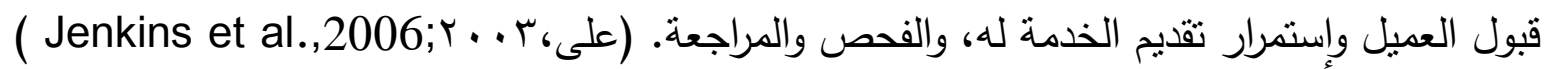
وفيما يتعلق بمحدات جودة المراجعة فقد ركزت بعض الدراسات ذات الصلة (laboya and (lyafekhe, 2014 المحاسبة والمراجعة على أساس أنها محددات رئيسية لجودة المراجعة تمنلت فى؛ حجم منشآة المحاسبة والمراجعة، سمعة مراقب الحسابات، مدة الارتباط بين مراقب الحسابات والعميل، الدعاوى القضائية،

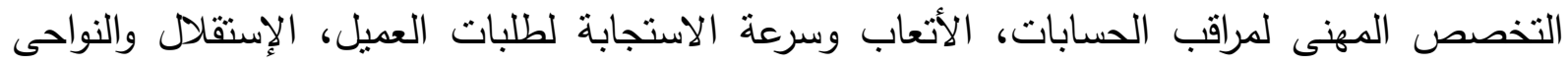
الأخلاقية والسلوكية، جودة نظم رقابة الجودة، والاتصال الفعال مع الإدارة. يضاف لما سبق، يتطلب تحسين جودة المراجعة توافر عدد من العناصر من أهمها؛ التزام

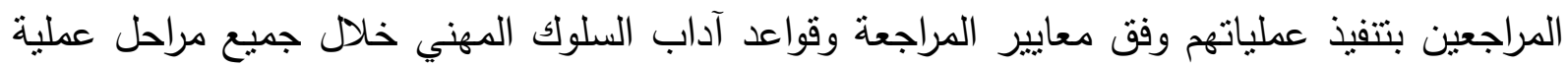

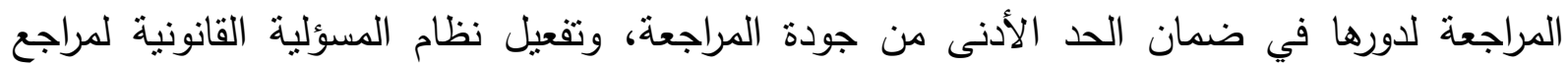

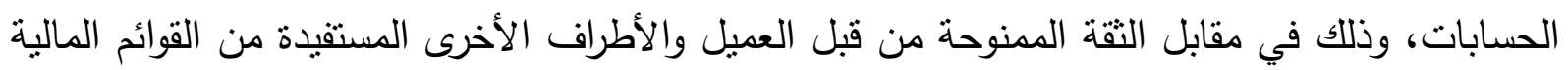

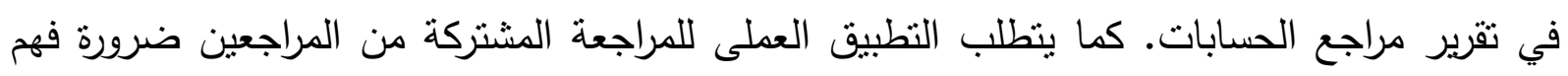

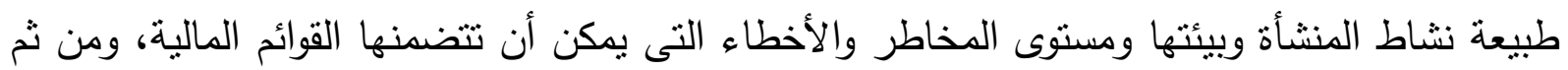
يتشاركا معاً فى وضع خطة وبرنامج مراجعة متكامل يتقاسمان تتفيذه يحاول تقليل أخطار المراجعة لأقل

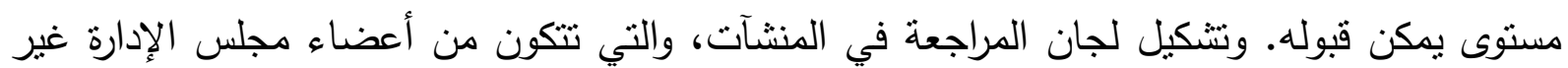

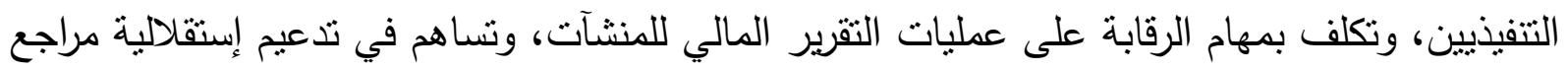

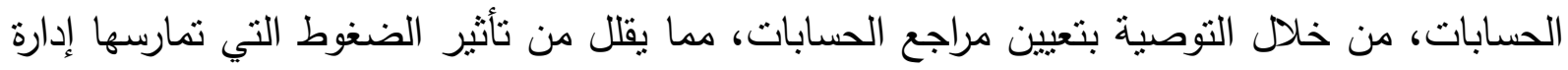

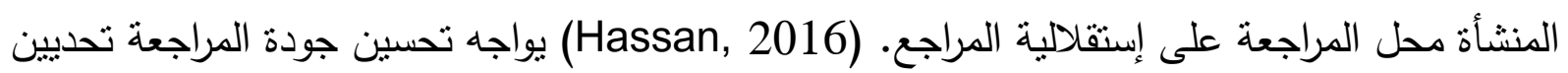
أساسيين هما؛ التحدى الأول، يتعلق بمطالبة المستثرين لمراقبى الحسابات بجودة المعلومات المالية

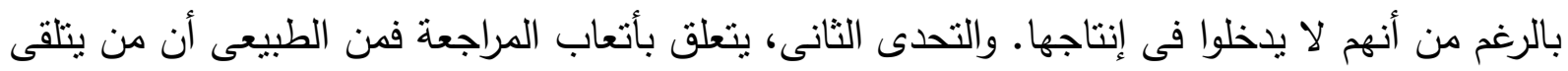


الخدمة هو من يدفع مقابلها، أما عقود المراجعة فتخضع لأنماط مختلفة حيث أن من يعين مراقب

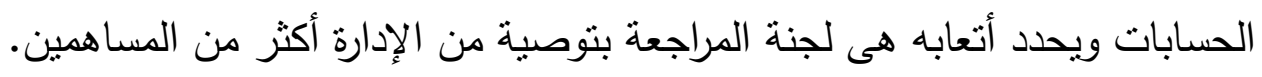
وبشكل عام يجب ان يشمل مفهوم الجودة الأبعاد الآتية؛ التخطيط الجيد لعملية المراجعة، التأهيل

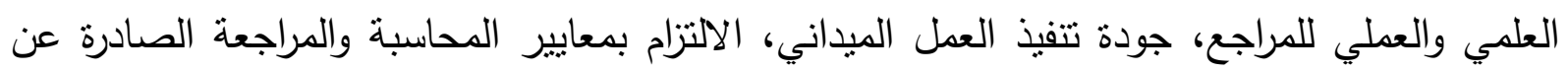

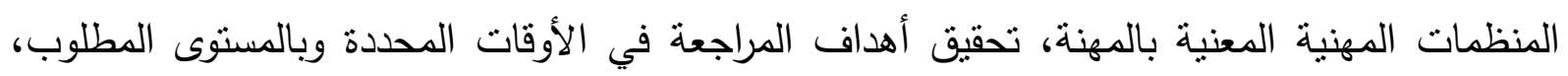

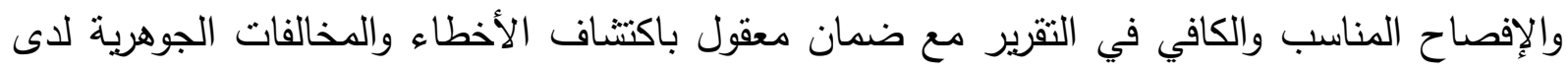
العميل. هناك اختلافات فى مدى ادراك أصحاب المصلحة من مراقبى الحسابات ومعدى القوائم المالية

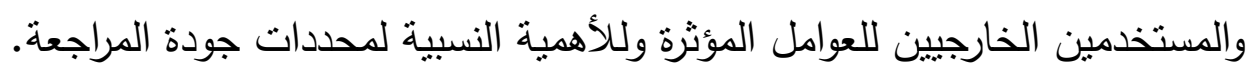

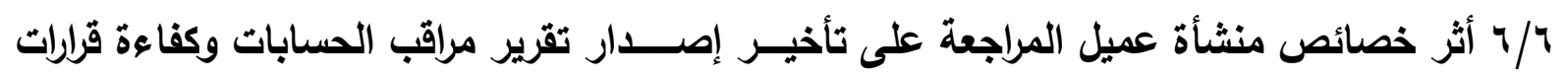

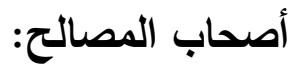

تعد التقارير المالية السنوية الوسيلة الفاعلة لتحقيق وظيفة الاتصال في المحاسبة، وقد شهدت بداية

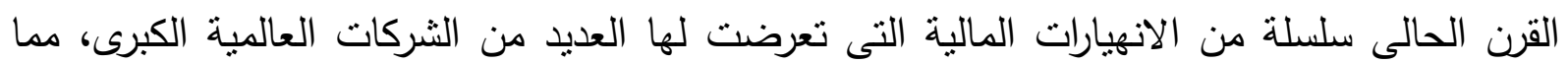

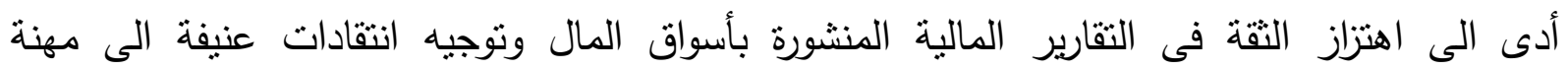

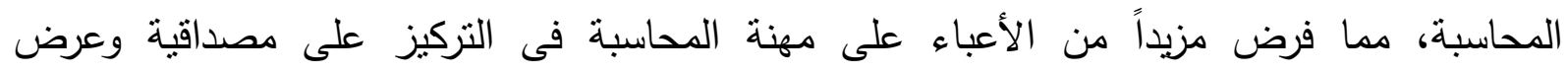

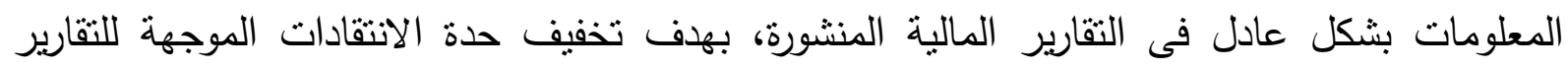

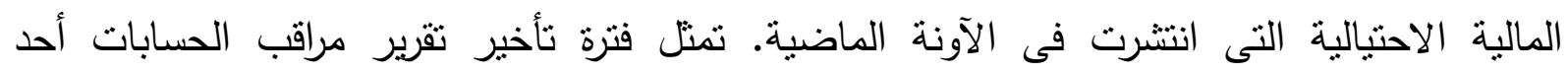

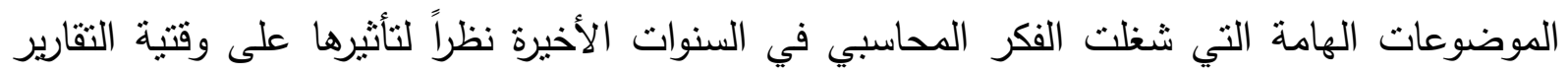

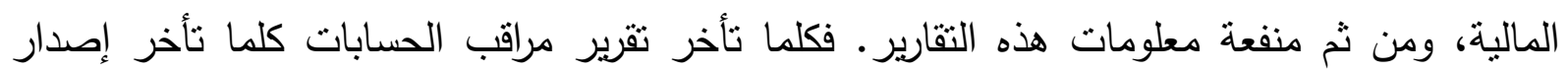

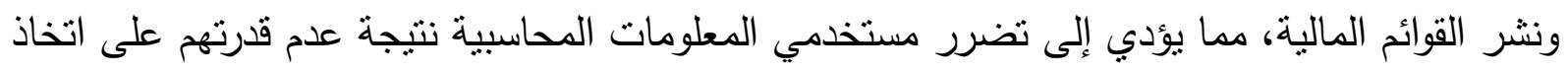

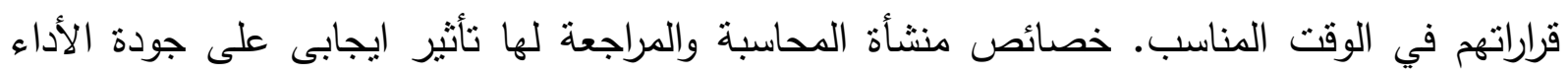

المهنى. (Che-Ahmed and Ahmed, 2016)

(Habib,2015; Hassan, وفى هذا السياق، تتاول الفكر المحاسبي مجموعة من الدراسات (2016 والتي نتاولت تأخر فترة إصدار تقرير المراجعة ومنها؛ خصائص منشأة العميل وتعد من أهم

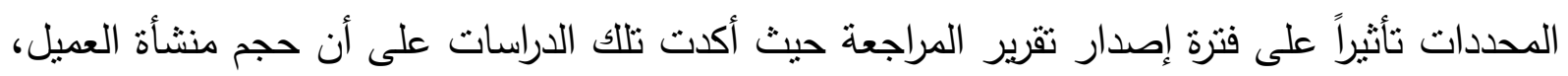

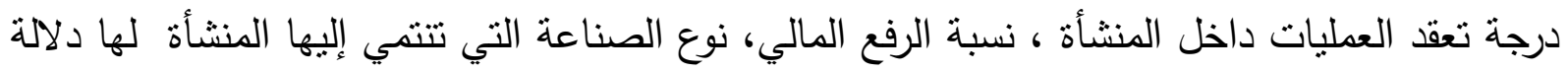

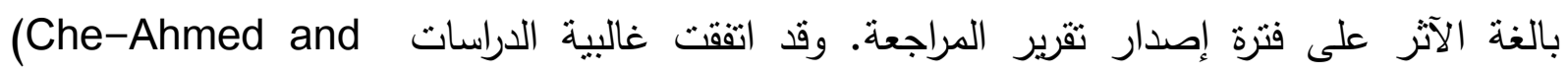
Ahmed,2016; Abdillah et al.,2019) تأخير إصدار نقرير مراقب الحسابات ومنها؛ مستوي الرفع المالي، حجم الثركة، وتاريخ نهاية السنة

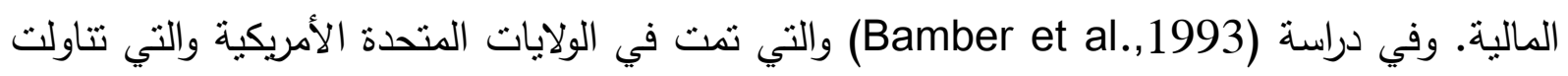

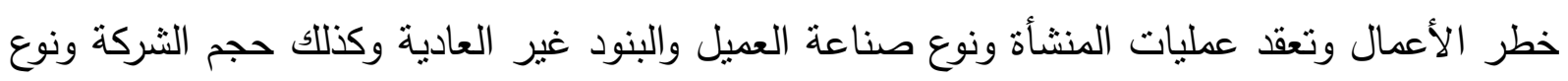


تقرير المراجع وهيكلة المراجعة كمتغيرات في الدراسة، وتوصلت إلى إن هيكلة المراجعة تؤدي إلى طول فترة إصدار تقرير المراجعة وتتطلب من المراجع إعادة العمل.

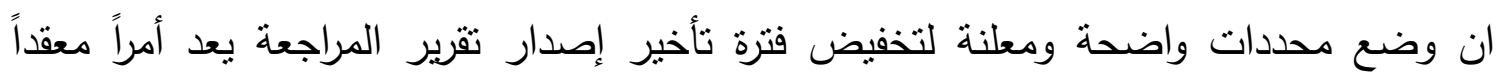

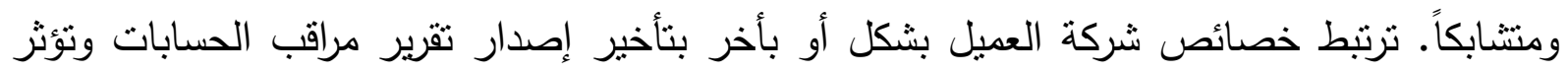

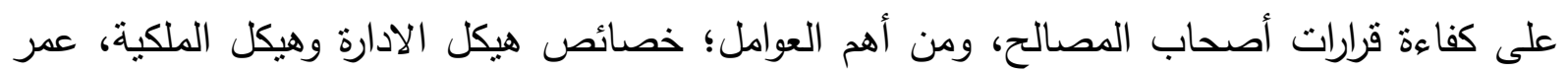

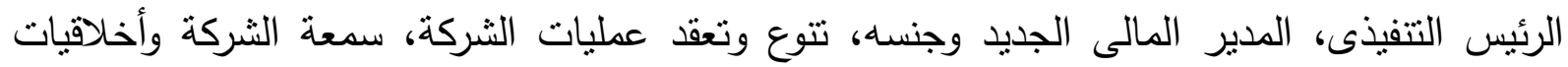

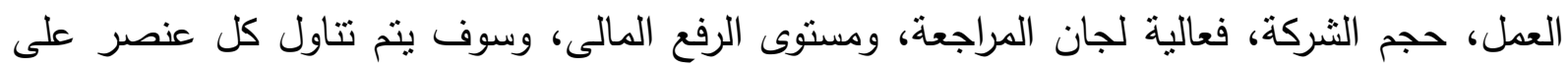

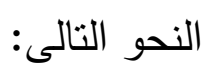

\section{-خصائص هيكل الادارة وهيكل الملكية:}

حازت أنماط الملكية وتعددها فى الثركات باهتمام، حيث يعد نمط الملكية هو المحدد لطبيعة مشكلة الوكالة داخل الثركة حيث ينعكس نمط الملكية على تكوين مجلس الادارة واللجان المنبثقة منه ومن ثم

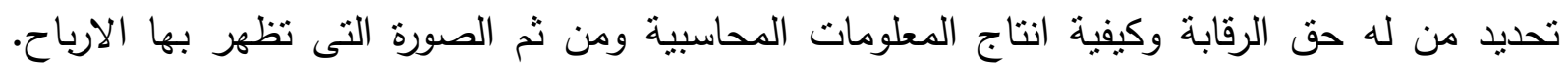

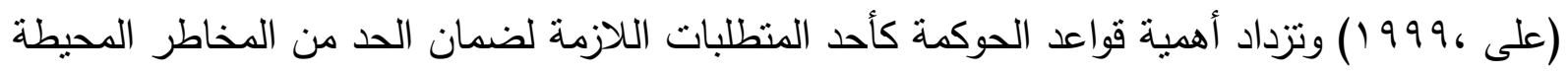
بالثركات وحماية للمساهمين والمتعاملين معها. وقد أدى انتشار الفضائح المحاسبية فى السنوات الفئمات الأخيرة

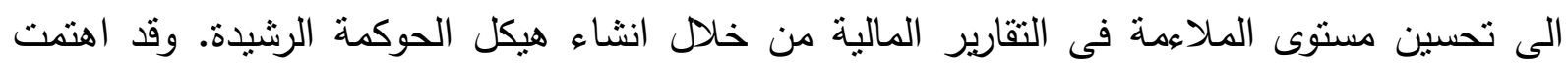
دراسة (Klai\& Omri,2011) باختبار أثز أليات الحوكمة على جودة التقارير المالية لعينة من الثركات التنونسية. واختبار أثز كل من خصائص مجلس الادارة وهيكل الملكية للشركات المدرجة فى بورصة

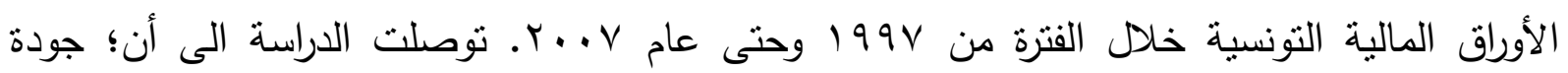

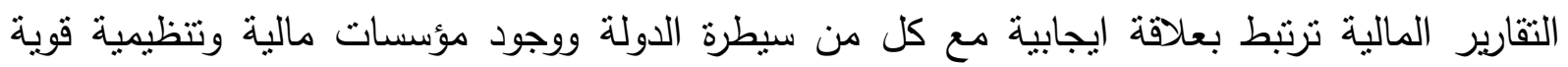

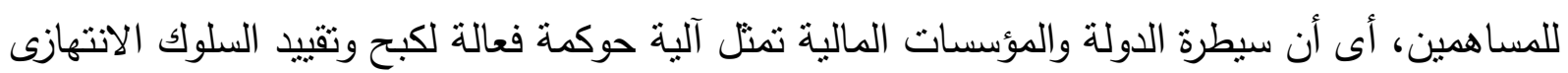

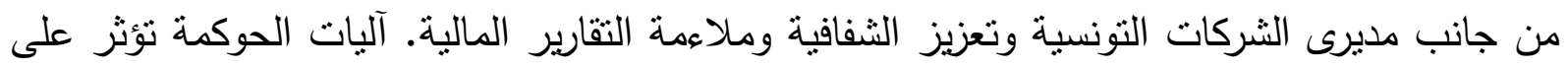

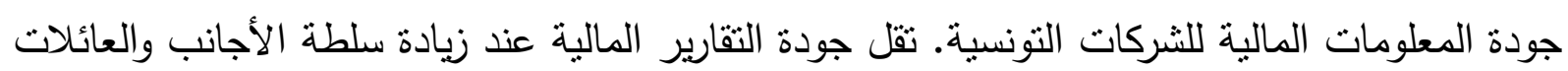

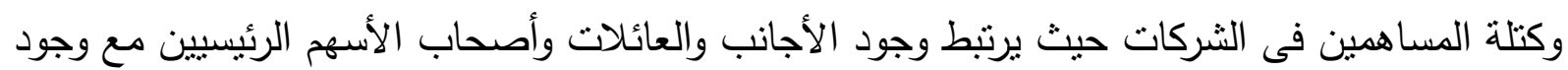

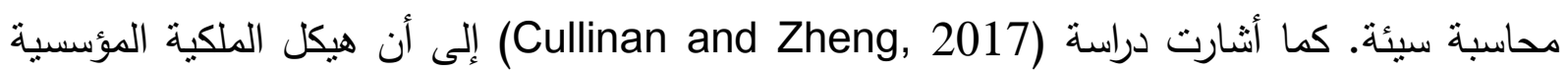

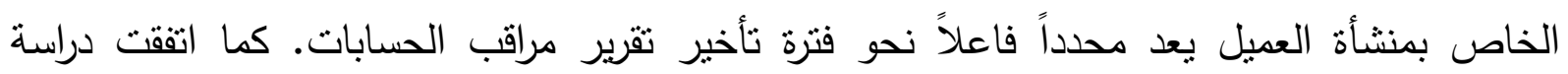

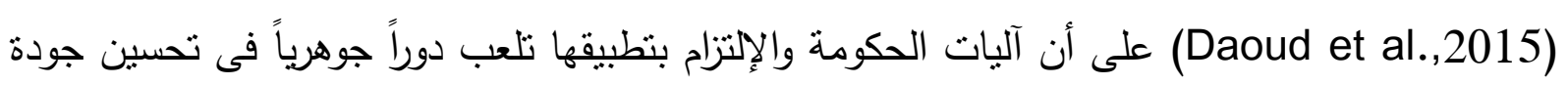

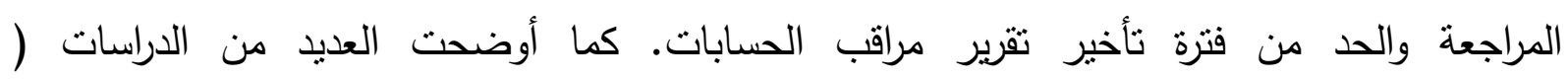
العيسى، (Dibia and Onwuchekwa, 2013 (مكانية التمييز بين نوعين من هياكل الملكية 
- الملكية المشتتة ومفادها وجود عدد كبير من المساهمين بالثركة والذين بمتلكون عدداً قليلاً من

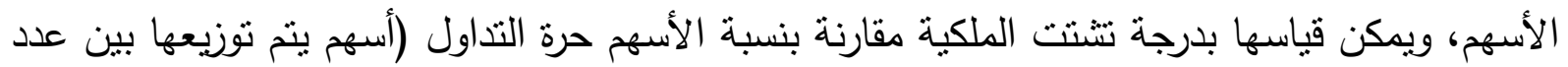

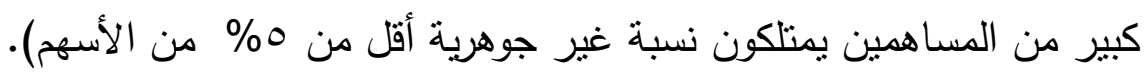

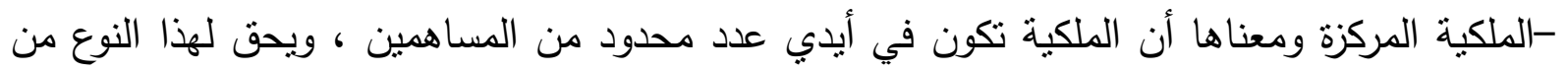
الملاك الاثتراك في إدارة الثركة وتوجيه سياساتها المالية والتشغيلية. ويمكن تصنيف الملكية المركزة وفقاً

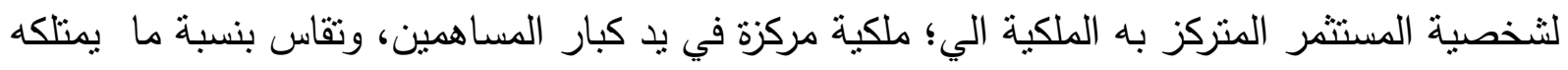

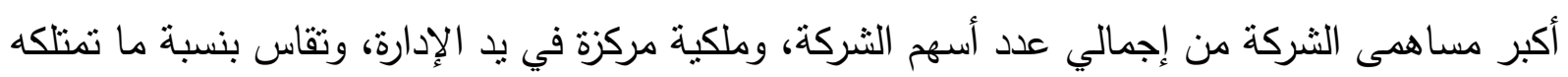

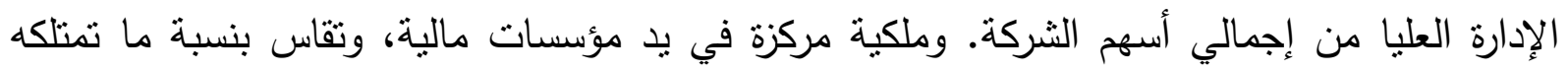

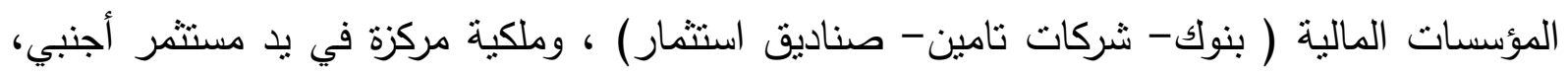

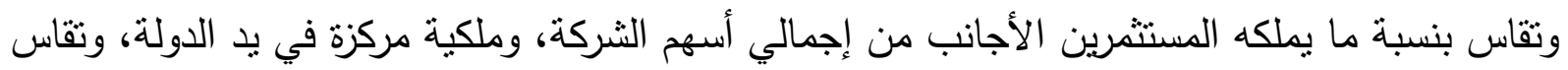

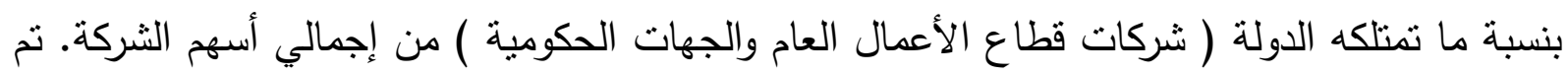
قياس مستوى تركز الملكية بنسبة عدد أسهم الثركات محل الاهتمام إلى عدد مساهميها. وقد أثنار (Hassan, 2016)

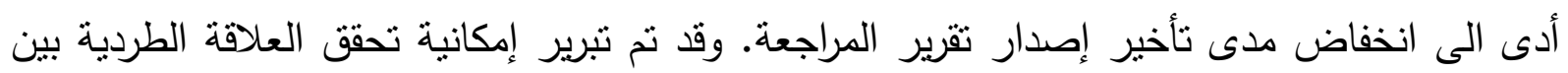

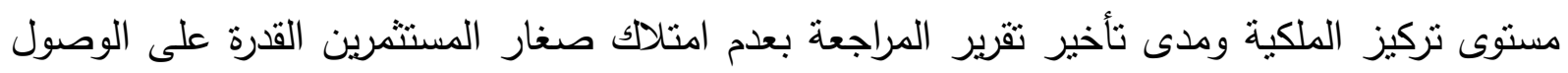

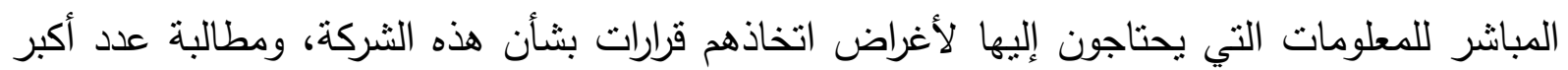

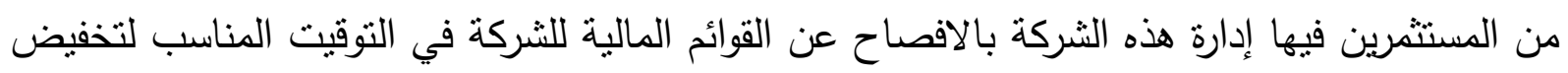

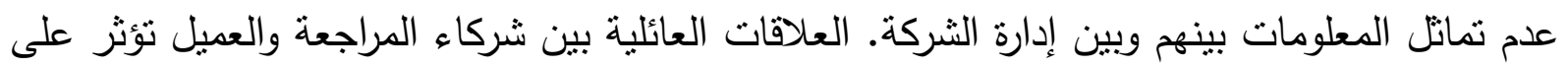
تأخر تقرير المراجعة حيث تقل الفترة الزمنية لاصدار تقرير المراجعة كلما زادت العلاقات العائلية بينهم. وقد توصلت دراسة (Asthana, 2014) الى وجود علاقة عكسية بين مستوى تركيز الملكية ومدى لاصى تأخير إصدار تقرير المراجعة، نتيجة لاعتماد عدد أكبر من المساهمين الأفراد على القوائم المالية

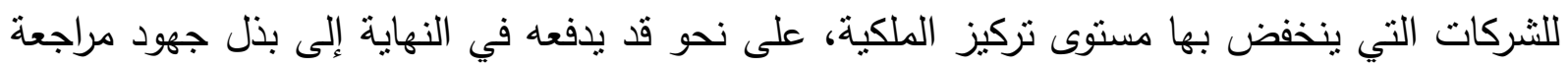

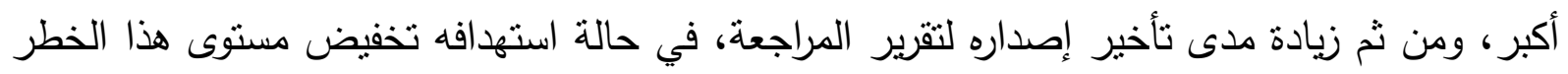

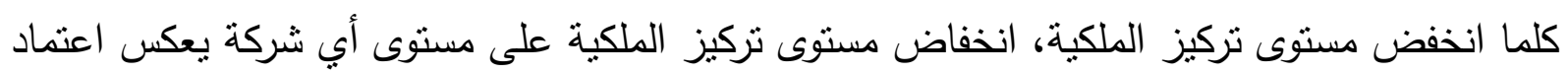

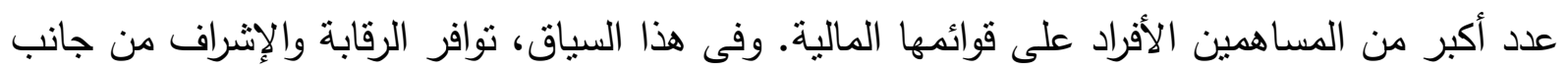

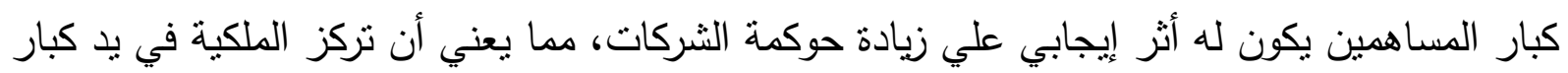
المساهمين يؤدي لتضيق الفجوة بين المصالح خاصة عندما ترتبط مصالح كبار المساهمين ارتباطاً وثثيقاً

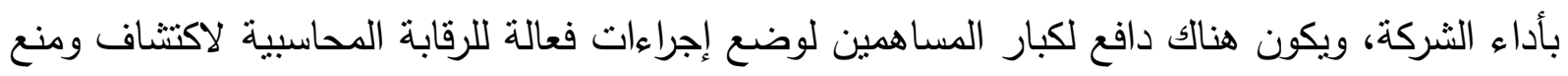

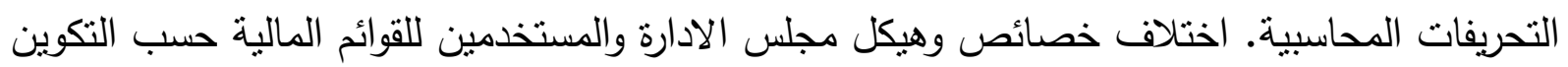
العام لمجلس الادارة، تختلف الثركات العائلية عن الثركات غير العائلية، وتختلف الشركات المقيدة فى الثى 
البورصة عن الثركات غير المقيدة فى البورصة وأيضاً وجود استحواذ، وحقوق ملكية لفئات صغيرة من

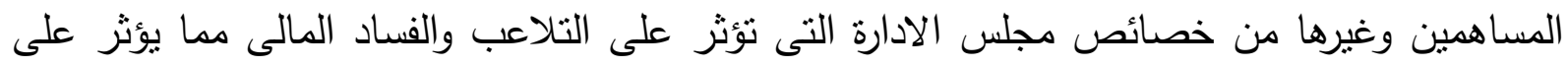
القرارات الاستثمارية للمستثمرين.

\section{- ت تنوع وتعقد عمليات الثركة:}

تعقد عمليات عميل المراجعة من العوامل التي لها تأثير معنوي على تأخير تقرير مراقب الحسابات، تونهات

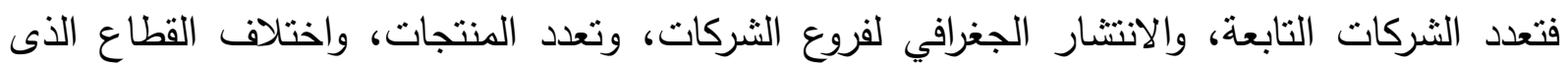
ينتمى إليه عميل المراجعة ينعكس على حجم النشاط ودرجة تعقد عمليات الثركة. كما أن استراتيجية

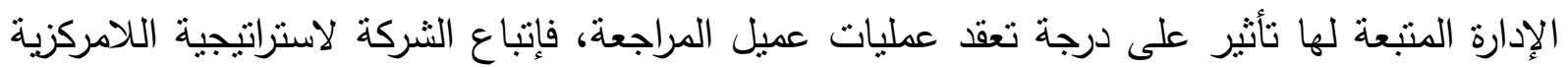

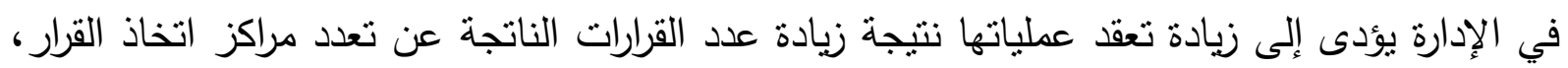

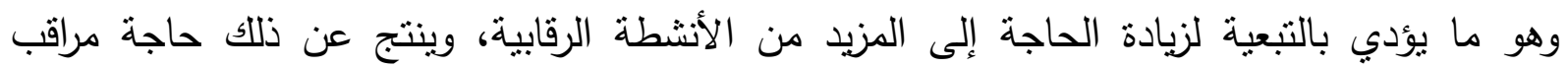

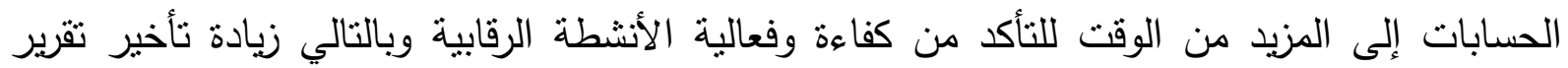
مراقب الحسابات. عندما تكون المخاطر معتدلة، فان مراقب الحسابات يقبل خيارات التقرير المالى غير المتحفظة بينما عندما تكون المخاطر مرتفعة فانه يفضل الخيار المتحفظ ـ المخاطر المرتفعة ترتبط سلباً

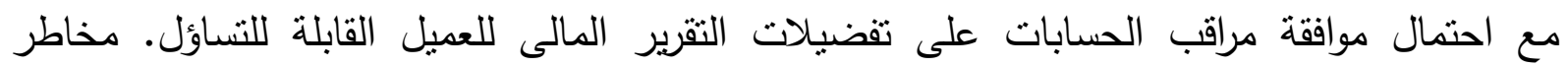

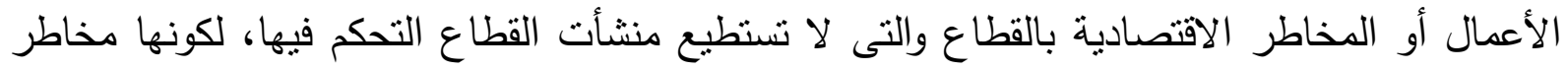

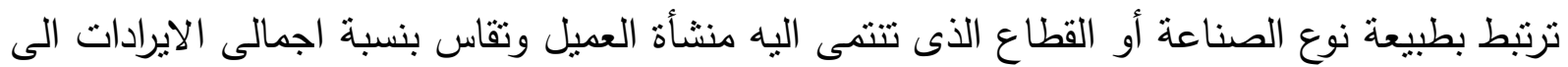

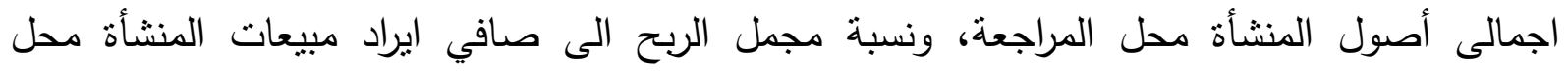

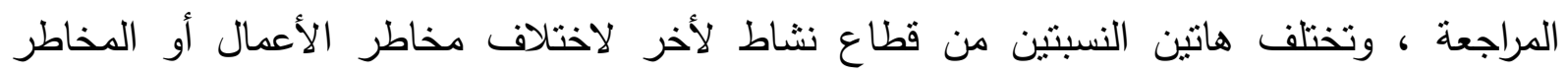

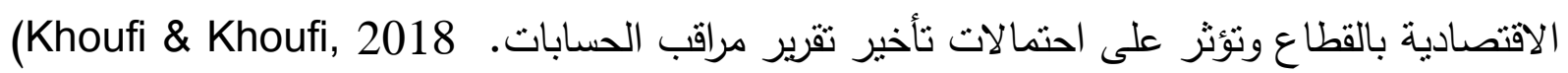
( Abernathy et al., 2017) - سمعة الثركة وأخلاقيات العمل: - مال يمثل الحفاظ على سمعة الثركة أحد العوامل الهامة المؤثرة فى جودة التقارير المالية، برغب المديرين فى إعداد ثقارير مالية عالية الجودة خوفاً على سمعة الثركة وحفاظاً عليها. ويكون لسمعة الثركة تأثير هام على السلوك الذى يتخذه كل من المراجعين والمحللين الماليين والبنوك الاستثمارية تجاه الثركات. الثركات التى لديها سمعة عالية تكون أقل عرضة لوجود تحريفات جوهرية فى القوائم المالية، وذلك لأن

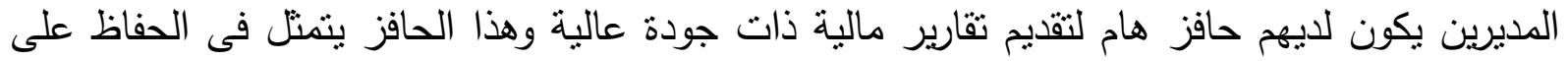

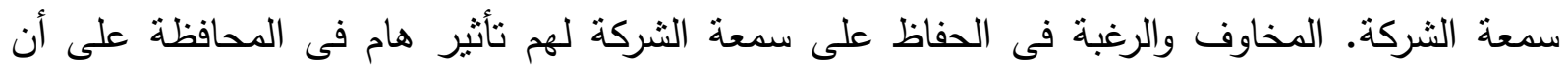
تكون التقارير المالية ذات جودة عالية. الثركات ذات السمعة العالية تكون أقل عرضة لوجود تحريفات

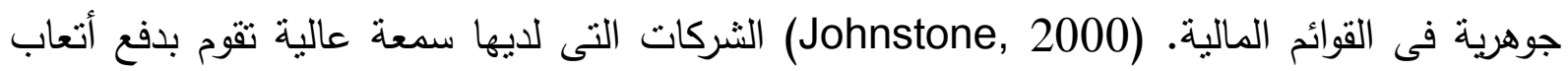
مراجعة أعلى، وذلك بسبب مخاوف نلإك الثركات على سمعتها ورغبتها فى الحفاظ عليها مما يجعل 
العميل بطلب مستويات أعلى من المراجعة مثل ساعات مراجعة أكثر أو خبرة أعلى للمراجع لضمان

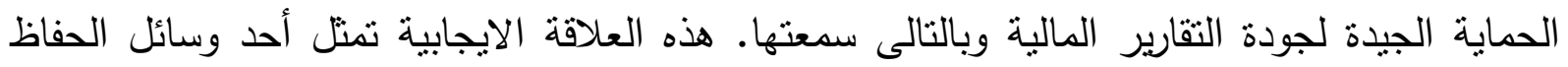

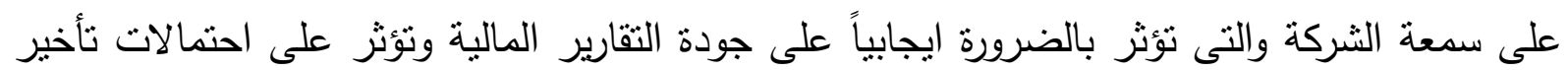
تقرير مراقب الحسابات.

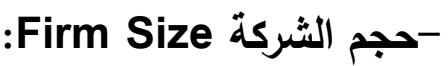

يعتبر حجم الثركة أحد المتغيرات الهامة، الثركات كبيرة الحجم تقصح عن معلومات أكثر، مقارنة

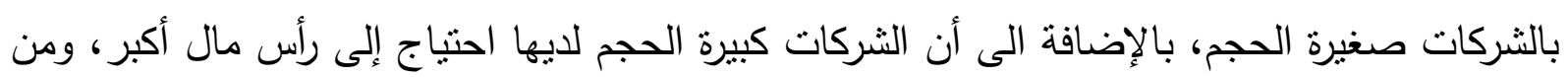

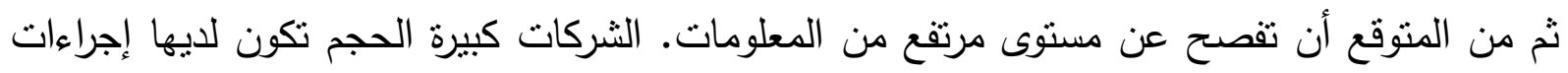

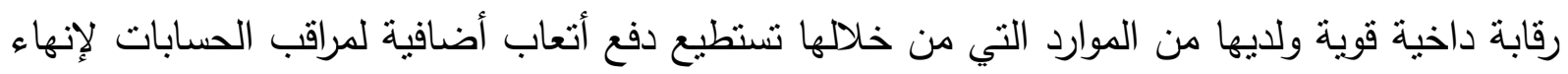
أعمال المراجعة في أقل فترة ممكنة بعد نهاية السنة المالية. هدفت دراسة ( Alkhatib \& Marji,2012)

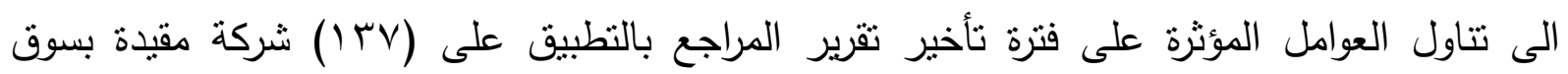

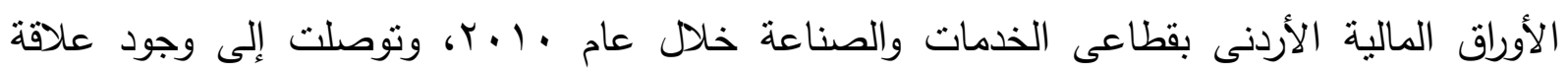

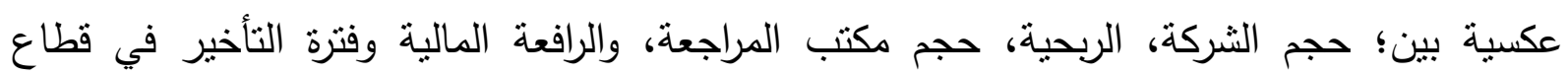

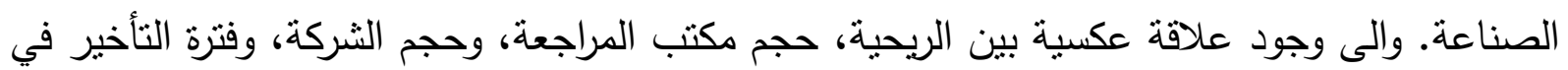

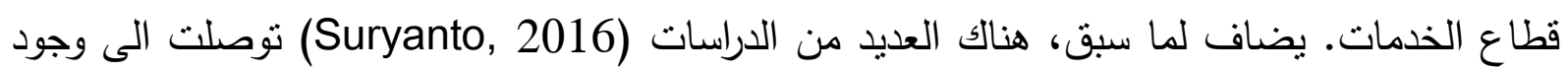
علاقة معنوية إيجابية بين حجم الثركة وفترة تأخير إصدار تثرير مراقب الحسابات حيث يكون لاتي

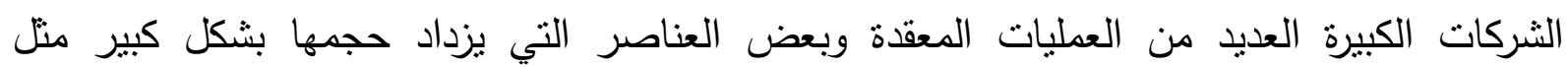
المخزون وتحتاج وقت أكبر للمراجعة. وهناك دراسات أخري (Dibia and Onwuchekwa, 2013)

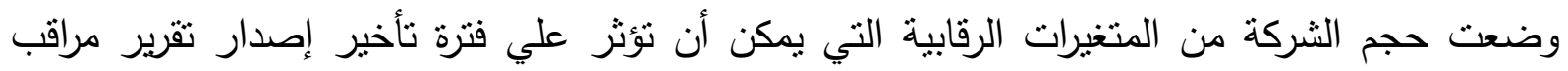

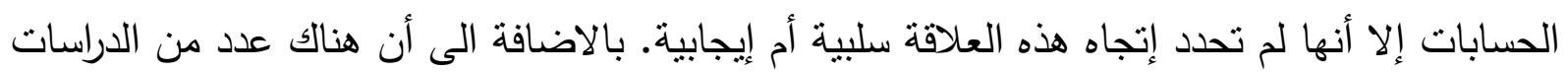
توصلت الى وجود علاقة معنوية بين حجم الثركة وفتزة تأخير (Hassan, 2016; Habib,2015) إصدار تقرير مراقب الحسابات في كلاً من الإقتصاديات المتقدمة والنامية. كلما زاد حجم المنشأة محل

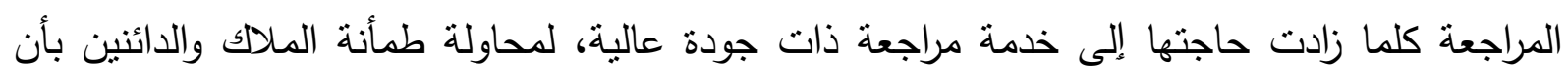

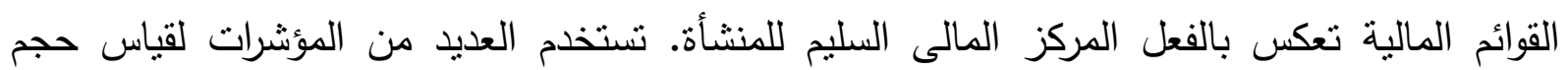

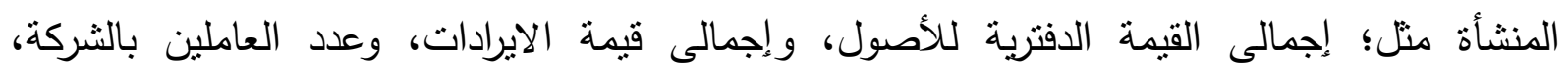
واللوغاريتم الطبيعى لاجمالى أصول المنشأة.

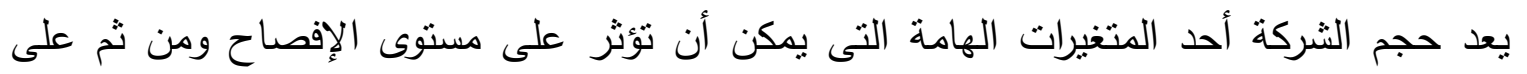

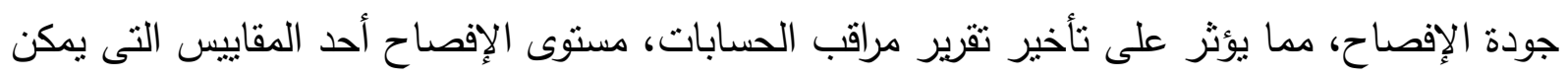

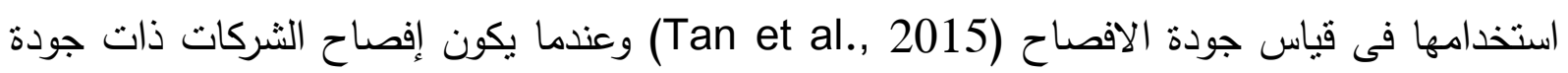


مرتفعة يحد ذلك من عدم تمانل المعلومات ين المديرين والمستثمرين، وبالتالى فمن المتوقع أن يحسن ذلك من كفاءة الاستثمار وقرارات أصحاب المصالح.

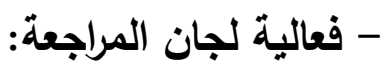

تشترط قواعد الحوكمة أن يتم تكوين لجنة المراجعة من أعضاء مجلس الإدارة ذوى الخبرة المالية.

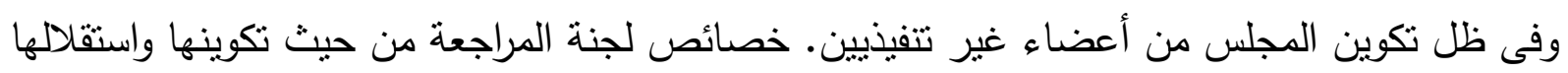

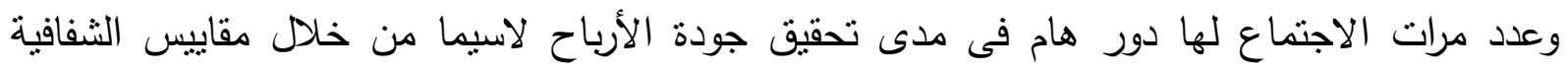

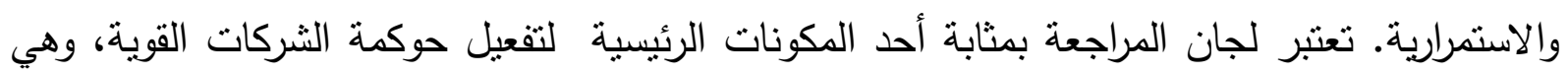

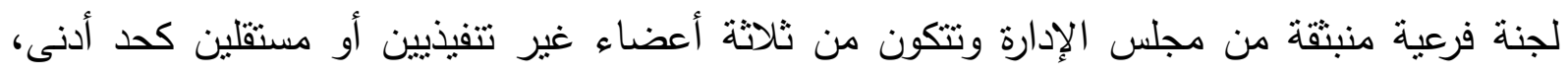
ويكون الحد الأقصى حسب حجم الثركة وطبيعة نثاطها، على أن ينوافر باللجنة خبرة مالية ومحاسبية

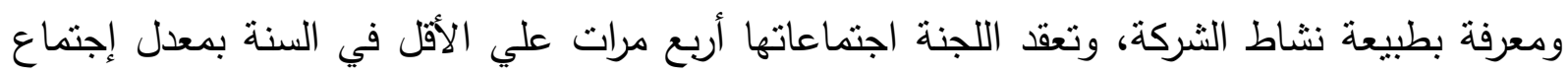

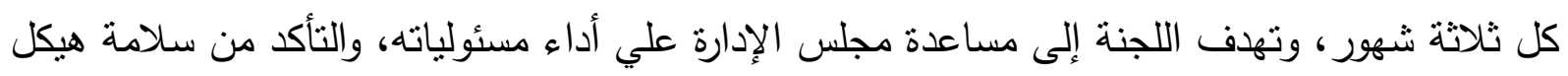

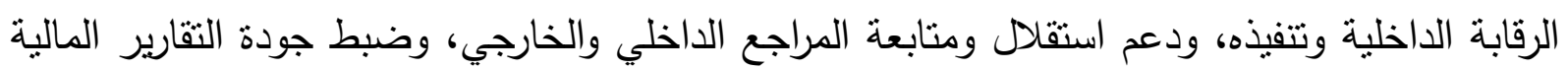

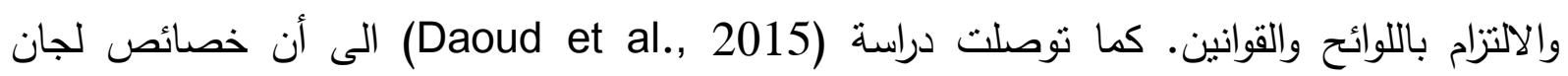
المراجعة المقاسة بإستقال لجنة المراجعة وخبرة لجنة المراجعة وعدد إجتماعاتها وحجم لجنة المراجعة

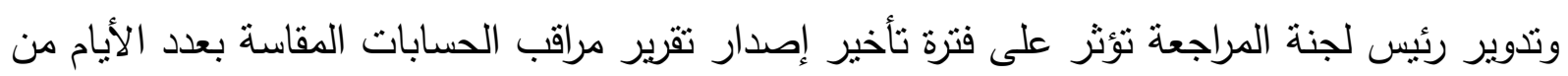

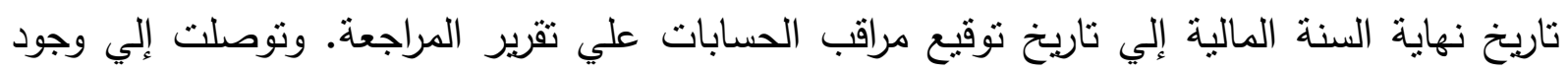

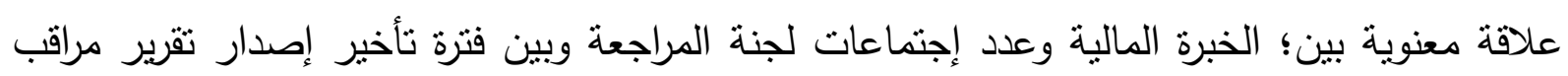

الحسابات.

وتجدر الاشارة فى هذا الصدد، قامت دراسة (Al-Qublani, 2016) باختبار العلاقة بين فعالية لجنة المراجعة وفترة تأخير إصدار تقرير مراقب الحسابات، وتقديم المعلومات المالية التي تم مراجعتها

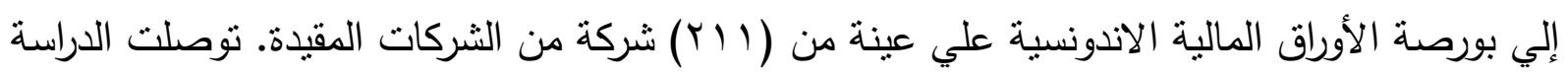

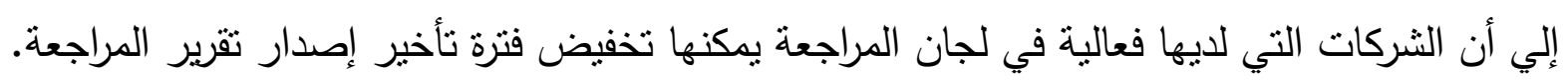

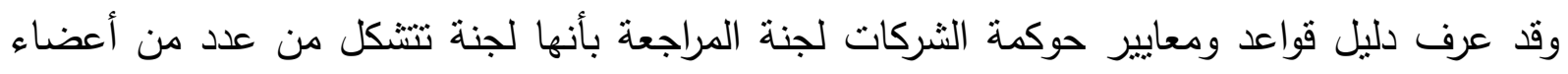

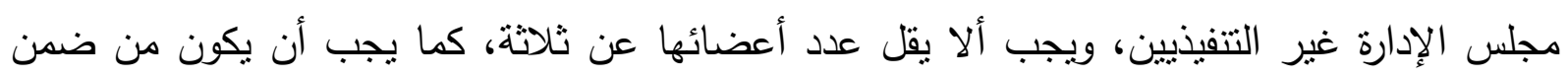

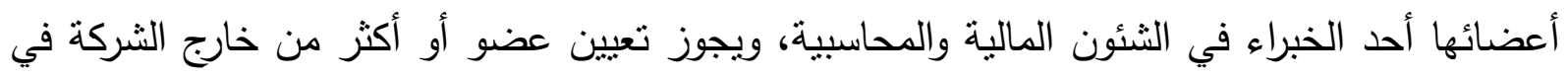

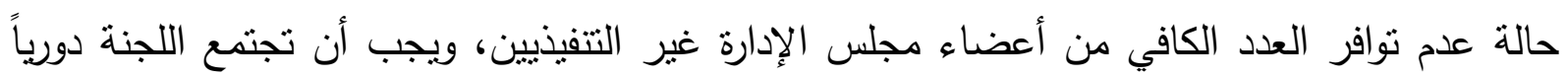

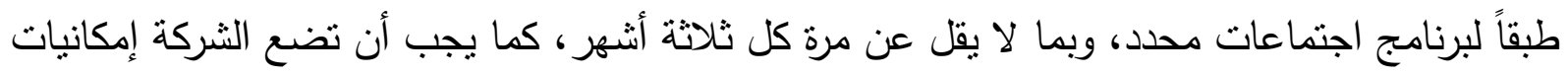

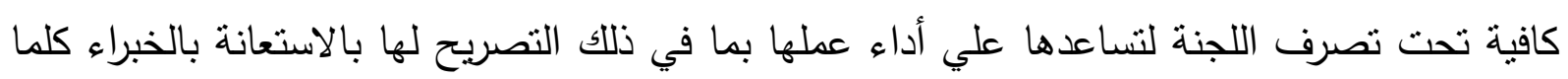
كان ذلك ضرورياً. 


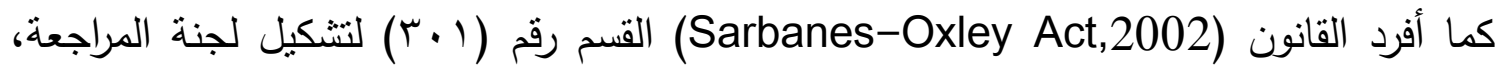

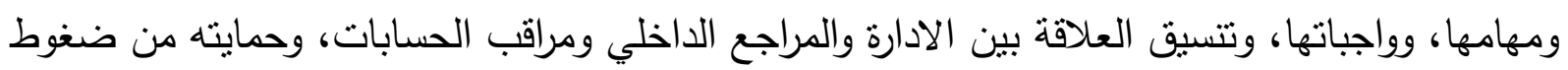

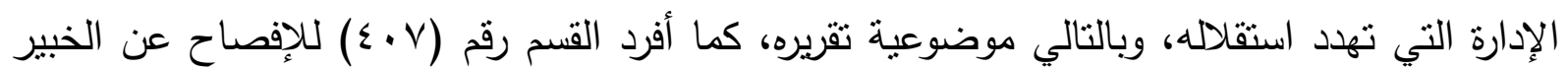
المالي للجنة المراجعة. كذللك أكد قانون (SOX) علي أهمية تحقق لجنة المراجعة من عدم تقديم مراقب

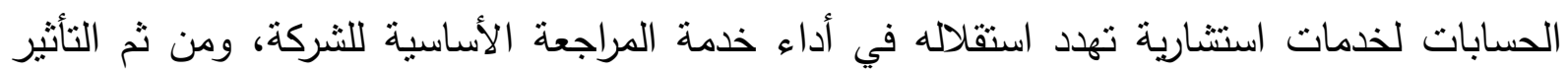
علي رأيه.

يتضح مما سبق، علي الرغم من وجود العديد من التعريفات للجان المراجعة؛ إلا أنها تتثابه في

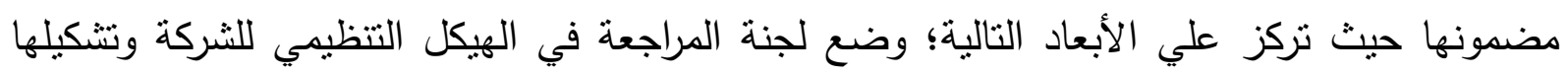
وخصائص أعضائها والمهام المنوطة بها ومدة بقاء اللجنة وتغييرها، وعدد اجتماعاتها. هناك العديد من الدراسات (Cullinan and Zheng, 2017) التى تتاولت العوامل التي تحدد ونداء

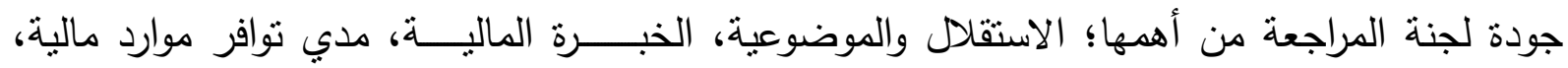

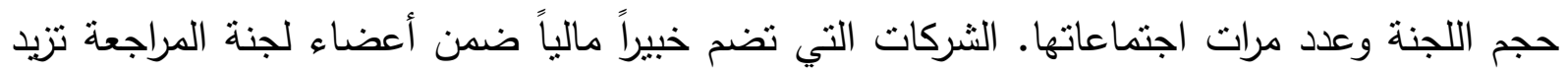

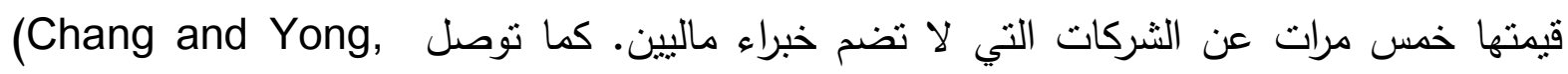

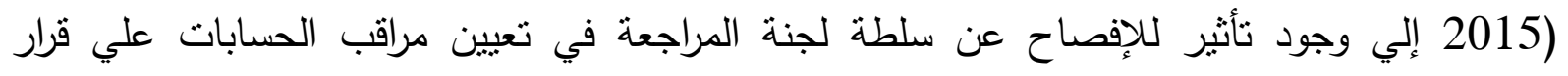

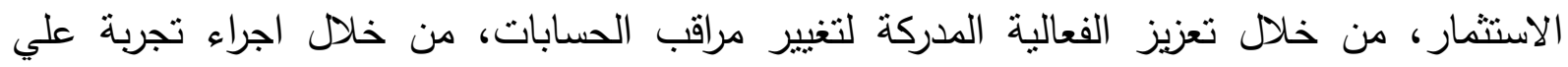

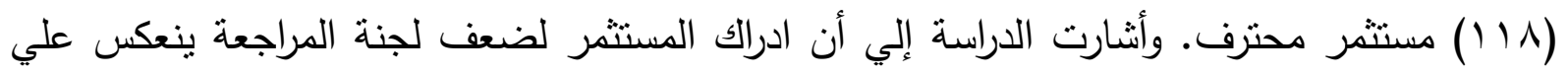

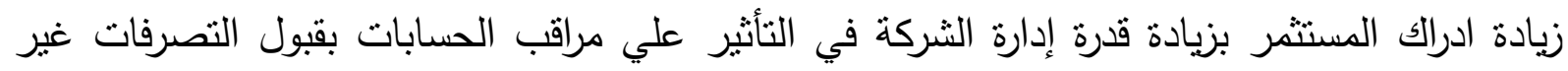

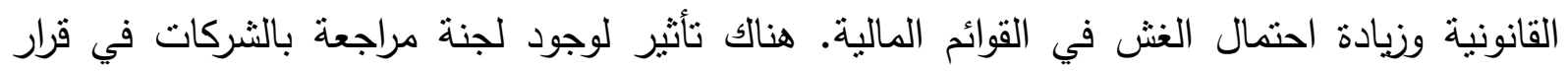
الاستثمار وجودة التقارير المالية. كما تطلب قانون SOX من كل شركة التقرير عن وجود لجنة المراجعة

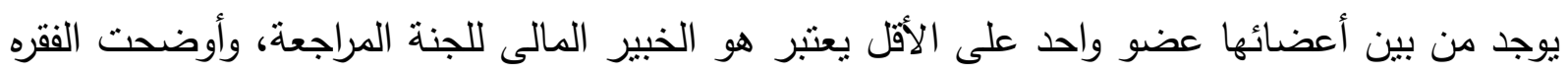

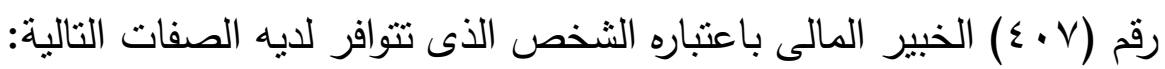

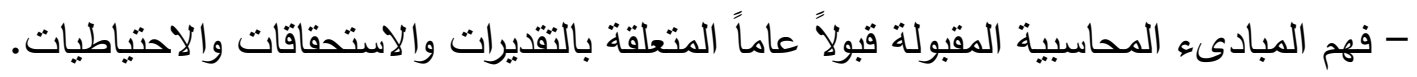
- خبرة تحليل وتقييم القوائم المالية.

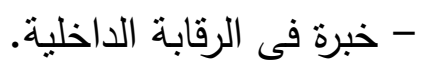

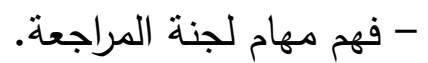
يعد استقال أعضاء لجنة المراجعة بنسبة . .. \% من خلال عدم وجود علاقات عائلية وعلاقات

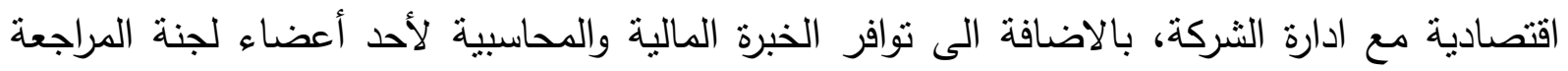

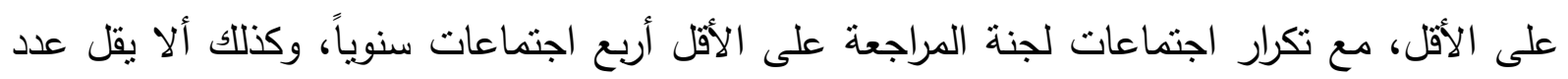

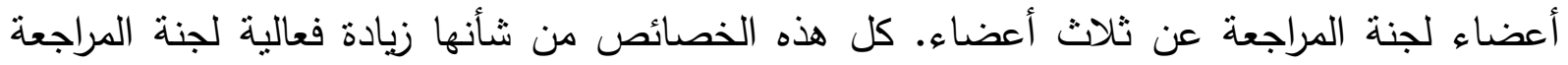
وبالتالى تخفيض احتمالات تأخير تقرير مراقب الحسابات. 


\section{- مستوى الرفع المالى لعميل المراجعة:}

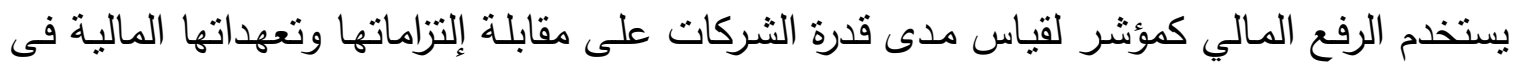

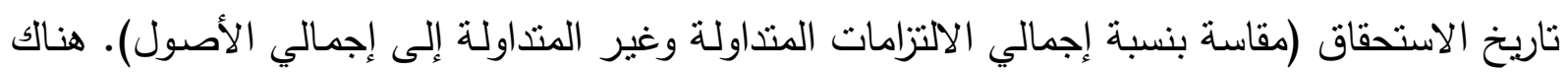

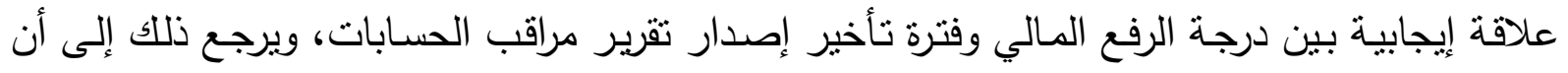

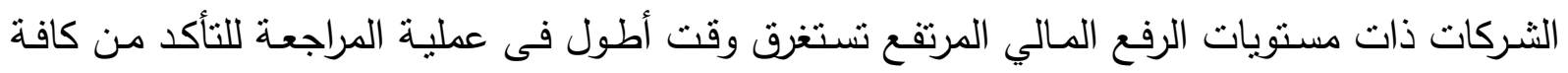

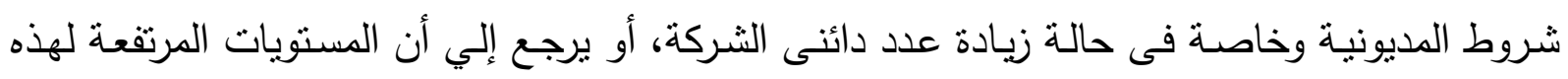

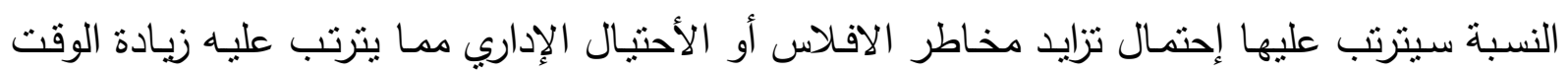

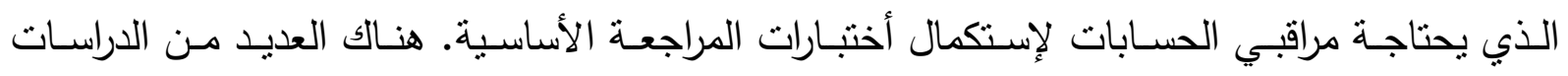
توصلت الى وجود علاقة سلبية بين نسبة (Blankley et al.,2014; Mohammed et al.,2018)

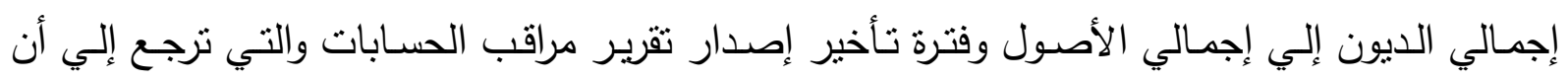

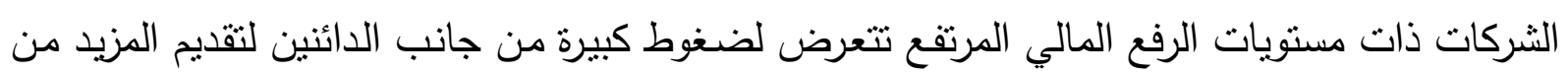

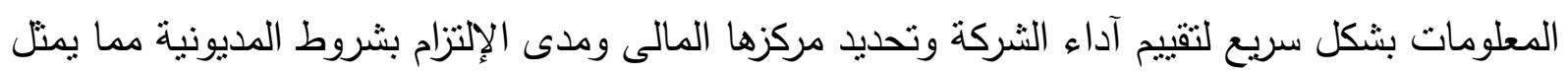
ضغوط علي مراقبي الحسابات في إستكمال عملية المراجعة في أقل وقت بعد إنتهاء السنة المالية.

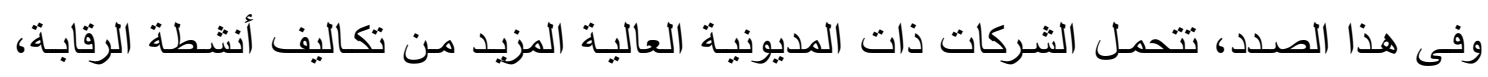
وبالتالي تعوض ذلك عن طريق تكبد المزيد من الديون. ويعتبر تأمين المزيد من الديون استراتيجية

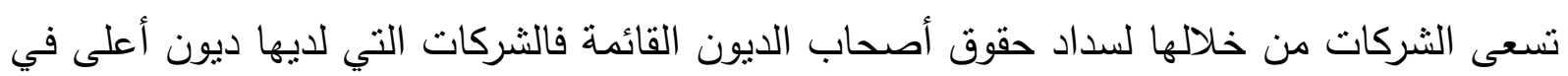

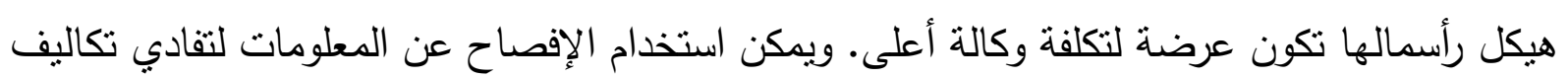

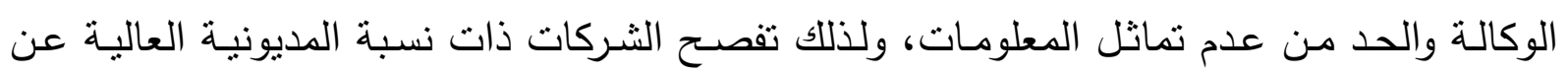

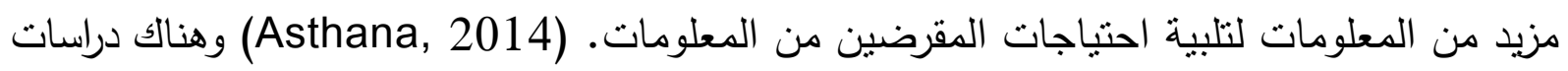

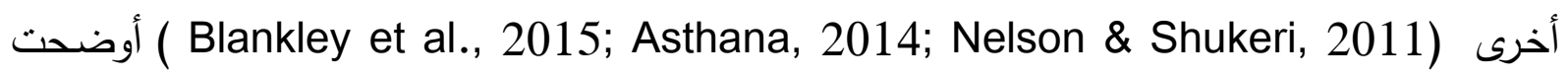
أن تدهور الوضع المالي لعملاء المراجعة يعكس ارتفاع مستوى خطر النقاضي لمراقب الحسابات ومن ثم

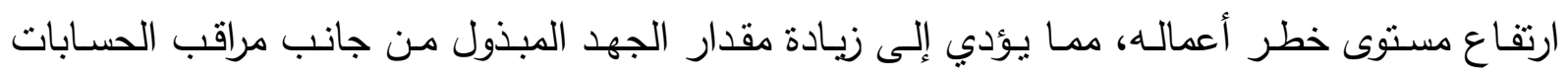

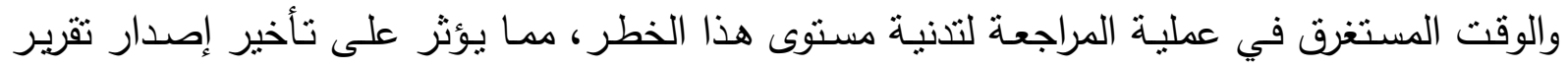

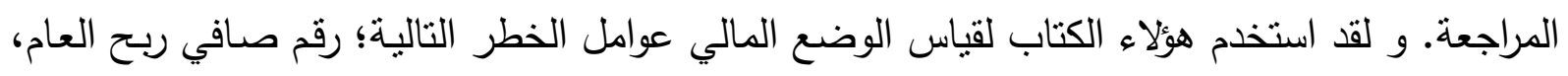

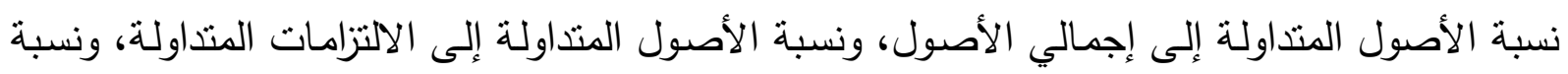

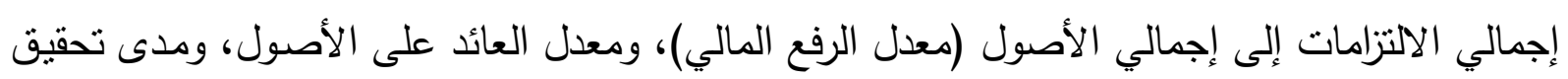

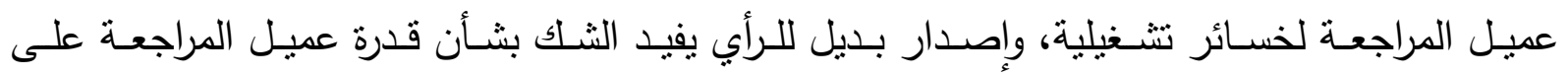
الاستمرار • وتوصلت بعض الدراسات (Abdillah, 2019; Blankley et al., 2015) إلى عدم معنوية علاقة مستوى عوامل الخطر التالية بمدى تأخير إصدار تقرير المراجعة؛ نسبة السيولة ، معدل العائد على الأصول ، ومعدل الرفع المالي. 
هناك تأثثير طردي لتدهور الوضع المالي لعملاء مراقبي حسابات الثركات المدرجة في البورصة

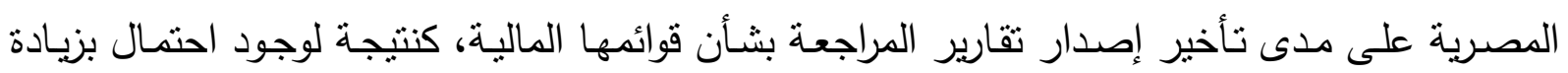

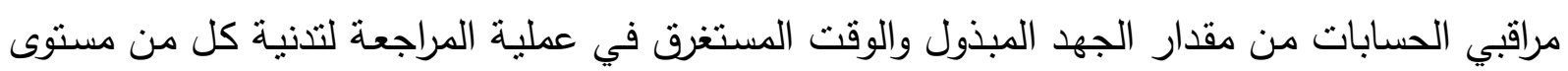
عدم التأكد المتعلق بالوضع المالي لنلاك الثركات، واحتمالات فثلهم في إصدار رأي مراجعة ملائم بشأن

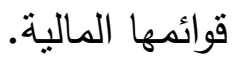

وتجدر الاثشارة فى هذا الصدد، الثركات التى لديها نسبة رفع مالى عالية من المحتمل أن تفصح

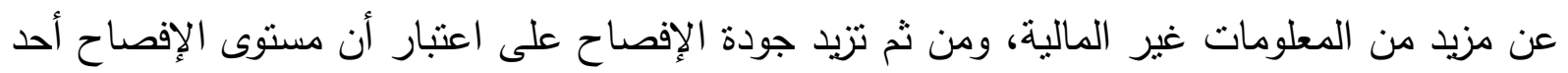

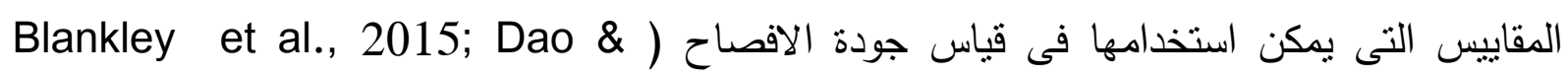
Trung, 2014 )، مما يؤثر تأثثر ايجابى على كفاءة الاستثمار وغيرها من قرارات أصحاب المصالح.

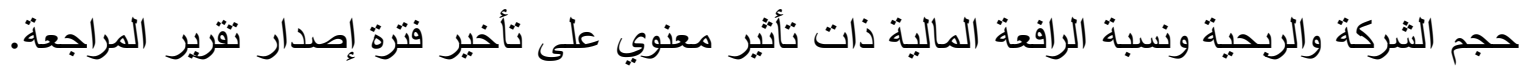

\section{- تاريخ نهاية السنة المالية Fiscal Year-End -}

(Hashim, 2017; Dao \& Pham, 2014 ; Khoufi and توصلت العديد من الدراسات Khoufi, 2018 (ألى أن تاريخ نهاية السنة المالية يمتل إحدى المتغيرات المؤثرة على توقيت إصدار

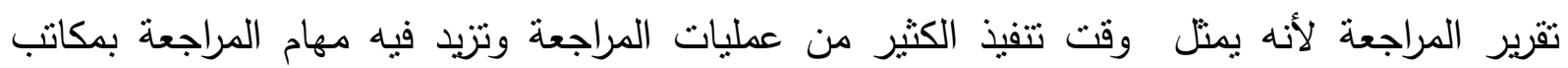

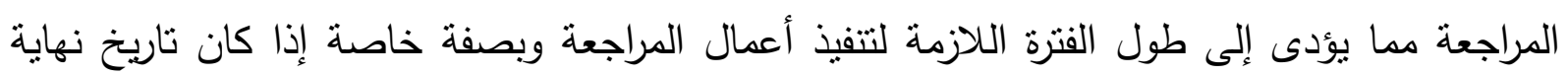
السنة المالية لمعظم الشركات هو نهاية ديسمبر · وتتاولت دراسة (Johnstone, 2000) محددات

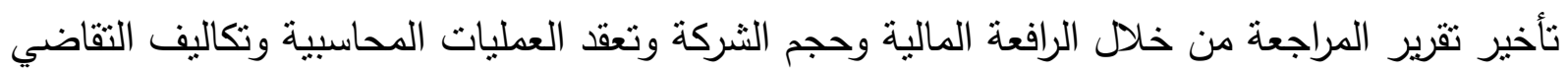

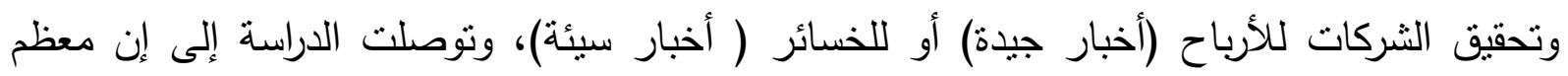

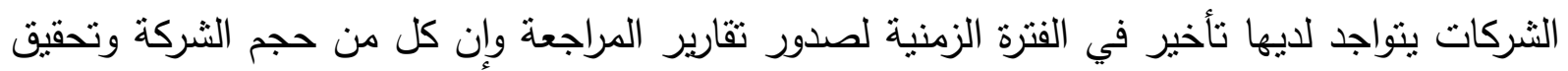

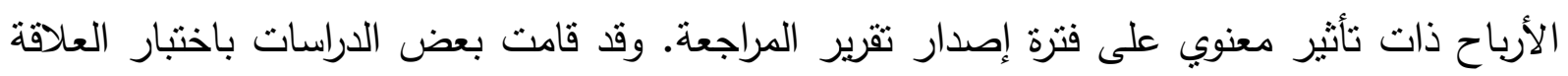

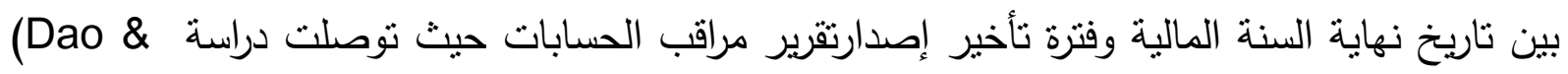
إلى وجود علاقة طردية بين تاريخ نهاية السنة المالية فى ديسمبر وفترة تأخير إصدار

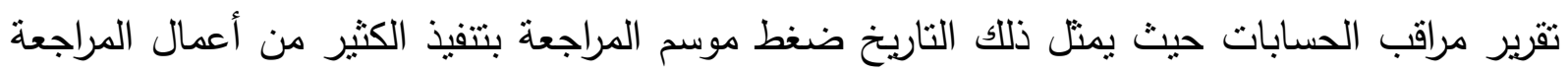
فى مكاتب المراجعة، بينما توصلت دراسة (Hashim,2017) إلى عدم وجود علاقة بين ناريخ نهاية السنة المالية وفترة تأخير إصدار تقرير مراقب الحسابات. حوكمة الثركات الجيدة بالتركيز على حوكمة

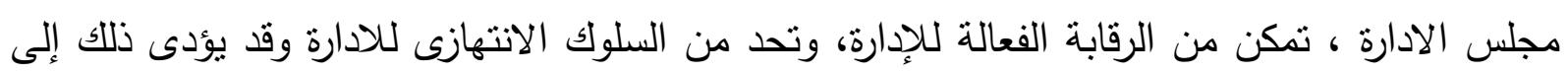

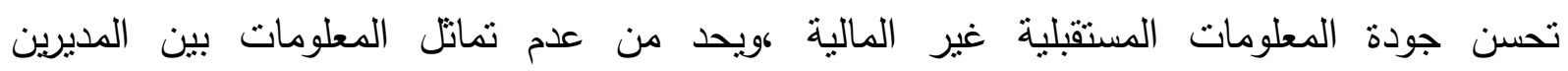

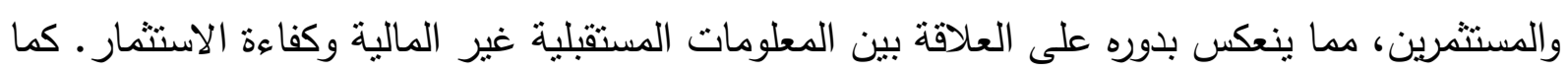

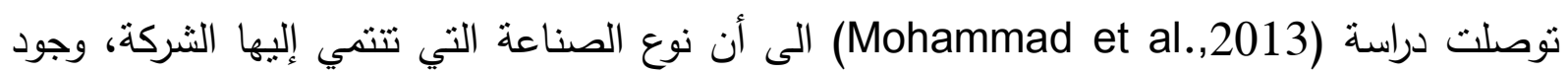


بنود غير عادية، العائد على الأسهم، نسبة الرافعة المالية، وحجم الثركة تؤثر على تأخر فترة إصدار تقرير المراجعة في طهران. T/T أثر جودة المراجعة على العلاقة بين تأخير إصدار تقرير مراقب الحسابات وكفاءة قـرارات أصحاب

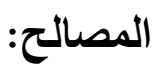

تؤدى جودة المراجعة دوراً حاسماً فى الحفاظ على جودة التقارير المالية، نظراً لأنها تمنل عنصراً

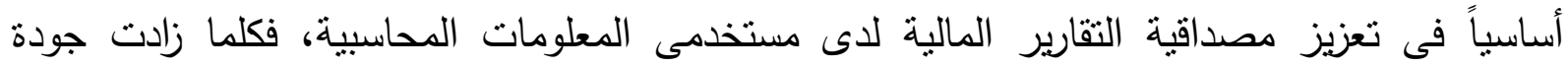

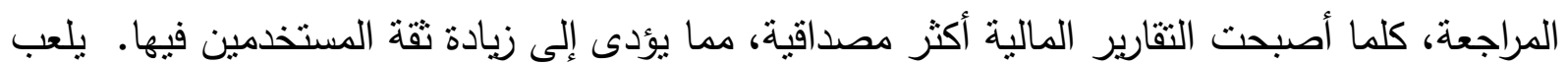

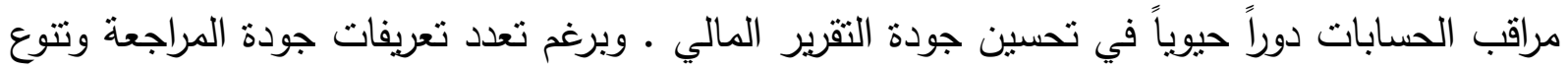
مقاييسها، سواء تلك المتمدة على مدخلات عملية المراجعة، مثل حجم مكتب المراجعة وخبرة واستقلال مراقبي الحسابات، أو تلاك المعتدة على مخرجات عملية المراجعة، مثل إعادة إصدار القوائم المالية هestatements هناك إتجاهاً نحو إجراء مزيد من البحوث التي تتتاول جودة المراجعة بأبعادها وآثنارها المختلفة، نظرا لأهميتها من وجهة نظر أصحاب المصالح ودورها في تحسين جودة التقرير المالي، مما يؤثر على نفعية المعلومات لمستخدميها في عملية اتخاذ القرارات. تتمنل البدائل المختلفة لتحسين جودة المراجعة لمواجهة التهديدات التى تحيط بجودة المراجعة فى: -انخفاض أنعاب المراجعة مما يتزتب عليه المنافسة على السعر ، وتقليص حجم اختبارات التحقق

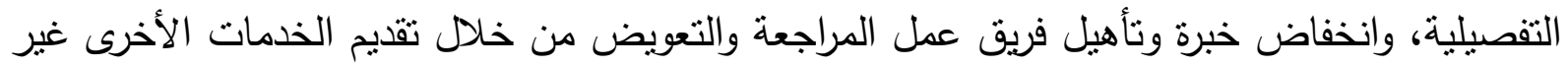
المرتبطة بالمراجعة. -زيادة هامش الربح المحقق من الخدمات الأخرى غير المرتبطة بالمراجعة. - زيادة حدة المنافسة فى الاستعانة بفرق عمل مؤهلة ذات خبرة طويلة. - ممارسة الضغوط على إدارة الثركات لادارة الأرباح كجزء من استراتيجية مواجهة الهنة المنافسة. وقد زاد اهتمام منشآت المحاسبة والمراجعة المصرية بتحسين جودتها وسمعتها من خـال انتماء التهاء العديد منها لمنشآت المحاسبة والمراجعة الكبرى. كما شهدت الفترة الأخيرة اهتمام الجهات الرقابية بجودة المراجعة من خـلال صدور العديد من القرارات، فقد صدر قرار رئيس هيئة سوق المال رقم 97 لسنة

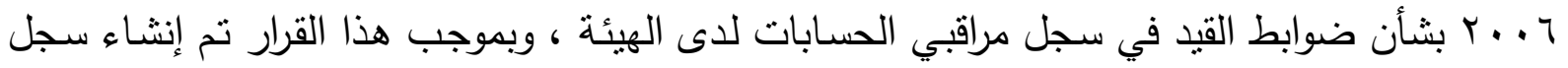

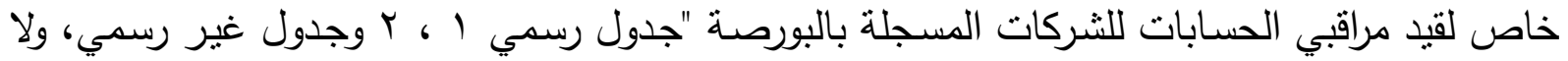

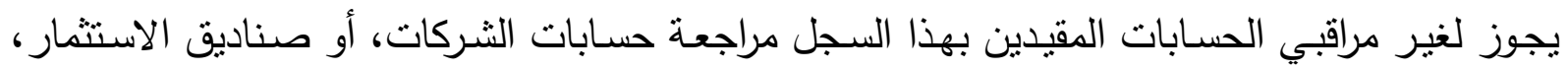

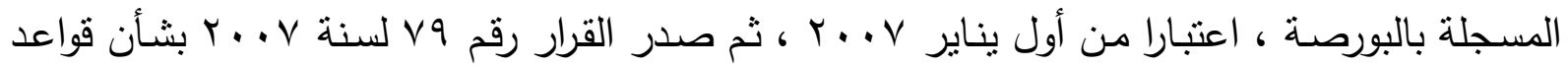
وآداب وسلوكيات مزاولي مهنة المحاسبة والمراجعة المقيدين بسجل الهيئة، ثم صدر قرار رئيس هيئة

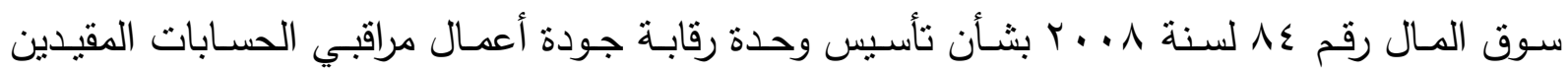


بسجلات الهيئة علي غرار مجلسPCAOB ـ كما صدر قرار رئيس الهيئة العامة للرقابة المالية رقم ب؟ لسنة 9 . . ب بشأن القيد واستمرار القيد والثطب في سجل مراقبي الحسابات لدي الهيئة.

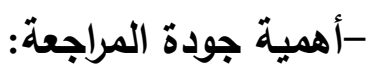

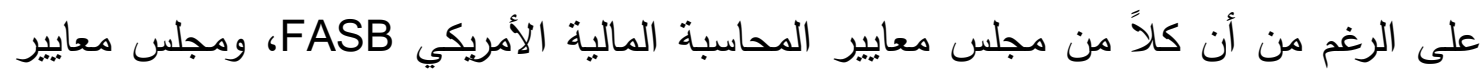
المحاسبة الدولية IASB يؤكدان على أهية أن تكون التقارير المالية ذات جودة عالية، إلا أن أحد المشاكل الرئيسية التي إهتمت بها الدارسات السابقة (Biddle et al.,2009) التي تتاولت جودة الثقارير المالية هو كيفية الصياغة العملية لهذه الجودة وكيفية قياسها، وذلك بسبب الطبيعة الخاصة لهذه الجودة

( Karami \& Akhgar,2014).

تتمثل أهمية جودة المراجعة فى:

1-المساهمة في تضييق فجوة التوقعات في المراجعة: تعتبر فجوة الجودة أحد المكونات الفرعية لفجوة التوقعات في المراجعة. تعرف فجوة الجودة بأنها الاختلافات بين توقعات المستخدمين والمراجعين تجاه

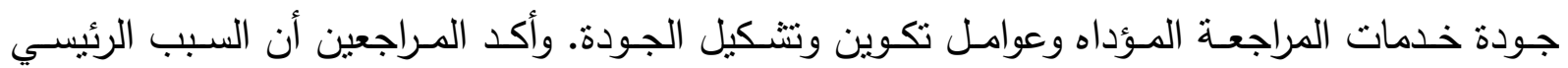
لوجودها هو انخفاض الأداء الفعلي للمراجع عن معايير المراجعة ومعايير الجودة المتعارف عليها. ץ-تخفيض صراع الوكالة: كلما زاد التعارض في المصالح بين الوكيل والأصيل كلما زادت تكلفة الوكالة، وكلما زادت تكلفة الوكالة زادت الحاجة الى مكاتب مراجعة لتقديم خدمات ذات جودة عالية. ب-تعزيز وامكانية اكتشاف المخالفات والاخطاء بالقوائم المالية: أكدت لجنة الى أن تحسين جودة المراجعة يزيد من اكتثاف الأخطاء والحد من التحريف بالقوائم المالية.

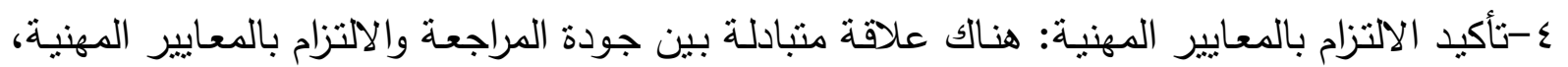

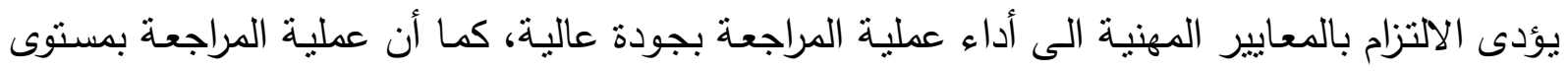
جودة ملائم يؤكد تمسك المراجعين بالمعايير المهنية. ه-أداة تتافسية جيدة: تعتبر المنافسة على الأتعاب أحد المخاطر التي تهدد مهنة المراجعة، ذلك للها فيها من تأثنر سلبي على استقلال المراجعين ونطاق إجراءات المراجعة وثم جودة المراجعة. ج-زيادة التقة في تقرير المراجعة ومصداقية القوائم المالية: يعتبر الاهتمام بجودة المراجعة لتدعيم التقة بتقارير المراجعة، وذلك للاور المهم الدى تلعبه التقارير في إضفاء المصداقية على القوائم المالية التي تستخدم في اتخاذ القرارات من جانب الأطراف المهنية.(Ilaboya and lyafekhe, 2014) وفى هذا السياق، تستوجب شروط منطلبات قيد مراقبى الحسابات بسجل مراقبى الحسابات لدى الهيئة العامة للرقابة المالية على مراقبى الحسابات الراغبين فى القيد بسجل مراقبى الحسابات لدى الهيئة

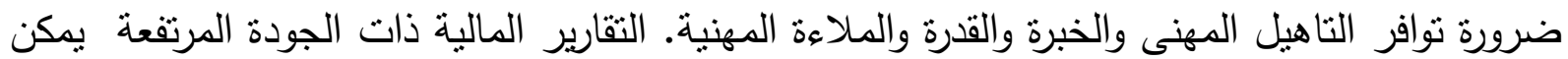
ان تساعد فى التقليل من عدم تمانل المعلومات بين الادارة والمستثرين ، مما يؤدى الى علاج مشكلات الانهيار الأخلاقى للمديرين والاختيار العكسى. تتمنل محددات جودة المراجعة فى؛ حجم منشأة المحاسبة 
والمراجعة والسمعة الطيبة لها، وعدم وجود دعاوى قضائية مرفوعة على منشأة الدحاسبة والمراجعة، وارتباطها باحدى منشأت المحاسبة والمراجعة العالمية ووجود نظام الرقابة على الجودة، والخبرة المهنية، ولهات

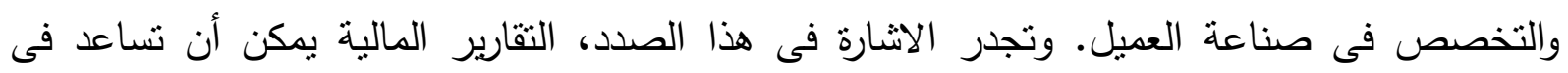

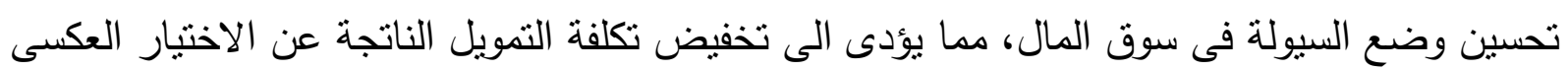

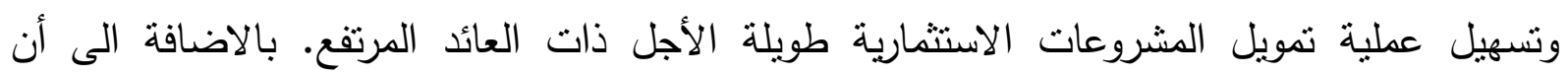

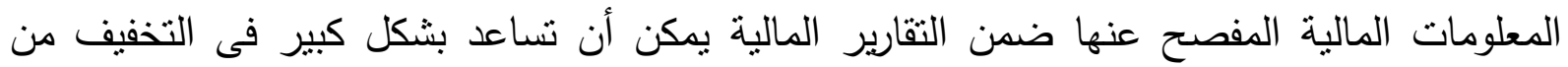

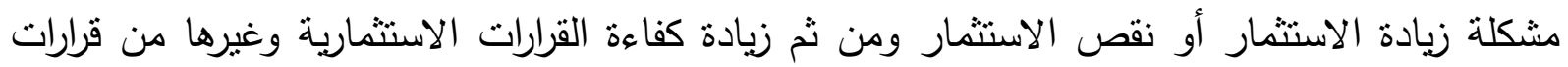

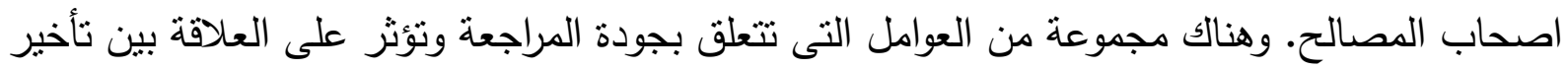

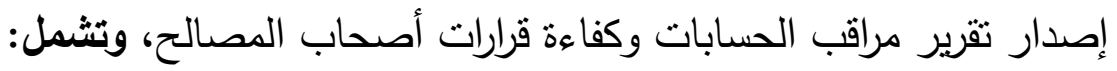

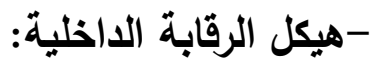

عرف المعهد الأمريكى للمحاسبين القانونيين الرقابة الداخلية بأنها الخطة التظظيمية وكل ما

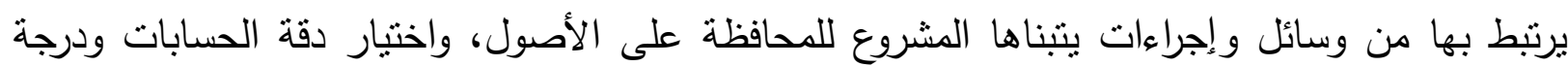

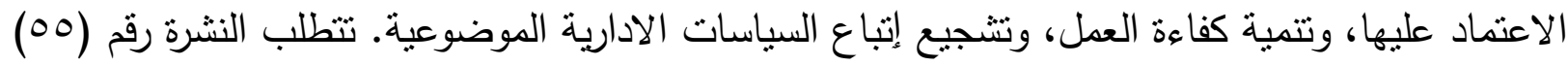

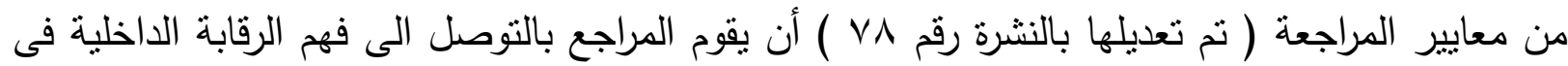

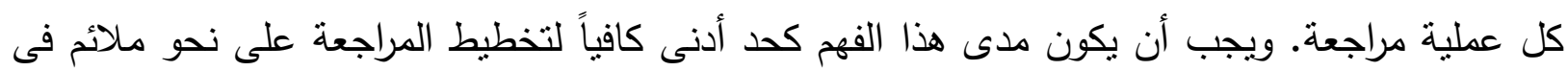

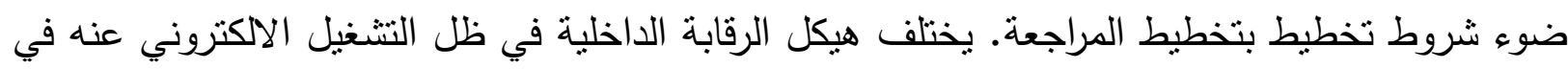

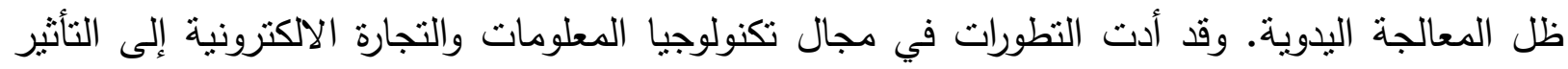

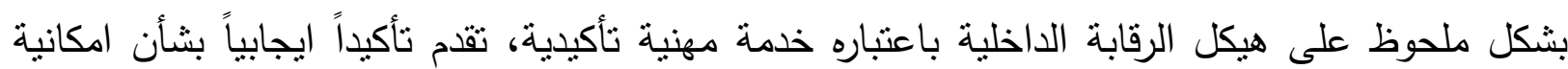

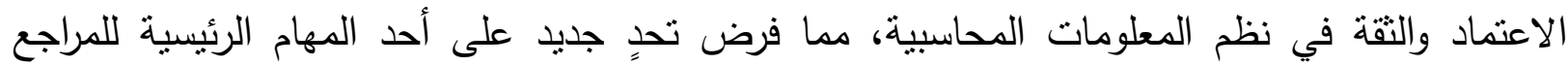
الخارجي وهي تقويمه لنظام الرقابة الداخلية الذي يعتبر نقطة البداية بالنسبة لعملية المراجعة. ومن ثم فعلى

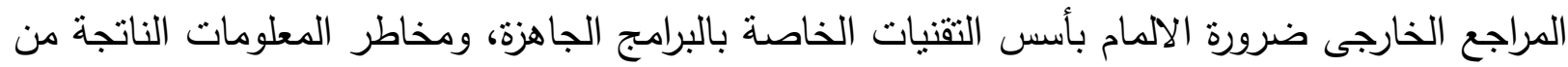

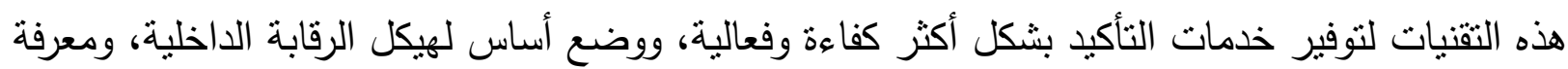

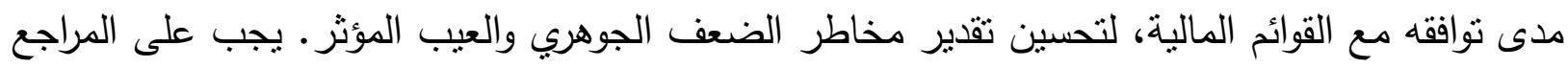

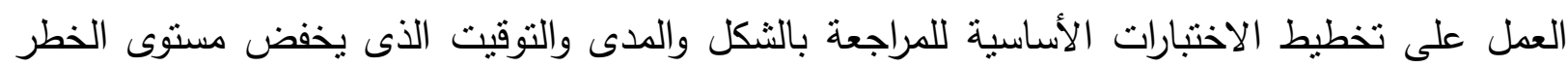

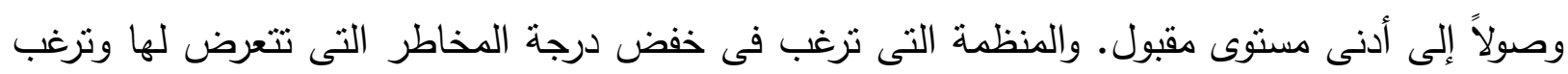

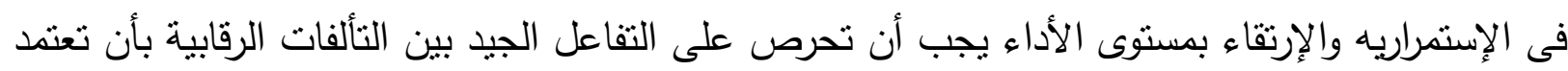

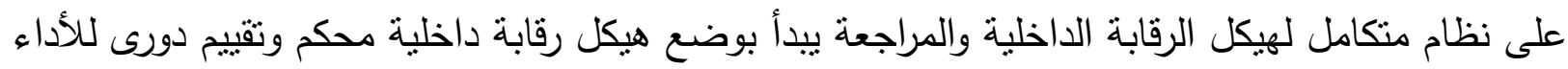

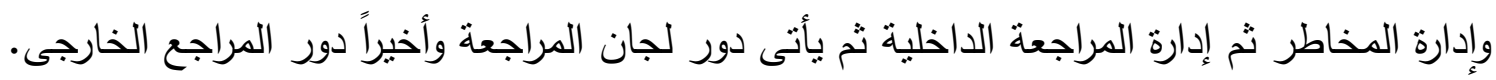


وقد توصلت العديد من الدراسات (Bamber et al.,1993; Pizzini et al.,2015) الى أثز هيكل الرقابة الداخلية على جودة المراجعة، وتوصلت إلى أن وجود هيكل رقابة داخلية فعال يعتبر أحد العوامل المؤثرة على جودة المراجعة. -مستوى خطر أعمال مراقب الحسابات: أهية الخبرة المهنية متمنلة فى استيفاء مراقب الحسابات لـنطلبات القبد بسجل مراقبى الحسابات

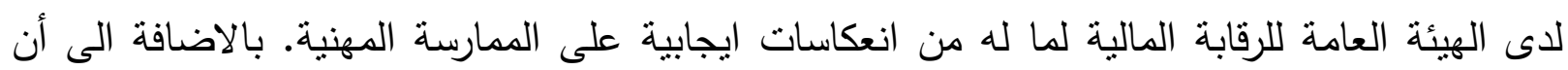

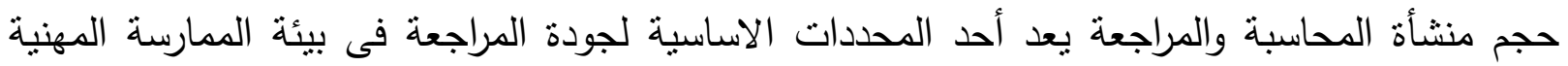

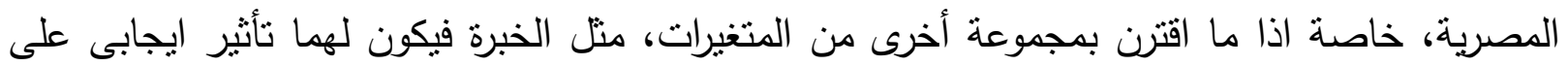
كفاءة مراقبى الحسابات فى اكتثاف التحريفات الجوهرية والتقرير عنها، ومن ثم على جودة المراجعة، بما

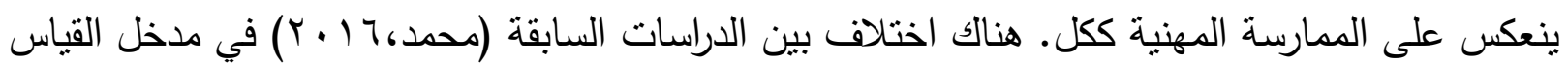

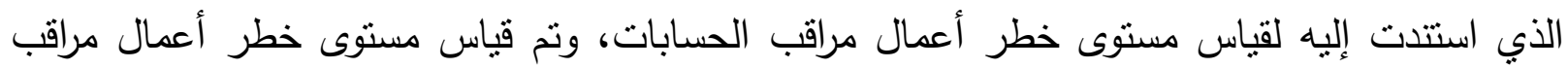

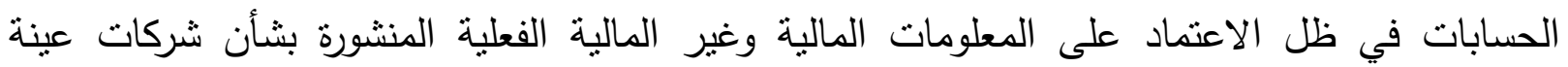

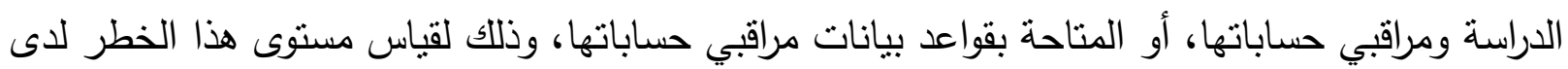

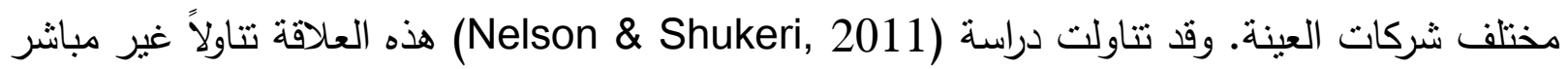

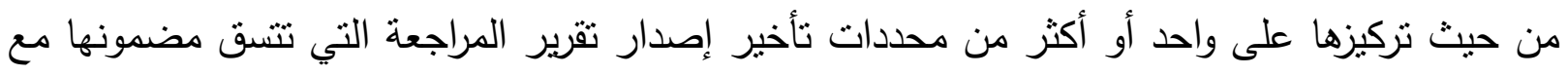

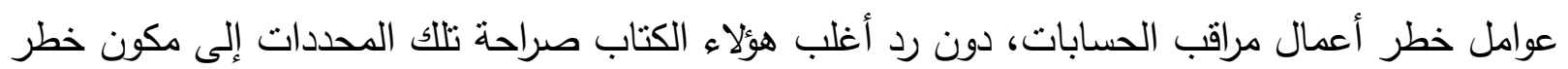

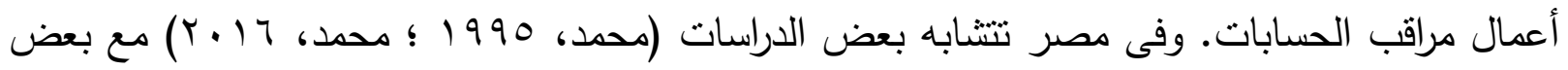

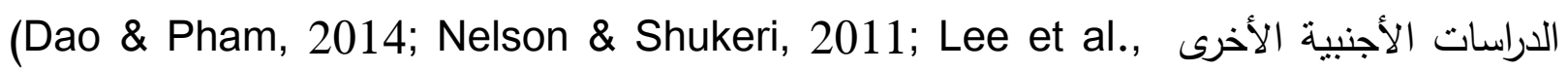

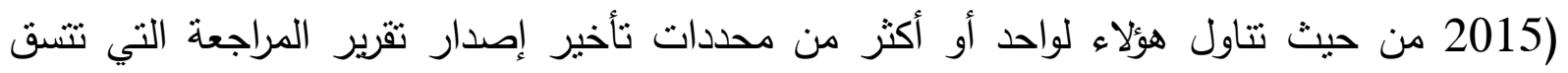

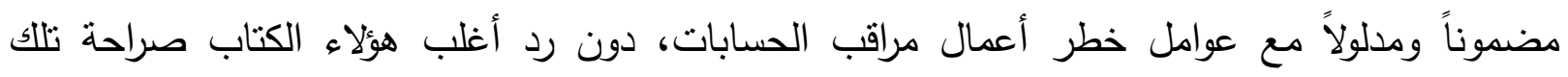

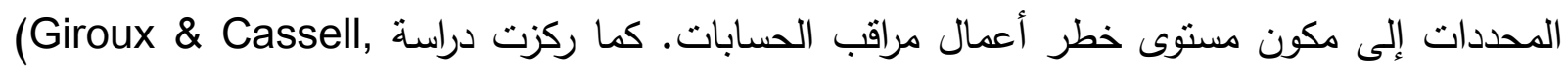
(2011 من حيث التركيز على تحديد مدى تأثير اختلاف مستوى خطر أعمال مراقب الحسابات على اعلى

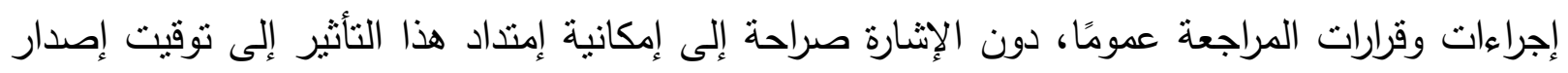

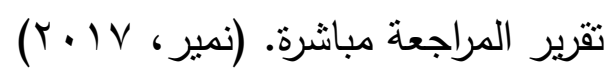
-خبرة المراجع والتخصص الصناعي لمراجع الحسابات:

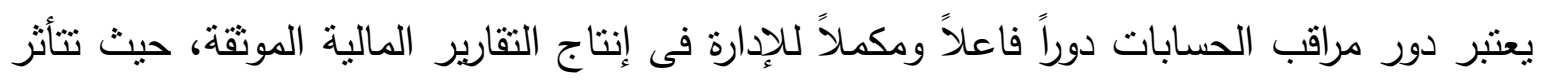
درجات التقة والمصداقية لكافة المستخدمين بالدور الذى يضطلع به فى الإرتقاء بمستوى مصداقية وشفافية

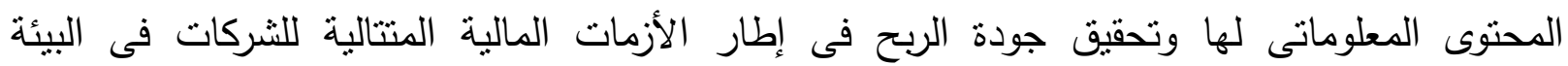

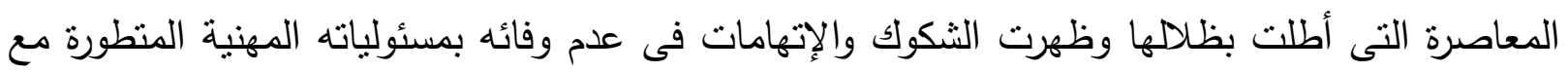
المستجدات وتوالت الدعوات إلى ضرورة تفعيل قدراته للإرتقاء بمستوى آدائه المننى، وتعظيم الثقة والثنفافية 
فى محتوى المعلومات فى التقارير المالية وتحقيق جودة الربح وزيادة قدرته التفسيرية. (يوسف، ب ا ـ؟؟

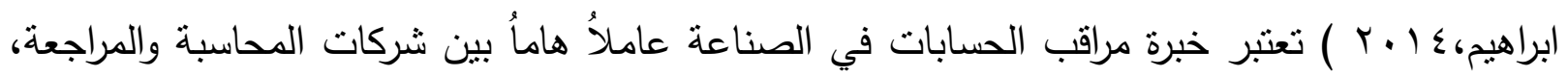

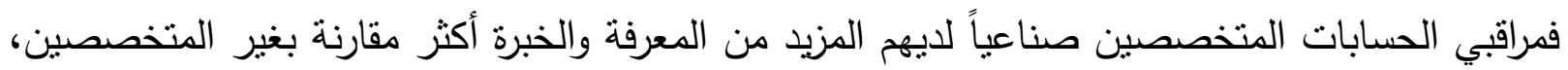

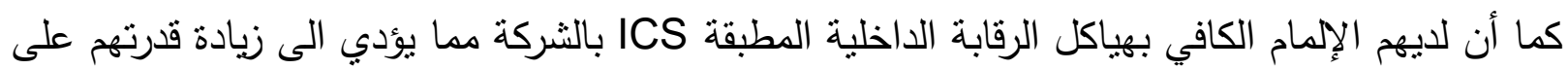

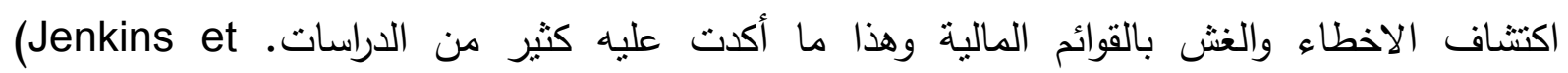
(al.,2006) خبرة مراقب الحسابات المتخصص له مزايا قد تختلف عن غيره من غير المتخصصين،

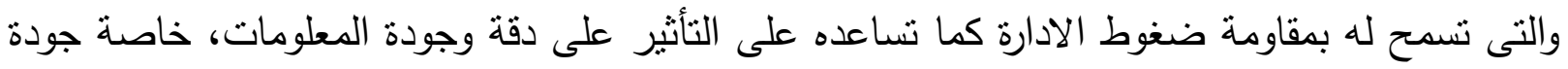

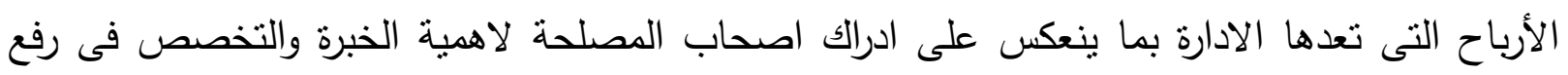

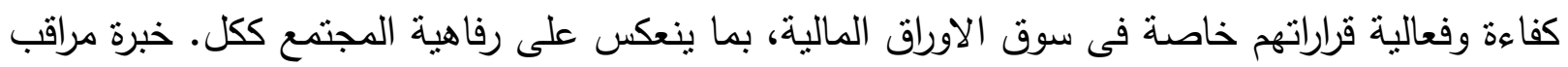

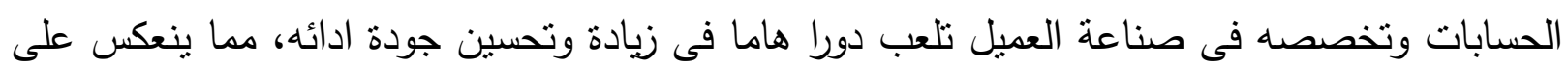

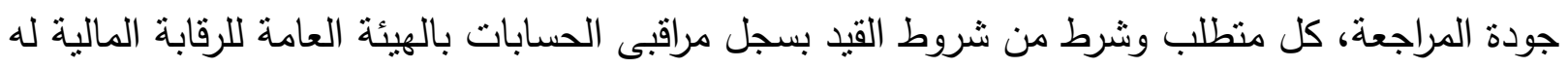

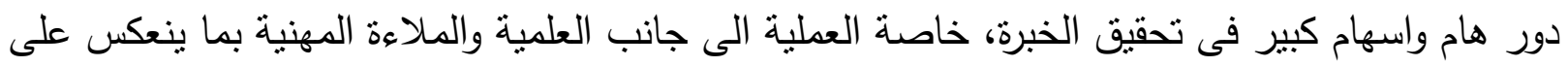

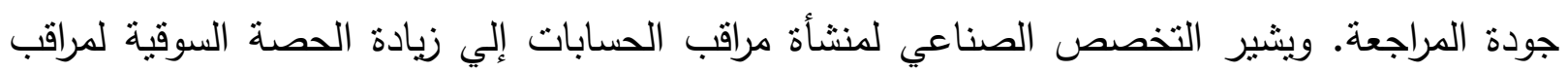

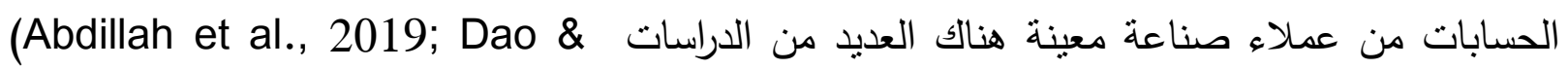
اختبرت العلاقة بين التخصص المهنى لمكتب المراجعة، كمقياس لجودة المراجعة، وفترة

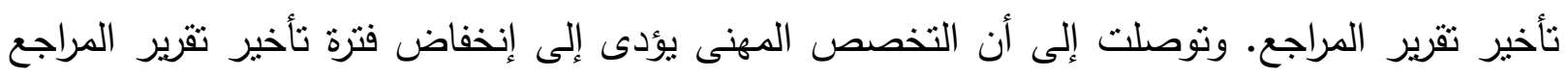

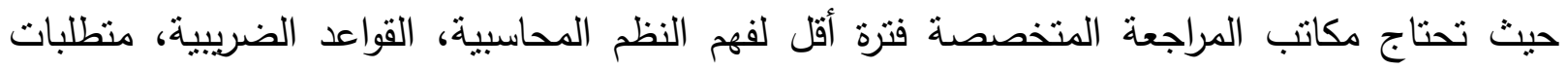

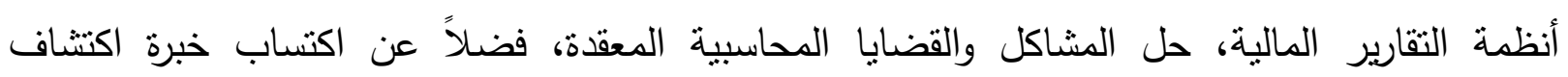
الأخطاء الهامة مقارنة بمكاتب المراجعة غير المتخصصة مما يؤدى إلى مراجعة القوائم المالية للشركات

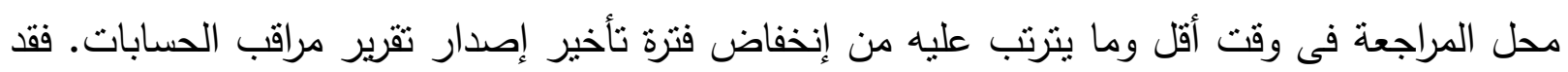

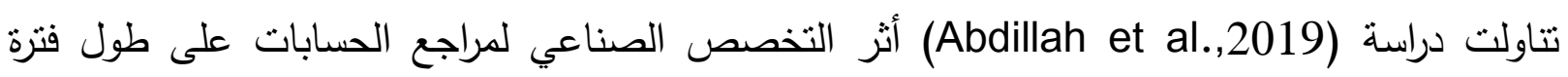

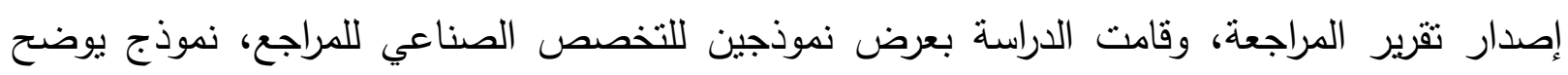

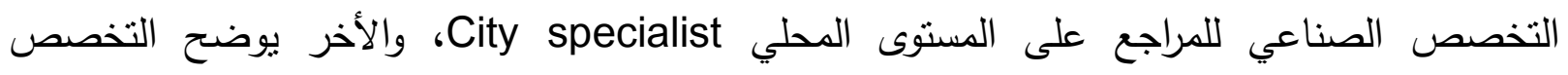

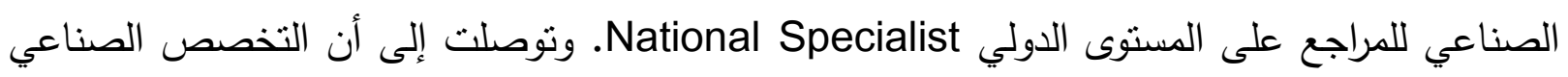

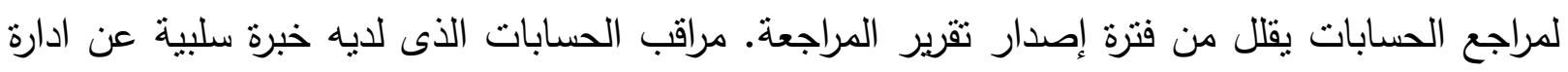

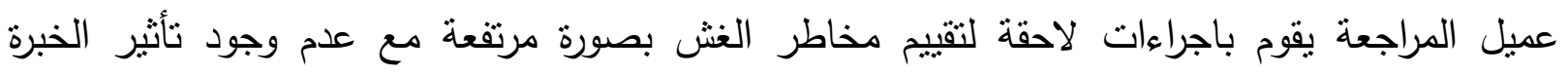

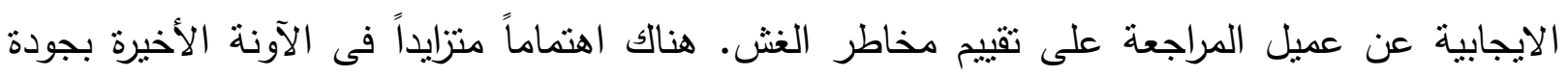

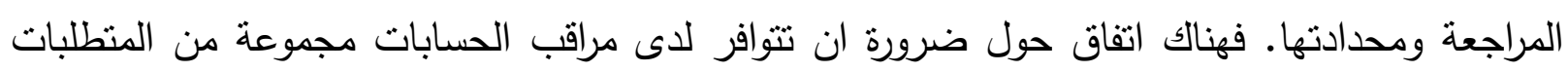

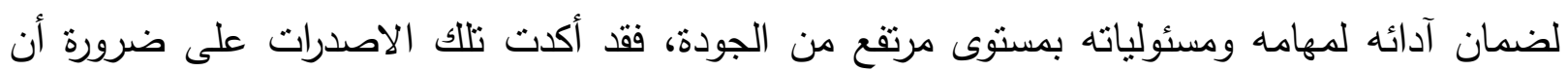
تتوافر فى مراقب الحسابات الكفاءة والملاءة المهنية اللازمة والتى ثأتى من المعرفة العلمية والخبرة العملية 
فى كافة المجالات المرتبطة بالمحاسبة والمراجعة، والتى لا تتوقق عند حد اكتساب المهارات الأساسية فقط

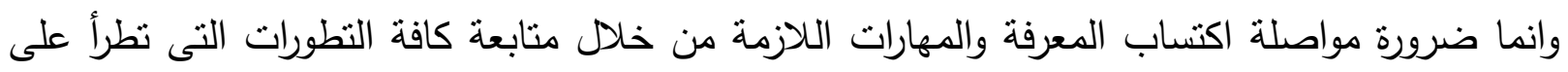
المهنة، عن طريق التدريب والتعليم المستمرين. تؤثر خبرة المراجع والتخصص الصناعي لمراجع الحسابات

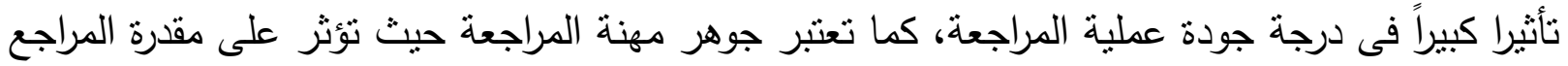

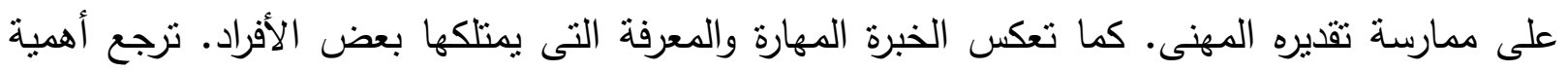

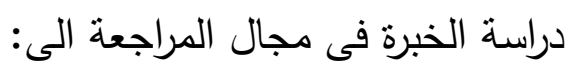
-العديد من تقديرات المراجع تعتبر تقديرات شخصية تلعب الخبرة دوراً هاماً فيها. - اختلاف تقييمات وتقديرات المراجعين طبقاً لحجم الخبرات المكتسبة لديهر.

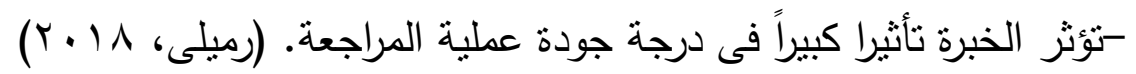
كما توصلت دراسة (Cullinan and Zheng,2017) إلى وجود علاقة عكسية بين الربحية ، حجم مكتب المراجعة، حجم الثركة، والرافعة المالية وفترة التأخير في قطاع الصناعة ، والى وجود علاقة

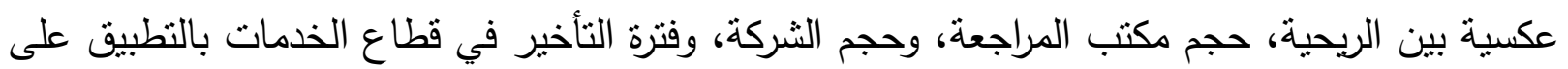

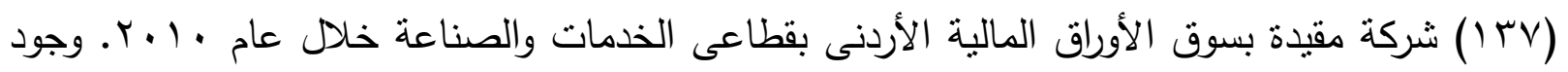

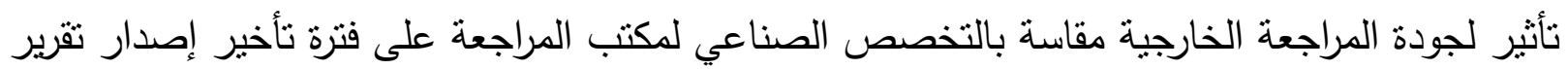

$$
\text { مراقب الحسابات. }
$$

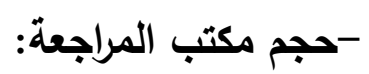

حجم مكتب المراجعة يعد مقياس لجودة المراجعة الخارجية، يتم تصنيف مكاتب المراجعة على أساس

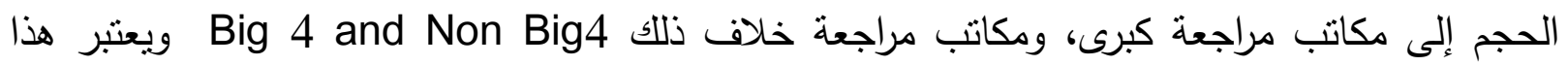
التقسيم من المداخل الأكثر شيوعاً في مجالات البحث العلمي كمؤشر للاستدلال على جودة المراجعة.

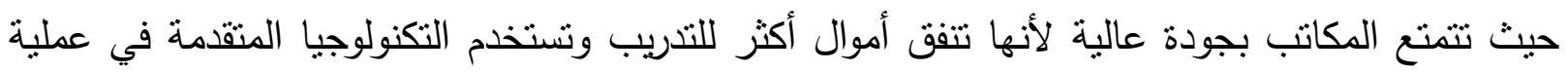

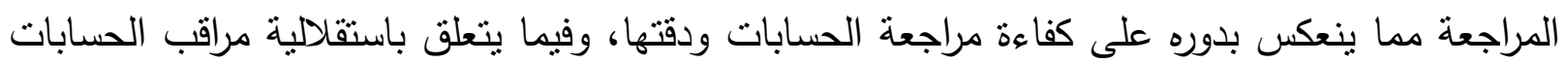
فإن مكاتب المراجعة الأكبر حجما تتمتع بقدر أكبر من الاستقال لأن لديها قاعدة كبيرة من العملاء

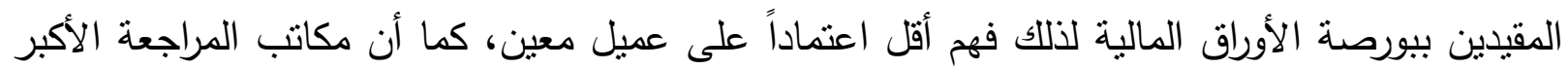

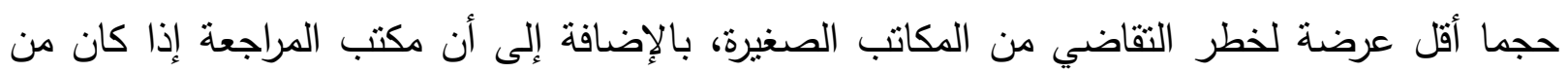

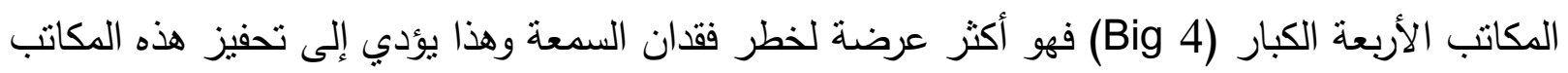

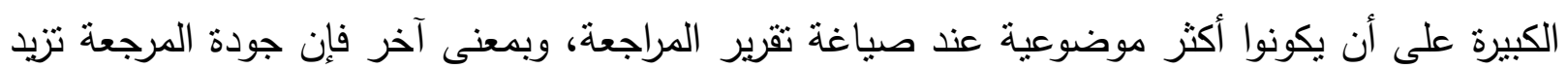

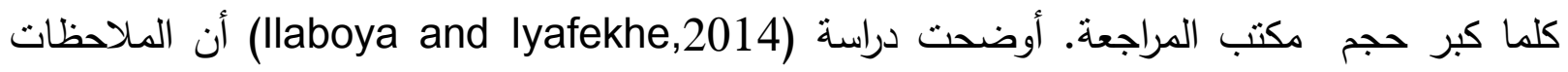
الموجودة في تقرير المراجعة، الاستعانة بمكاتب المراجعة الدولية نوع تقرير المراجعة، وأتعاب المراجعة لها الها

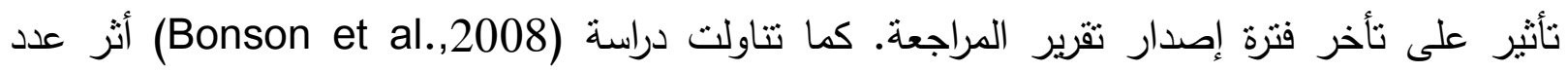

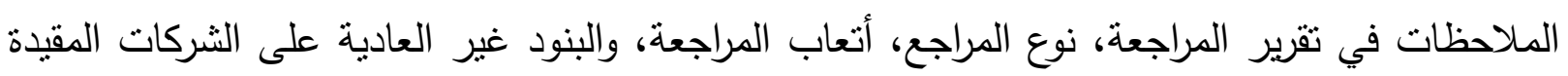


في البورصة في اليونان. وتوصلت الى ان حجم مكتب المراجعة يؤثر على توقيت إصدار تقرير المراجعة.

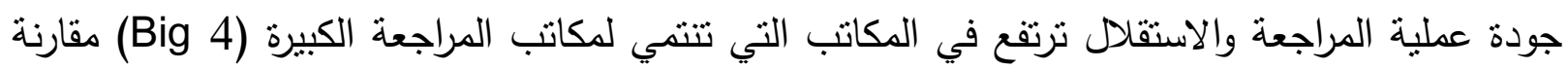

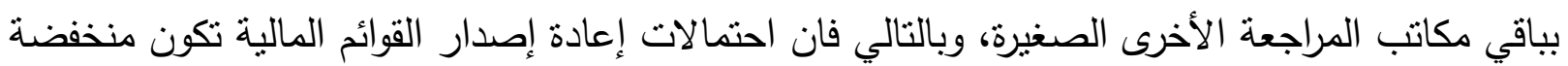
في الثركات التي ينت مراجعتها بواسطة مكاتب مراجعة صغيرة مقارنة بتلك الثركات التي ينت مراجعتها

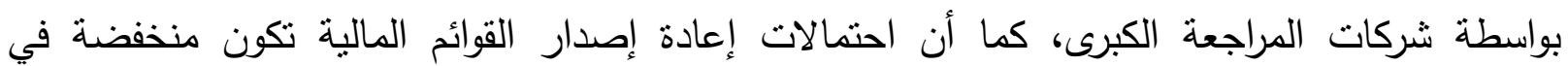
الثركات التي يتم مراجعتها من خلال مكاتب مراجعة كبيرة مقارنة بتلك الثركات التي يتم مراجعتها من

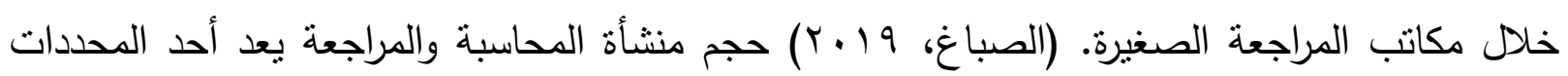

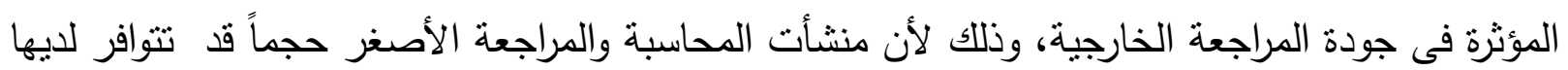
الامكانيات لمواكبة التغيرات فى بيئة الممارسة المهنية العالمية، بالاضافة الى ألى أن مراقب الحسابة العابات الأكثر خبرة سيكون أكثر حرصاً على الارتقاء بجودة المراجعة، وتكون تلك الجودة أعلى كلما كبر حجم منشأة الأنة المحاسبة والمراجعة التى ينتمى اليها.

وتجدر الاشارة فى هذا الصدد، حجم منشأة المحاسبة والمراجعة يلعب دوراً هاماً فى كونه محدداً

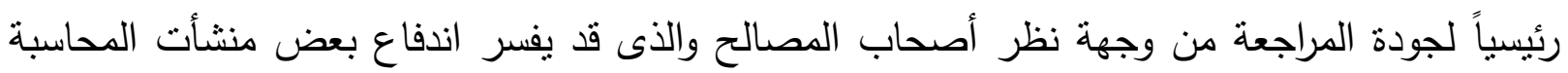

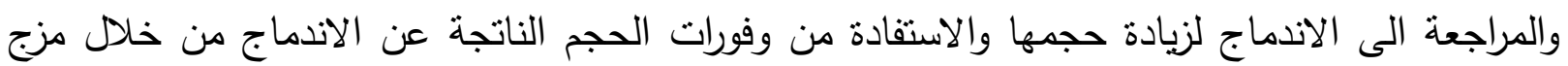

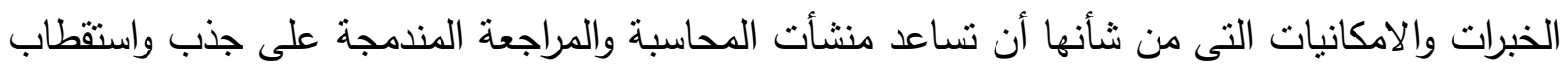
الكفاءات والخبرات المهنية واتاحة فرص التدريب الجيد لمراقبى الحسابات بما ينعكس على آدائهم ومن ثماتث

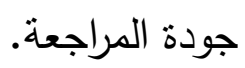

- التناوب الإلزامى لمراقب الحسابات (طول فترة علاقة المراجع مع الثركة):

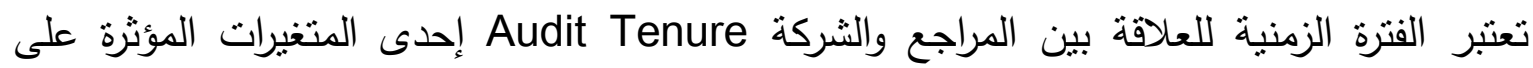
توقيت إصدار تقرير المراجعة. وقد نال موضوع التناوب الإلزامى لمراقب الحسابات لمنشآت الأعمال

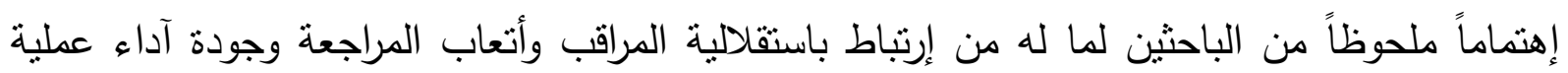

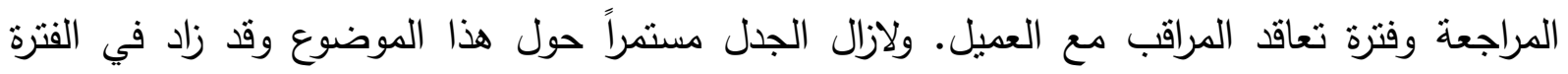

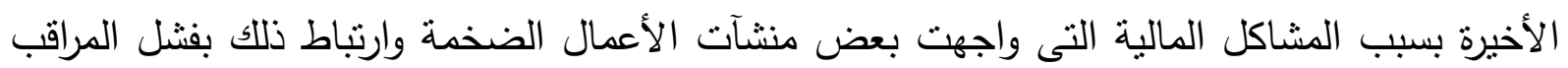

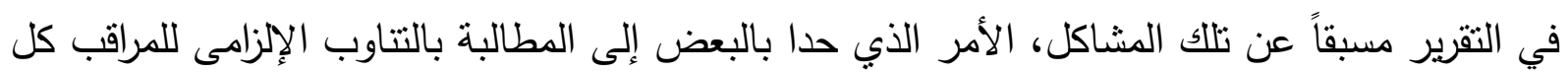
فتره معينة (أي ضرورة إجراء تتاوب للمراقبين على المنشأة كل فترة محددة. وقد طالبت الهيئة الأمريكية لتبادل الأوراق المالية (SEC) مؤخراً باجراء أبحاث حول العلاقة بين فترة إرتباط المراقب بالثركة محل

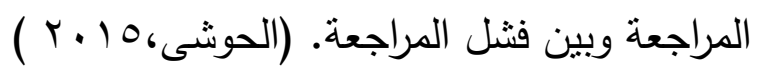
وفى هذا الصدد، تأخر التقرير فى السنة الأولى للتعاقد مع المراجع، يمثل أمر طبيعى نظراً لأثر التعلم

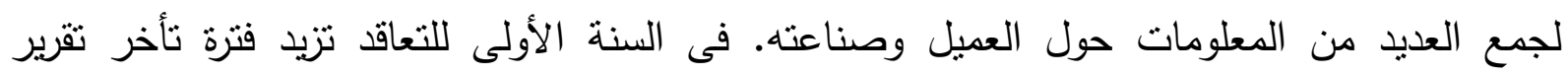

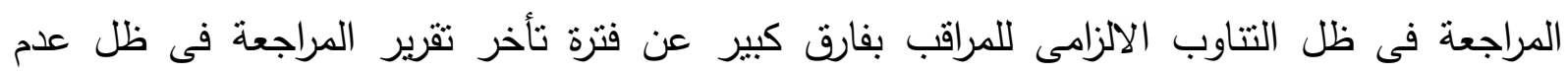


التتاوب الالزامى للمراقب، أما فى السنة الثانية للتعاقد لا يوجد أى فروق جوهرية بين نوعى التغيير ـ هناك دراسات مؤيدة، ودراسات معارضة لنطبيق التتاوب الإلزامى لمراقب الحسابات وعلاقته بجودة التقارير

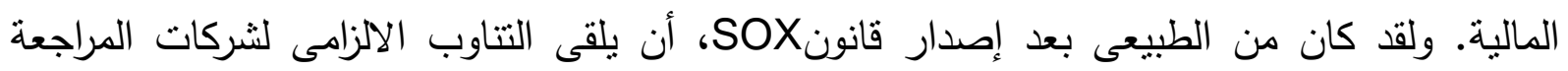

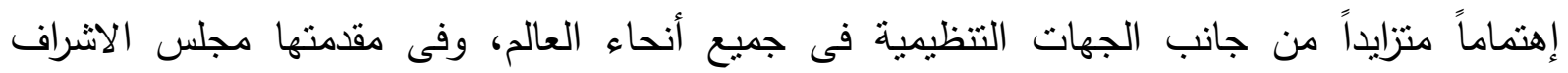

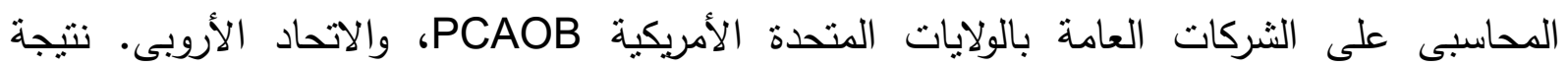

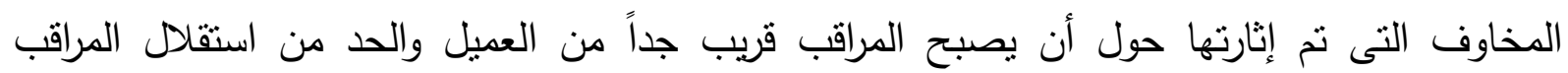
وضعف كل من؛ الموضوعية، والثكك المهنى لديه، مما يؤدى الى الحد من جودة المراجعة، ويضعف من الثقة فى جودة التقارير المالية. لذا يجب على مراقب الحسابات الحريص الإرتقاء بجودة المراجعة من خلال الالتزام بمعايير المراجعة المتعارف عليها GAAS فى كل مراحل عملية المراجعة، بدءاً من قبول التكليف ومروراً بتخطيط إجراءات المراجعة ثم آداء هذه الإجراءات وجمع الأدلة الكافية والملائمة وإنتهاءاً باعداد وعرض تقريره الذى يحمل رأيه الفنى على القوائم المالية وايضاحاتها المتممة.(Asthana,2014)

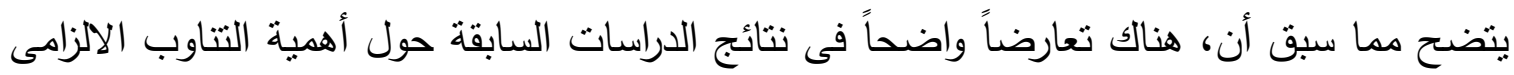

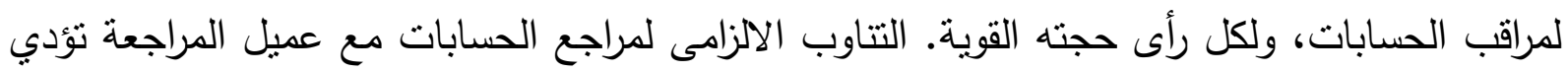

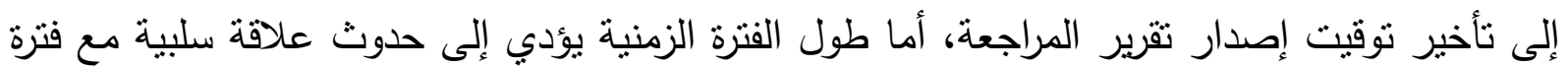

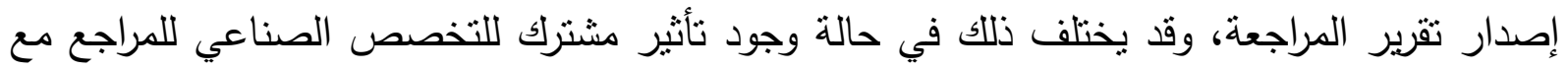
قصر أو طول الفترة الزمنية لإصدار تقرير المراجعة. طول فترة التعاقد يترتب عليها زيادة حجم التحريفات الجوهرية في محتوى القوائم المالية، وإنخفاض جودة وشفافية التقارير المالية الموثقة. ويساعد التتاوب

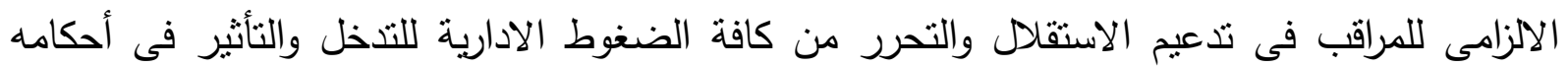
المهنية، وتدعيم الاستقال فى المظهر والواقع الفعلى وإستقرار الحالة الذهنية والنفسية والتى نعد من الإنى

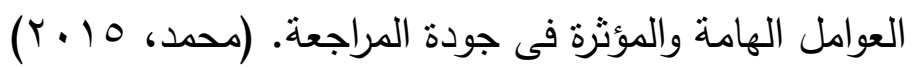
ومن جهة أخرى، قد يكون للتتاوب الإلزامى للمراقبين آثار إيجابية على إستقلال المراقب خاصة

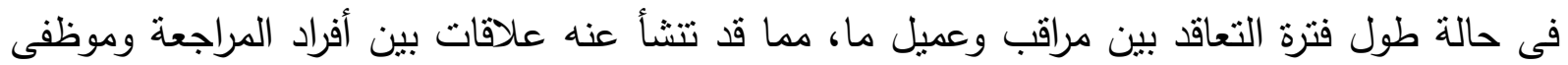

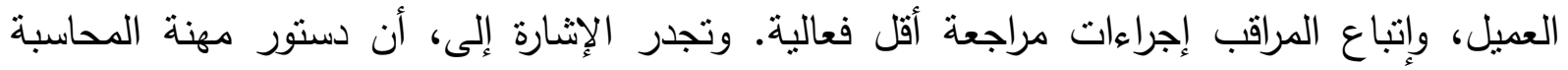

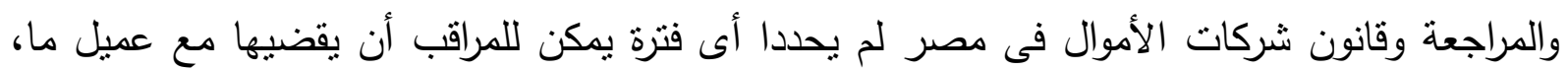

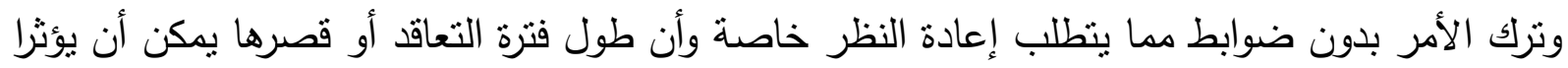

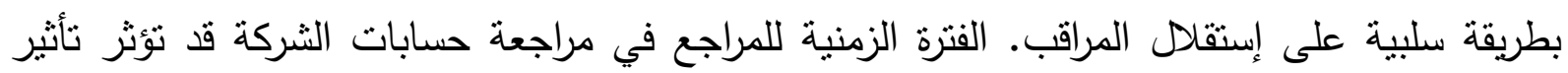
إيجابي أو تأثثر سلبي على تأخير نوقيت إصدار تقرير المراجعة وذلك حسب قصر أو طول الفترة. 


\section{- أهمية دراسة فترة المراجعة :}

ترجع أهمية دراسة فترة المراجعة الى :

1- استعادة نقة المستثمرين فى الأسواق المالية وتحقيق مطالبهم من معلومات محاسبية تتسم بالموثوقية

وفى التوقيت المناسب.

ץ-زيادة أهية المنظمين والمستثرين بتوقيت الثقارير المالية نتيجة للأزمات المالية الكبرى وحاجتهر

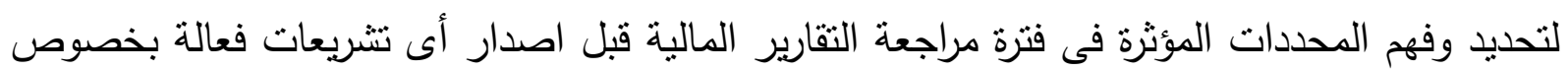
تلك الفترة. r- دراسة أى محدد لهذه العوامل يجعل لفترة المراجعة تأثثر على كفاءة وفعالية المراجعة، كما يتضمن تقرير المراجع رأى المراجع الذى يأخذ بعين الاعتبار مصداقية القوائم المالية.

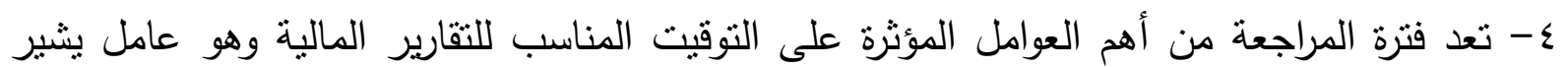
لكفاءة عمل سوق المال . 0- التأخير غير الملائم فى الافصاح عن المعلومات المالية يزيد من عدم التأكد المصاحب للقرارات

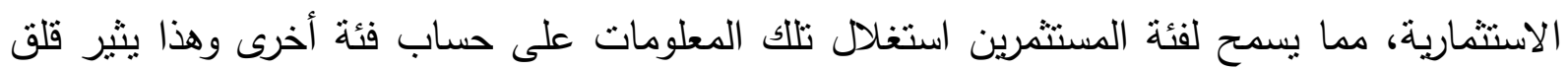

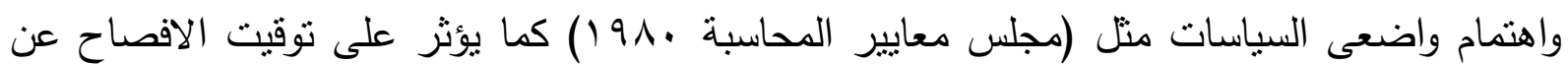
· الأرباح ؟- ثأثير فنترة المراجعة على توقيت عملية المراجعة والمعلومات المالية الناتجة عنها. (رضوان

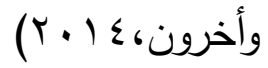

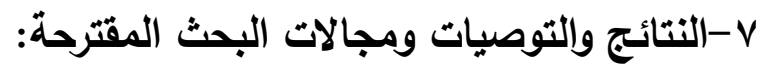
يمكن بلورة أهم نتائج البحث على النحو التالى الته كيعد تقرير مراقب الحسابات Auditor Report المنتج النهائي لعملية المراجعة ويعتبر وسيلة أو أداة لتوصيل الرأي الفني المحايد لمراقب الحسابات على القوائم المالية محل المراجعة إلى مستخدمي القوائم

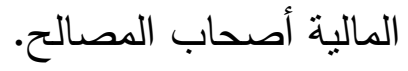
- هناك اهتمام بقياس تأثثير بعض المتغيرات المؤسسيه على مستوى الإفصـاح، وعلى فترة فترة اصدار تقرير المراجعة، ومن أهم تلك المتغيرات نجد نوع الصناعة، حجم الثركة، الرافعة المالية ، كفاءة الإدارة.

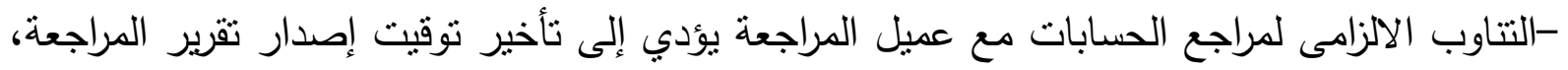

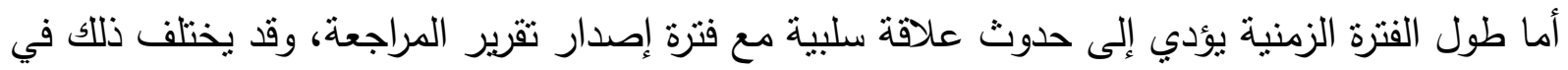
حالة وجود تأثثر مشترك للتخصص الصناعي للمراجع مع قصر أو طول الفترة الزمنية لإصدار تقرير 
-اختيار الثركات لمراقب حسابات متخصص في الصناعة لمراجعة قوائمها المالية سيؤدي إلى تقليل فترة

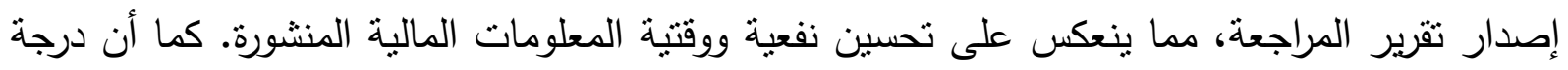
تتوع وتعقد عمليات عميل المراجعة لهما تأثير ايجابي معنوي على نأخير تقرير مراقب الحسابات.

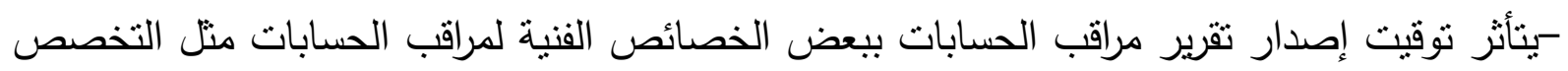
الصناعي لمراقب الحسابات وبعض الخصائص التشغيلية للشركات منل درجة تتوع وتعقد عمليات

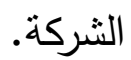

-الثشركات كبيرة الحجم تزداد وتتعقد عملياتها مما يتطلب من المراجع بذل مزيد من الجهد في عملية

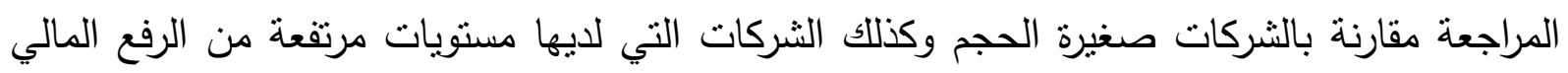

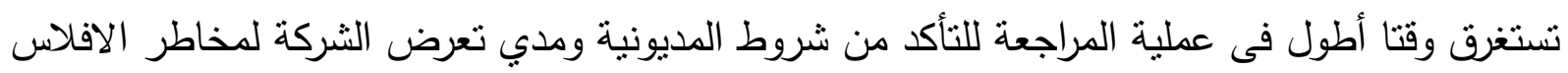

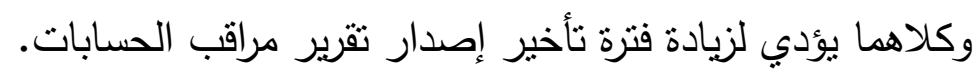
وفى ضوء النتائج السابقة توصى الباحثة بالآتى:

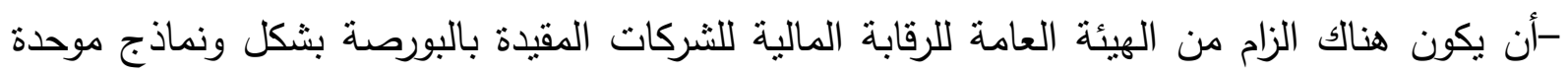

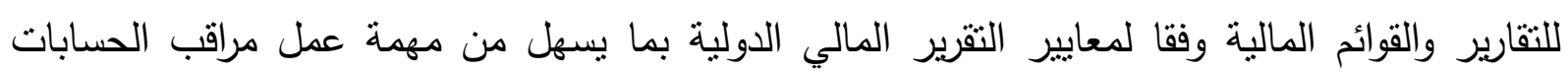
واصدار تقريره في وقت أقل. -ضرورة قيام هيئه الرقابه الماليه بالتعاون مع البورصده بعمل برامج توعيه للعاملين بالثركات المتثاوله

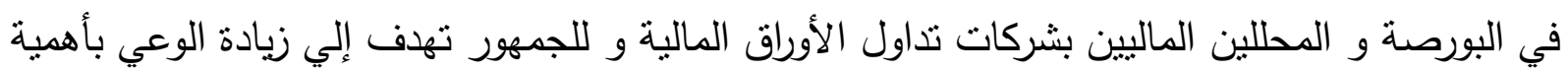
الإفصاح و الفوائد التي سوف تعود علي الثركات وكافة المستخدمين. - اهمية إعادة النظر في منطلبات التأهيل العلمي والعملي لمراقب الحسابات، وتوكير وكئ الأمكانيات المادية والبشرية للتخصص في قطاع صناعي معين، لما له من مردود إيجابي على كل من منشأة عميل المراجعة وأصحاب المصالح فيها. -أهمية قيام الهيئة العامة للرقابة المالية بتخفيض فترابة الهية الإفصاح عن الثقارير المالية من ( •9) من تاريخ

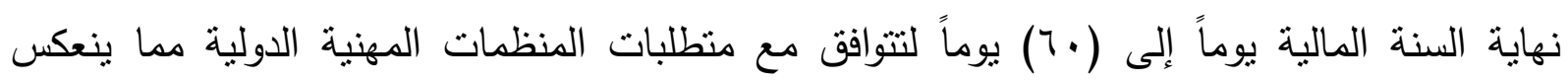
إيجابياً على كفاءة المعلومات فى سوق الأوراق المالية المصرى.

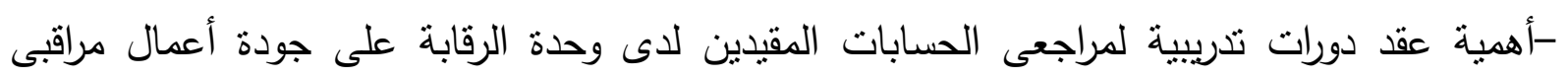

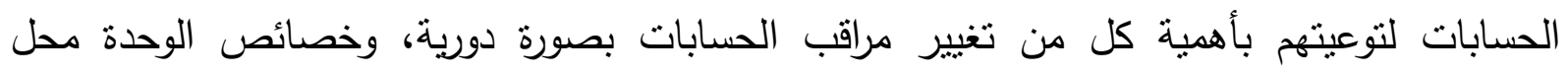
المراجعة لما لذلك من أثر فى جودة أعمال المراجعة الخارجية وتقليل فترة تأخير مراجع الحسابات.

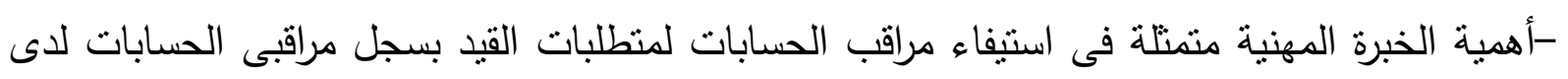

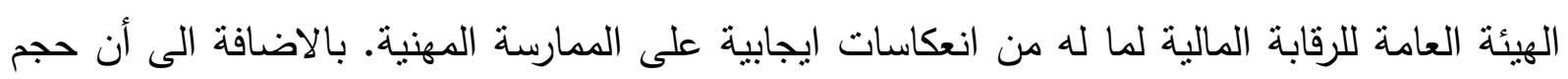

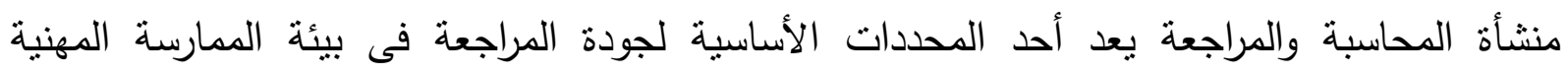

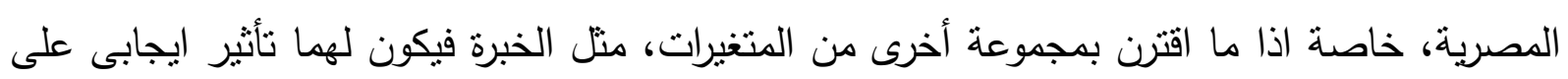


كفاءة مراقبى الحسابات فى اكتثاف التحريفات الجوهرية والتقرير عنها، ومن ثم على جودة المراجعة، بما ينعكس على الممارسة المنية ككل والتقليل من فترة تأخير اصدار تقرير المراقب. - مقترحات لأبحاث مستقبلية: فى ضوء حدود البحث وما إنتهى إليه من نتائج، تعتقد الباحثة بأهمية البحث مستقبلاً فى لى

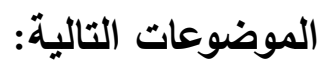
- إجراء دراسة تطبيقية لتقييم العلاقة بين العوامل الداخلية والخارجية المحددة لفترة تأخير إصدار تقرير

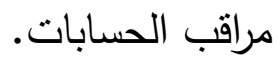
- إجراء دراسة تجريبية حول أثر تبني معايير التقرير المالي الدولية في مصر عام 9 ــ علي فترة تأخير إصدار تقرير مراقب الحسابات. - إجراء دراسة تجريبية حول أثز اجراءات المراجعة الخارجية على فترة تأخير إصدار تقرير مراقب

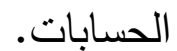
- إجراء دراسة مقارنة لأثز الخصائص التشغلية للثركة علي العلاقة بين جودة وظيفة المراجعة الداخلية والمراجعة الخارجية وفترة تأخير إصدار تقرير مراقب الحسابات. - إجراء دراسة تطبيقية لتقييم العلاقة بين العوامل الداخلية والخارجية المحددة لفترة تأخير إصدار تقرير

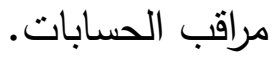
- دراسات أخرى فى البيئة المصرية تهدف للتوسع في حصر ودراسة المحددات والعوامل المؤثرة فى فنرة تأخير إصدار تقرير مراقب الحسابات ومقارنتها بالموجودة فى بلدان أخرى.

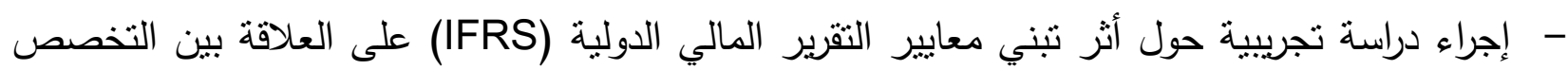
الصناعي لمراقب الحسابات وتأخير تقريره.

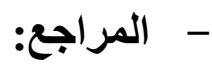

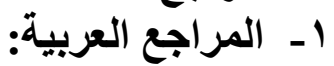

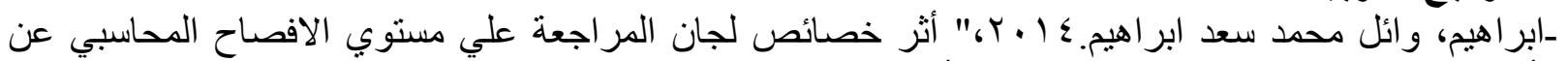

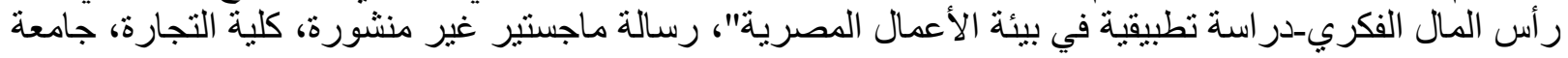

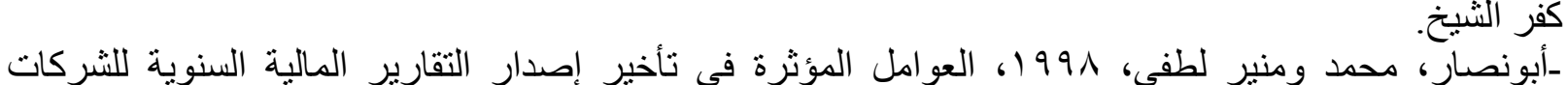

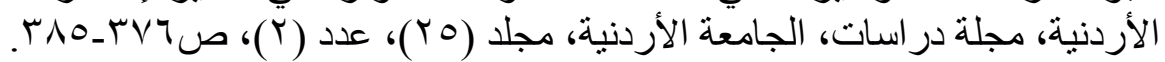

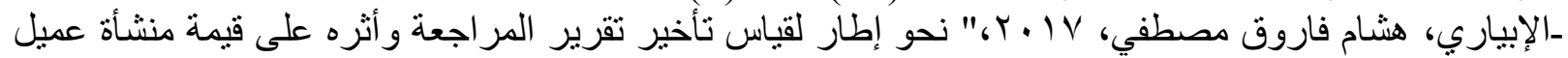

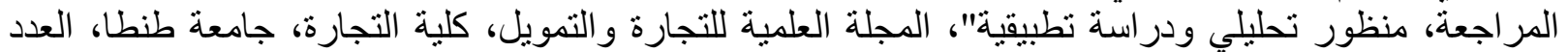

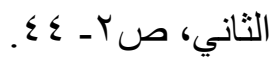
ـالفضل ، مؤيد محمد و عبد الناصر إبر اهيم نور، ج ج . ب ، ، "تحليل أهمية العو امل المؤثرة في تأخير إصدار التقارير

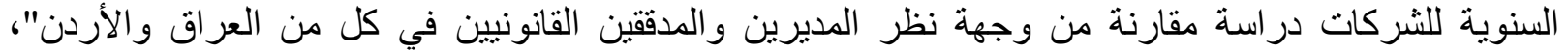

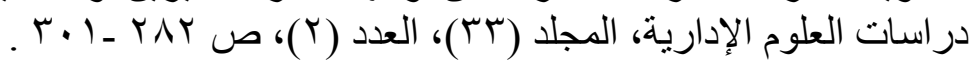

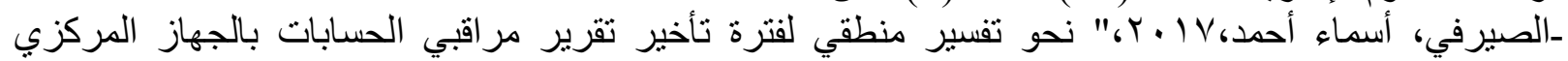

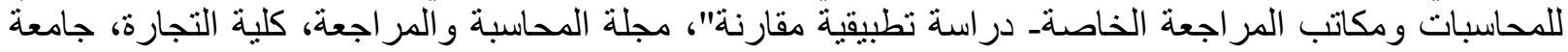

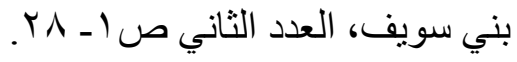


ـالدليل المصرى لحوكمة الثركات، أغسطس، 1 أ.ب، مركز المديرين المصرى بالهيئة العامة للرقابة المالية،

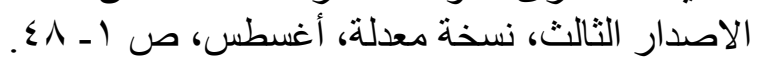

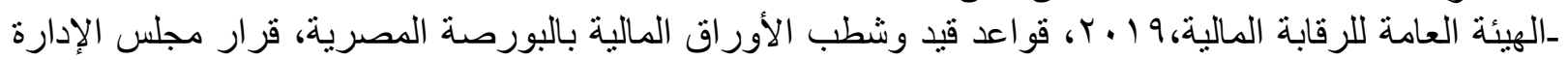

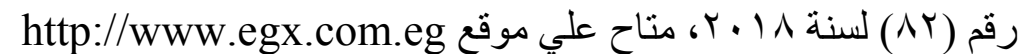

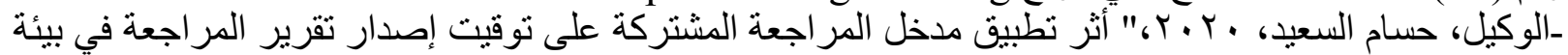

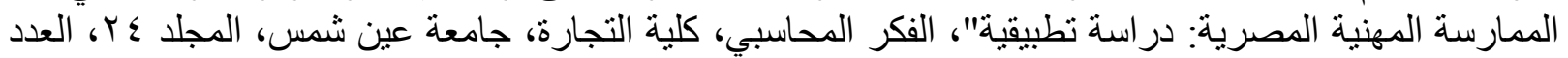

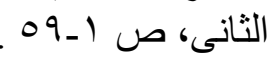
http://search.mandumah.com/Record/1065511

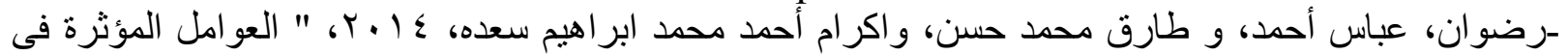

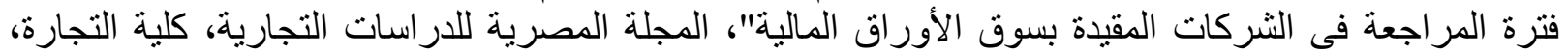

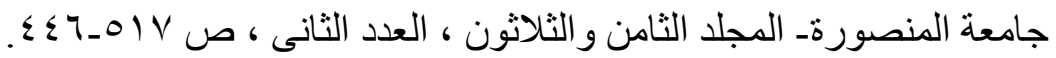

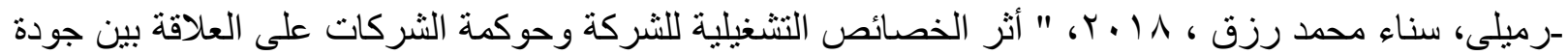

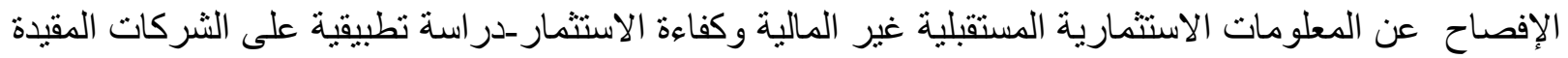

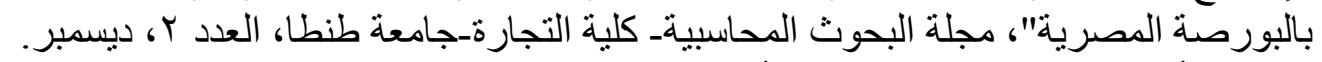

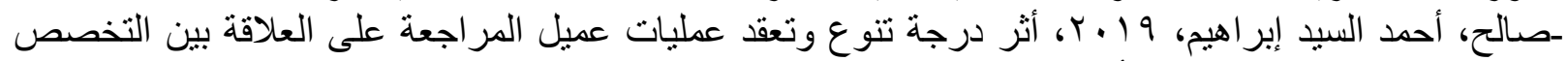

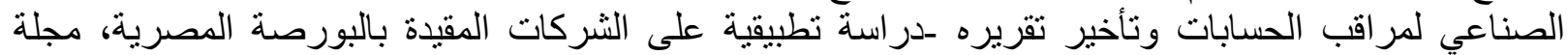

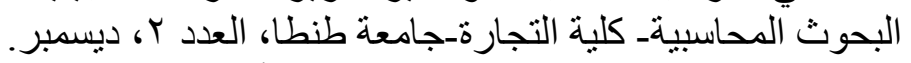

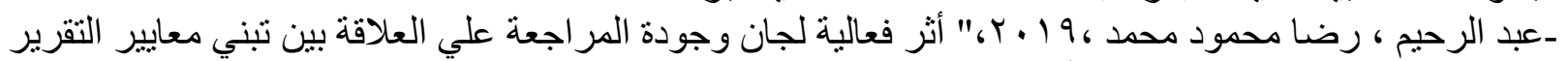

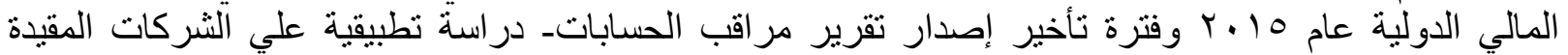

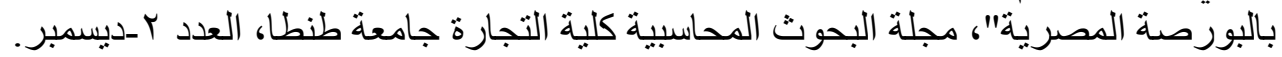

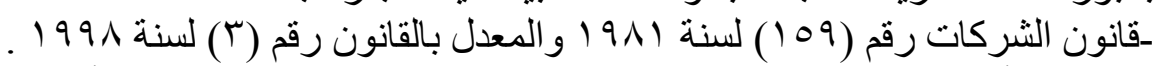

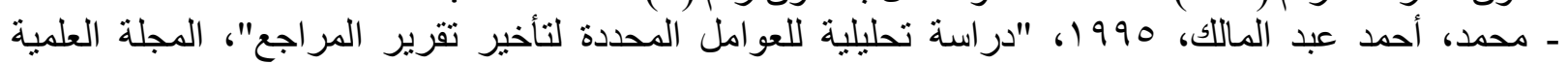

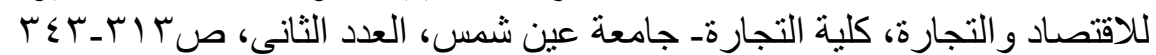

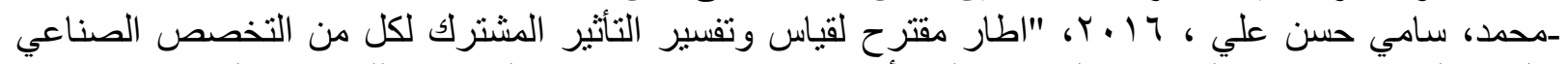

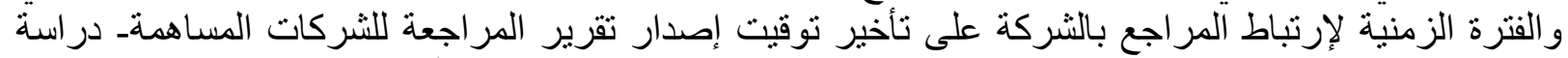

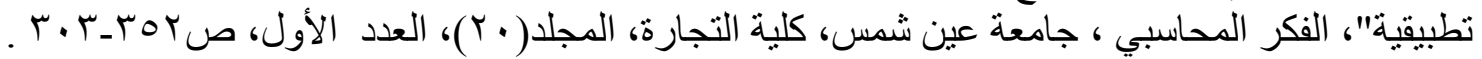

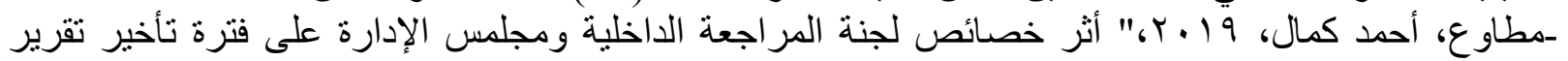

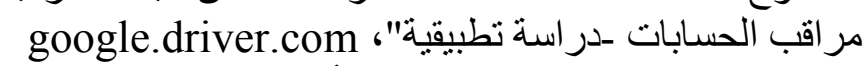

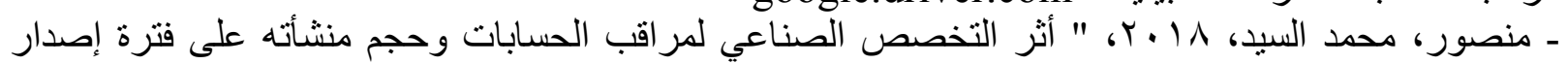

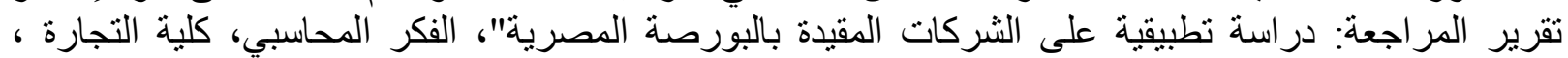

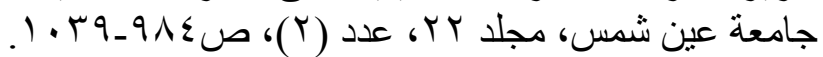

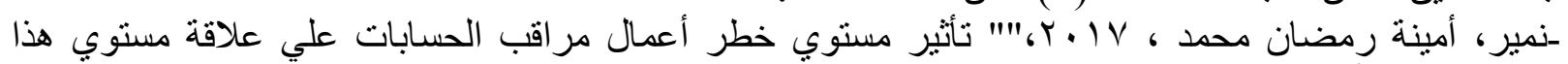

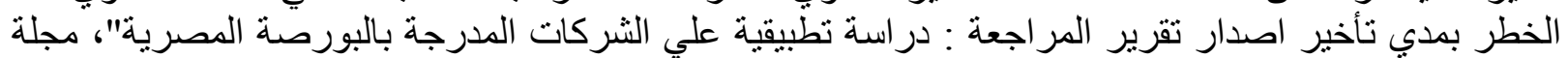

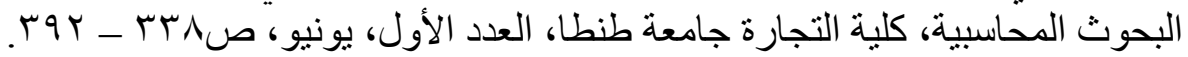

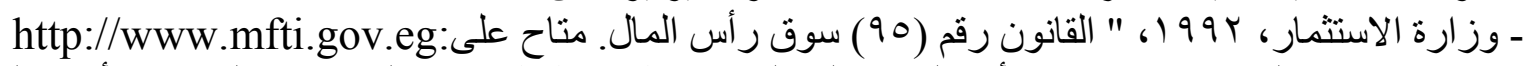

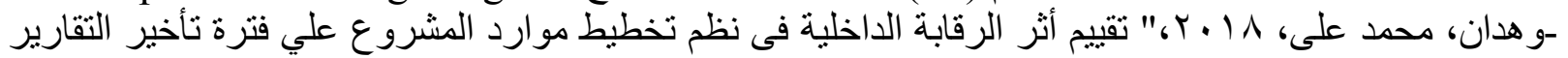

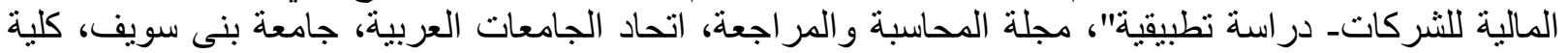

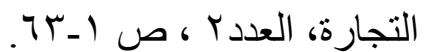

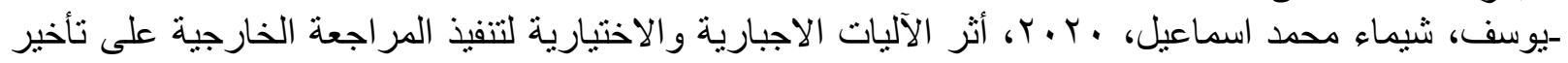

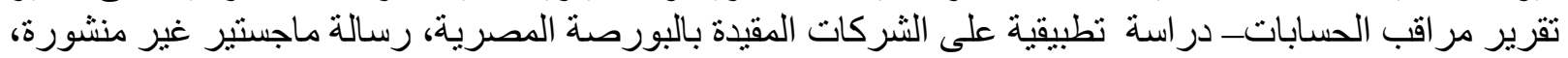

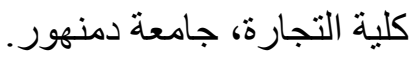

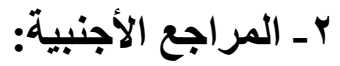

-Abdillah, M.R., Mardijuwono, A.W. and Habiburrochman, H., 2019. The Effect of Company Characteristics and Auditor Characteristics to Audit Report Lag, Asian Journal of Accounting Research. 4 (1), pp. 129-144. 
- Abdollahibli, Fatemeh, 2018. Joint Audit and The Implications of Its Use, Proceedings of Academicsera. 20th international Conference, Montereal, Canada, pp. 7:13

- Abernathy, John L., Michael Barnes; Chad Stefaniak \& Alexandria Weisbarth, 2017. An International Perspective on Audit Report Lag: a Synthesis of the Literature and Opportunities for Future Research", International Journal of Auditing (21), pp.100-127. -Accounting Standard Board.1991. The Objective of Financial Statements and the Qualitative Characteristics of Finanical Information, UK.

-Ahmad, M., Mohamed, H., and Nelson, S., 2016.The Association Between Industry Specialist Auditor and Financial Reporting Timeliness - Post MFRS Period, Procedia Social and Behavioral Sciences, 219, pp. $55-62$.

- American Institute of Certified Public Accountants (AICPA). 2015. AU-C Section 210Terms of Engagement: Statements on Auditing Standards (SASs), Available at www.aicpa.org.

-Asthana, S., 2014. Abnormal Audit Delays, Earnings Quality and Firm Value in The USA, Journal of Financial Reporting and Accounting, Vol. 12 No. 1, pp. 21-44.

- Bamber, E. Michael; Linda Smith Bamber \& Michael P. Schoderbek, 1993. Audit Structure and other Determinants of Audit Report Lag: an Empirical Analysis, Auditing: a Journal of Practice \&Theory, Vol. 12, No. 1, pp.1-23

-Blankley, Alan I.; David N. Hurtt \& Jason E. MacGregor, 2015. Practitioner Summary: Are Lengthy Audit Report Lags a Warning Signal?, Current Issues in Auditing, Vol. 9, Issue.2, pp.19-28.

-Blankley, Alan I.; David N. Hurtt \& Jason E. MacGregor, 2014.The Relationship between Audit Report Lags and Future Restatements, Auditing: A Journal of Practice \& Theory, Vol. 33, No. 2, pp. 27-57.

-BonsónDPonte, E., Escobar Rodríguez, T., \& BorreroDDomínguez, C., 2008, ". Empirical

Analysis of Delays in the Signing of Audit Reports in Spain, International Journal of Auditing, 12, (2), 129-140.

-Chang, H. and Yong, S., 2015. The Effect of Audit Report Lag and Management Discretionary Report Lag on Analyst Forecasts: Evidence from Korea, Investment Management and Financial Innovations, Vol. 12, No.1, pp. 318-328.

-Che-Ahmed, A. and Ahmed, M., 2016. Effects of Board Size, Board Committees Characteristics and Audit Quality on Audit Report Lags, The European Proceedings of Social and Behavioral Sciences, International Soft Science Conference.

http://dx.doi.org/10.15405/epsbs.2016.08.114.

-Cullinan, Ch. P., and X. Zheng, 2017. Accounting Outsourcing and Audit Lag", Managerial Auditing Journal , 32 (3), PP. 276-294.

- Dao, Mai \& Trung Pham, 2014. Audit Tenure, Auditor Specialization and Audit Report Lag", Managerial Auditing Journal, Vol. 29, No.6, pp.490-512.

-Daoud, K., Ismail, K. and Lode, N., 2015. The Impact of Internal Corporate Governance on the Timeliness of Financial Reports of Jordanian Firms: Evidence Using Audit and Management Report Lags, Mediterranean Journal of Social sciences, Vol.6, No.1, pp.430442.

-Dibia, N. and Onwuchekwa, J., 2013. An Examination of the Audit Report Lag of Companies Quoted in The Nigeria Stock Exchange, International Journal of Business and Social Research, Vol. 3, No. 9, pp. 8-16. 
-Financial Accounting Standard Board(FASB), 2010. Conceptual Framework for Financial Reporting: Statement of Financial Accounting Concepts No. 8, available at www.fasb.org -Hashim, U., 2017. Does Ownership Characteristics Have Any Impact on Audit Report Lag? Evidence of Malaysian Listed Companies, World Applied Sciences Journal, Vol. 35, No.9, pp. 1826-1838.

-Hassan, Y., 2016. Determinants of Audit Report Lag: Evidence from Palestine, Journal of Accounting in Emerging Economies, Vol. 6, No. 1, PP. 13-32.

-Ilaboya, O. and Iyafekhe, C., 2014. Corporate Governance and Audit Report Lag in Nigeria, International Journal of Humanities and Social Science, Vol. 4, No. 13, pp.172-180.

- International Auditing and Assurance Standards Board (IAASB), 2015. Agreeing the Terms of Audit Engagements: International Standard on Auditing (ISA No.210), Available at www. web.ifac.org

-Karami A. , and Akhgar M. , 2014. Effect of Company Size and Leverage Features on The Quality of Financial Reporting of Companies Listed in Tahran Stock Exchange, Journal of Contemporary Research in Business, Vol. 6, No. 5, pp. 71-81.

-Khlif, H., \& Samaha, K., 2014. Internal Control Quality, E gyptian Standards on Auditing and External Audit Delays: Evidence from the Egyptian Stock Exchange, International Journal of Auditing, 18(2), pp.139-154.

-Khoufi, N. and Khoufi, W.,2018 . An Empirical Examination of the Determinants of Audit Report Delay in France, Managerial Auditing Journal, Vol. 33, No. 8/9, pp. 700- 714. -Meckfessel, Michele D. \& Drew Sellers, 2017. The Impact of Big 4 Consulting on Audit Reporting Lag and Restatements, Managerial Auditing Journal, Vol.32, Iss.1 pp.19 - 49

-Mohammed, I., Ahmad, A. and Malek, M., 2018. Shareholder's Involvement in the Audit Committee, Audit Quality and Financial Reporting Lag in Nigeria, Business and Economic Horizons, Vol. 14, No. 2, pp.355-374.

- Nelson, Sherliza Puat \& Siti Norwahida Shukeri, 2011. Corporate Governance and Audit Report Timeliness: Evidence From Malaysia, Research in Accounting in Emerging Economies, Vol. 11, pp.109-127

-Oussii, A. and Taktak, N., 2018. Audit Report Timeliness: Does Internal Audit Function Coordination with External Auditors Matter? Empirical evidence from Tunisia, Euro Med Journal of Business, Vol. 13, No. 1, pp.60-74.

- Pizzini, Mina; Shu Lin \& Douglas E. Ziegenfuss, 2015. The Impact of Internal Audit Function Quality and Contribution on Audit Delay, Auditing: a Journal of Practice \& Theory, Vol. 34, No. 1, pp. 25-58

-Quick, R., and Schmidt, F. ,2018. Do audit firm rotation, auditor retention, and joint audits matter? -An experimental investigation of bank directors' and institutional investors'perceptions. Journal of Accounting Literature, 41, 121

-Rusmin, R., \& Evans, J., 2017. Audit Quality and Audit Report Lag: Case of Indonesian Listed Companies, Asian Review of Accounting, 25(2), pp. 191-210.

-Sarbanes ,P. , and M. Oxley, 2002. Sarbanes Oxley Act of 2002, Washington, Dc: U.S.

Congress.

- Sultana, Nigar; Harjinder Singh \& J-L.W. Mitchell Van der Zahn, 2015. Audit Committee Characteristics and Audit Report Lag, International Journal of Auditing, 19, pp.72-87.

-Suryanto, T., 2016. Audit Delay and Its Implication for Fraudulent Financial Reporting: A study of Companies Listed in the Indonesian Stock Exchange, European Research

Studies, 19(1),p. 18. 